Universidade de São Paulo - USP

Escola de Engenharia de São Carlos - EESC

Departamento de Engenharia Elétrica

\title{
Redução do tempo de zapping em serviços IPTV sobre redes GPON utilizando vídeos escaláveis
}

\author{
Autor: Marcos Perez Mokarzel
}

Dissertação apresentada à Escola de Engenharia de São Carlos da Universidade de São Paulo, como parte dos requisitos para obtenção do titulo de Mestre em Ciências, Programa de Engenharia Elétrica.

Área de conhecimento: Telecomunicações

Orientadora: Profa. Dra. Mônica de Lacerda Rocha

São Carlos, SP

Agosto de 2010 
AUTORIZO A REPRODUC̆̃O E DIVULGAÇÃO TOTAL OU PARCIAL DESTE TRABALHO, POR QUALQUER MEIO CONVENCIONAL OU ELETRÔNICO, PARA FINS DE ESTUDO E PESQUISA, DESDE QUE CITADA A FONTE.

Ficha catalográfica preparada pela Seção de Tratamento da Informação do Serviço de Biblioteca - EESC/USP

Mokarzel, Marcos Perez
Reduçăo do tempo de zapping em serviços IPTV sobre
redes GPON utilizando vídeos escaláveis / Marcos Perez
Mokarzel ; orientadora Mônica de Lacerda Rocha. -- São
Carlos, 2010.

Dissertação (Mestrado-Programa de Pós-Graduação em Engenharia Elétrica e Área de Concentraçăo em Telecomunicações) -- Escola de Engenharia de São Carlos da Universidade de Săo Paulo, 2010.

1. Rede de telecomunicações. 2. GPON. 3. IPTV. 4. Tempo de zapping. I. Título. 
FOLHA DE JULGAMENTO

Candidato: Engenheiro MARCOS PEREZ MOKARZEL.

Dissertação defendida e julgada em 11/08/2010 perante a Comissão Julgadora:

Shónecia de Reacurde Roche Aprovado Prof ${ }^{\text {a }}$. Dr ${ }^{\mathrm{a}}$. MÔNICA DE LACERDA ROCHA - (Orientadora) (Escola de Engenharia de São Carlos/USP)

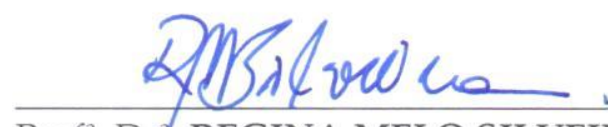

Prof ${ }^{a}$. Dr\%. REGINA MELO SILVEIRA (Escola/Politécnica/USP)
Aprovado

Aprowado

Dr. DANIEL MOUTINHO PATACA (CPqD)

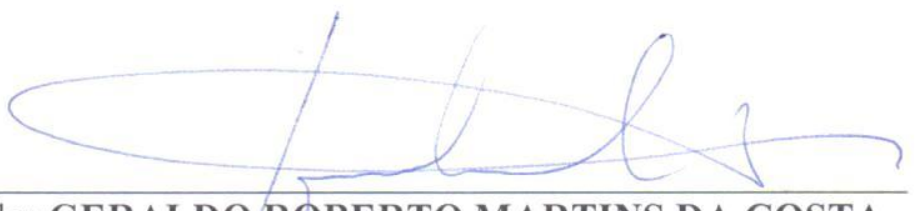

Prof. Titular GERALDO ROBERTO MARTINS DA COSTA Coordenador do Programa de Pós-Graduação em Engenharia Elétrica e Presidente da Comissão de Pós-Graduação 



\section{Dedicatória}

À minha esposa Sueli e meu filho Pedro, com amor, admiração e gratidão por sua compreensão, carinho, presença e incansável apoio ao longo do período da elaboração deste trabalho. 


\section{Agradecimento}

A Deus por me conceber a graça de estar vivo e com saúde e por se fazer sempre presente.

À minha esposa Sueli e a meu filho Pedro pelo amor, incentivo, apoio e compreensão. Vocês são maravilhosos e os amo muito.

À minha orientadora Profa. Dra. Mônica Lacerda Rocha pela oportunidade de trabalharmos juntos, pelos ensinamentos, paciência e compreensão durante todas as etapas deste trabalho.

A meu amigo Sandro Marcelo Rossi não só pela amizade e convívio, mas também pelas inestimáveis críticas que engrandeceram este trabalho.

Aos meus professores, Prof. Dr. Murilo Romero, Prof. Dr. Amilcar Careli Cesar, Prof. Dr. Marcelo Andrade da Costa Vieira, Prof. Dr. Ivan Nunes da Silva e Profa. Dra. Maria Stela Veludo de Paiva pelos ensinamentos que formaram as pilastras, que sustentam este trabalho.

À Fundação CPqD, em especial a João Luiz Mercante, Alberto Paradisi, Marcos Brandão Sanches e Marcos Rogério Salvador, que incentivaram e apoiaram meus estudos de pósgraduação, minhas pesquisas e desenvolvimentos que culminaram nos resultados apresentados neste documento.

Aos meus colegas de trabalho e amigos Ivonete, Fernanda, Renata, Aline, André e Mariela pela amizade e convívio. 


\section{Resumo}

Mokarzel, M. P., "Redução do tempo de zapping em serviços IPTV sobre redes GPON utilizando vídeos escaláveis" 2010. Dissertação de Mestrado - Faculdade de Engenharia, Universidade de São Paulo, Campus de São Carlos, 2010.

Com a padronização das redes óticas passivas, em particular do GPON (gigabit-capable passive optical network) adotada no Brasil, uma nova gama de serviços passou a ser viável, dentre eles a transmissão de canais de TV para assinantes usando o protocolo IP (Internet protocol), sistema conhecido como IPTV. Este processo apresenta inúmeras vantagens, dentre elas a possibilidade de um número maior de canais e com qualidade variável. O grande inconveniente neste sistema é que em qualquer sistema de transmissão de TV digital o tempo de troca de canais, conhecido como tempo de zapping, pode chegar a alguns segundos. Para reduzir este problema, este trabalho descreve um processo de codificação e transmissão de IPTV em redes GPON que reduz o tempo de zapping, podendo chegar ao tempo de recuperação de um quadro (frame). O estudo foi baseado na codificação escalável em qualidade (SNR, signal to noise ratio) proposta no padrão MPEG-2 (Moving Picture Experts Group) e pode ser facilmente portado para outros padrões de codificação como os FGSs (fine grain scalability) do MPEG-4. O transporte utiliza a característica multicast das redes GPON além do protocolo IGMP (Internet Group management protocol). Uma vez que o sistema IPTV propicia ao assinante vantagens como, o aumento do número de canais e a melhoria da qualidade de cada um deles devido à flexibilização da banda, este trabalho pressupõe que o assinante aceitará uma qualidade de vídeo inferior, no momento do zapping, desde que aumente com o decorrer do tempo. $\mathrm{O}$ aumento da qualidade é ilustrado por curvas comparativas, que mostram os tempos entre a mudança do canal, a entrada dele em baixa resolução e a melhora progressiva até a estabilidade em qualidade máxima.

Palavras-chave: GPON, IPTV, tempo de zapping 


\section{Abstract}

Mokarzel, M. P., Reducing zapping time in IPTV service over GPON networks using scalable video. 2010. Master Dissertation - Sao Paulo University, Sao Carlos Site, 2010.

With the standardization of passive optical networks, in particular GPON (gigabit-capable passive optical networks), which is adopted in Brazil, a new range of services become feasible, among them TV channels transmission to subscribers using the IP (Internet Protocol), known as IPTV System, is one of the most important. This process has many advantages, including the possibility of offering a greater number of channels with variable quality. The greater inconvenience of this solution is that in any system of digital TV transmission the time to exchange channels, known as zapping time, can reach some seconds. To reduce this problem, this M.Sc thesis proposes a coding and transmission process for IPTV in GPON networks that reduces the zapping time to values smaller than one frame time. This work is based on the scalable SNR (signal to noise ratio) proposed in MPEG-2 standard and can be easily ported to other standards like FGS (fine grain scalability) in MPEG-4. Transport uses GPON multicast characteristics beside IGMP (Internet Group management protocol). Once IPTV system offers many advantages like, increasing number of channels and better image quality per channel since bandwidth can be flexible. It is assumed that the IPTV subscriber will accept low video quality, at the zapping moment, but quality will increase progressively. Comparative graphics show the quality increase in terms of time between zapping, low quality video starting and the progressive quality increase up to stability in full quality.

Keywords: GPON, IPTV, Zapping Delay 


\section{Sumário}

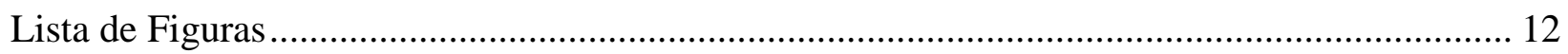

Lista de Tabelas ................................................................................................................. 15

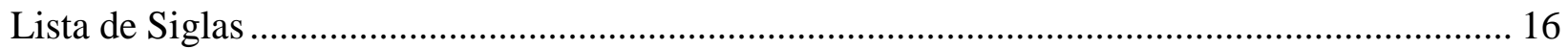

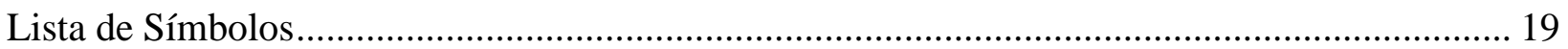

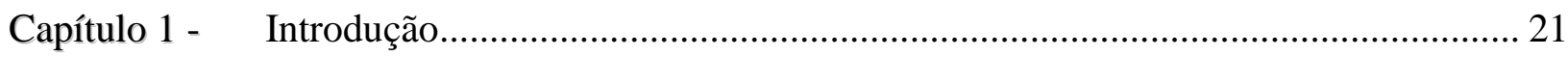

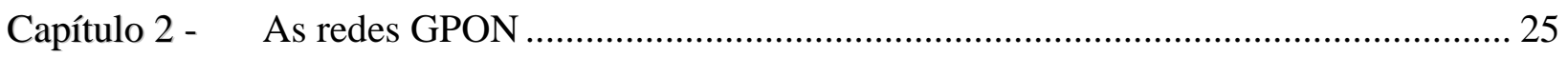

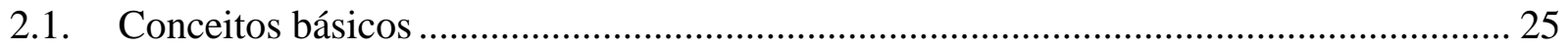

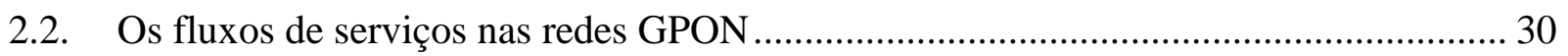

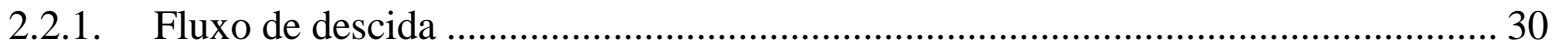

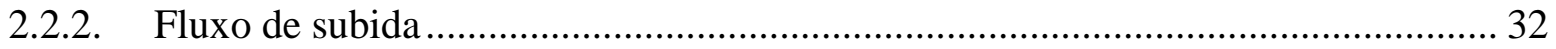

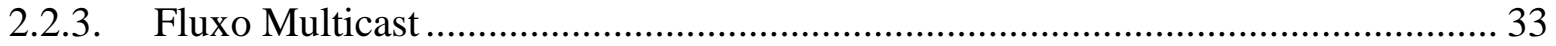

2.3. Transmissão de TV em sistemas GPON ……………................................................. 34

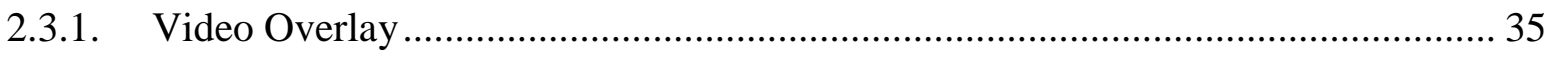

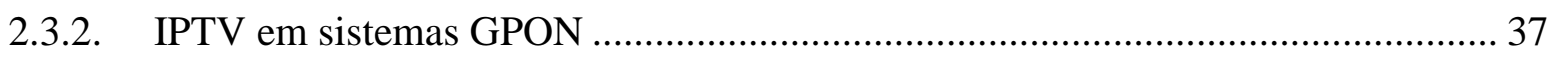

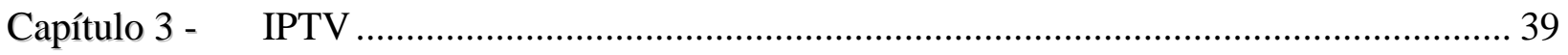

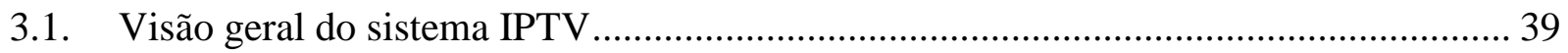

3.2. Topologia da rede para prover serviço IPTV em rede GPON ....................................... 40

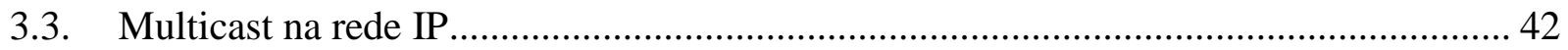

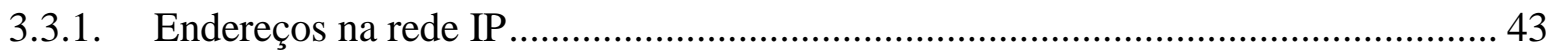

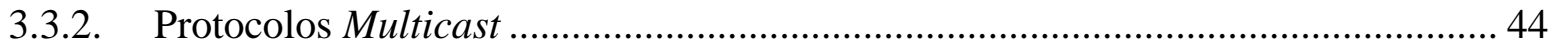

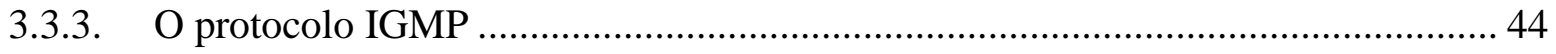




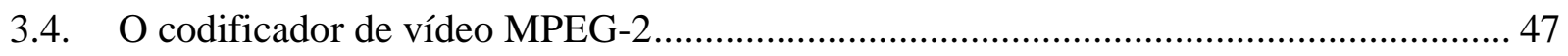

3.4.1. A técnica de compressão ....................................................................................... 48

3.4.2. Uma visão geral do codificador MPEG-2 2....................................................... 48

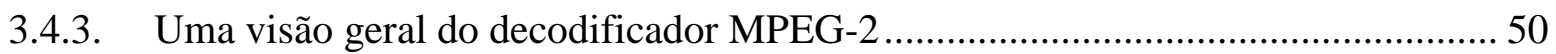

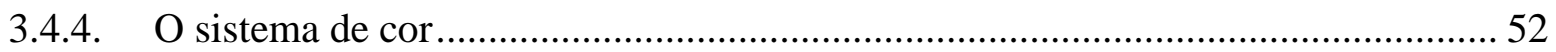

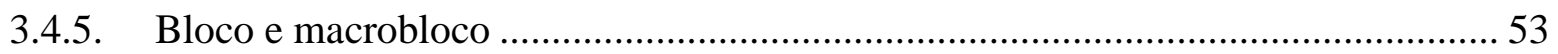

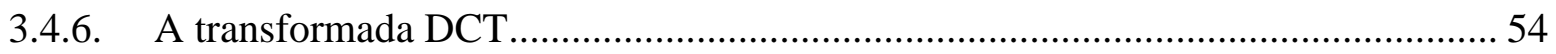

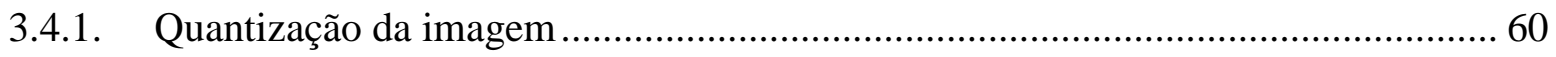

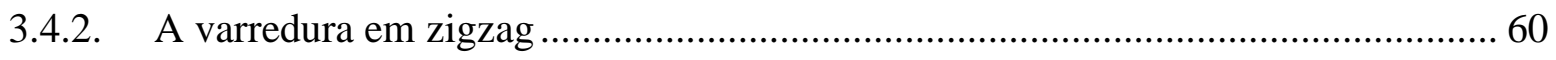

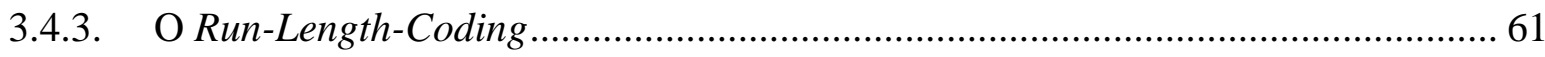

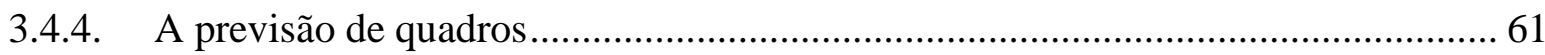

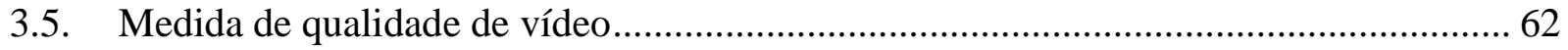

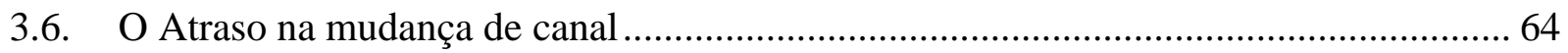

3.6.1. Origem do atraso na mudança de canal em IPTV .................................................. 65

3.6.2. Possíveis soluções para reduzir o atraso na mudança de canal................................. 66

Capítulo 4 - Proposta para redução do atraso na mudança de canal ......................................... 71

4.1. Servidor de vídeo escalável....................................................................................... 71

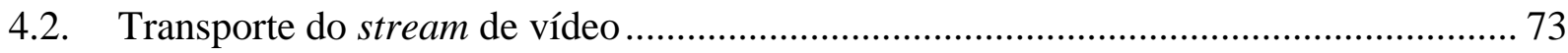

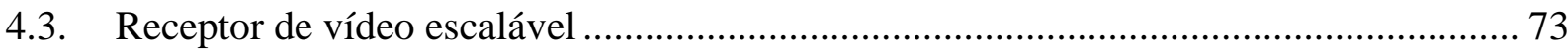

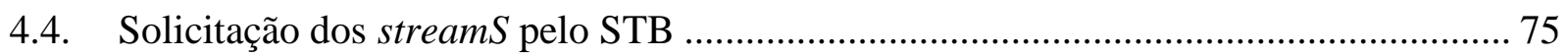

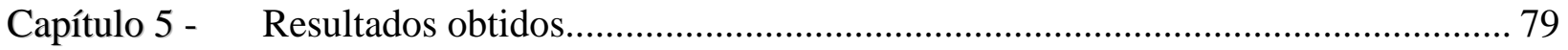

5.1. Simulador para prova de conceito ............................................................................ 79

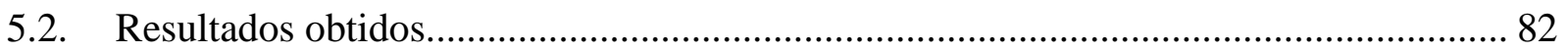

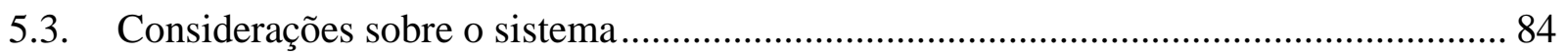

5.3.1. Possibilidade de resoluções distintas .......................................................................... 84 
5.3.2. Qualidade no momento da mudança do canal

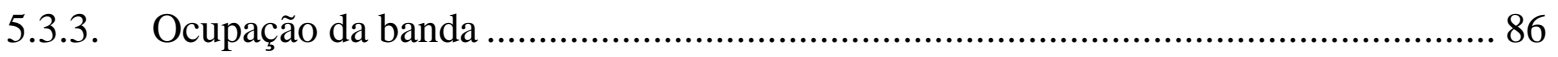

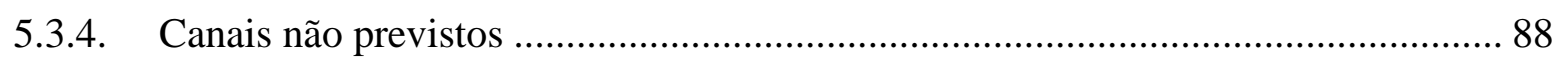

Capítulo 6 - Conclusão e sugestões de trabalhos futuros ...................................................... 89

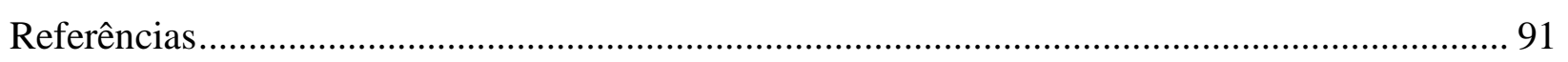




\section{Lista de Figuras}

Figura 1 - Comparação entre as diversas redes de acesso na relação banda por distância. 32

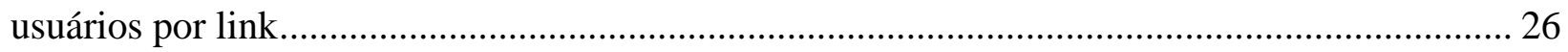

Figura 2 - Comparação entre as três tecnologias de acesso, a) acesso ponto-a-ponto, b) acesso ponto-multiponto com nó ativo e c) acesso ponto-multiponto com nó passive (PON) ................. 27 Figura 3 - Multiplexação no tempo (TDMA) dos dados na rede PON evitando colisão nos acopladores ópticos para o tráfego de subida e distribuindo corretamente o tráfego de descida . 28 Figura 4 - Composição mínima de um sistema GPON, com um Switch, uma OLT e uma ONU 30 Figura 5 - Conexão física para fluxo de dados de descida do servidor S1 para o cliente C1 ....... 30 Figura 6 - Conexão lógica para fluxo de dados de descida do servidor S1 para o cliente C1 ...... 31 Figura 7 - Conexão física para fluxo de dados de subida do cliente C1 para o Servidor S1 ........ 32 Figura 8 - Conexão lógica para fluxo de dados de subida do cliente C1 para o Servidor S1 ....... 33 Figura 9 - Fluxo multicast de descida, as 3 ONUs recebem o conteúdo da porta 03 ................... 34 Figura 10 - Comparação da utilização da banda por sistema VoD e Broadcast. Em VoD cada assinante ocupa um fluxo independente de vários assinantes estarem assistindo ao mesmo vídeo ou não. Em IPTV (broadcast) um único fluxo atende a todos os assinantes que estão assistindo

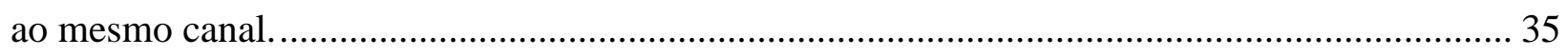

Figura 11 - Exemplo de Video Overlay em sistema GPON …………………………................. 36

Figura 12 - Exemplo de serviço IPTV em sistema GPON .......................................................... 37

Figura 13 - Diferença do transporte dos canais na rede de acesso para um sistema CATV e para

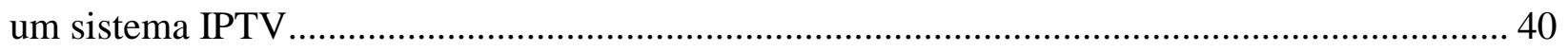

Figura 14 - Modelo básico de rede para serviço IPTV sobre rede GPON ...................................... 40 Figura 15 - Tráfego multicast no protocolo GEM. No contexto da figura o termo "Multicast Header" significa os cabeçalhos necessários para o encaminhamento dos pacotes multicast do stream de vídeo ...................................................................................................................... 41

Figura 16 - Diagrama de sequência da exibição de um novo canal ................................................ 42

Figura 17 - Arquitetura para tráfego de stream de vídeo usando o protocolo IGMP .................... 46

Figura 18 - Diagrama de blocos simplificado para um codificador MPEG .................................. 49 
Figura 19 - Diagrama de blocos simplificado para um decodificador MPEG.....

Figura 20 - Imagem dividida em blocos de 8 x 8 pixel, os blocos podem ser codificados em RGB ou $\mathrm{YCbCr}$

Figura 21 - Três tipos de macroblocos previstos no padrão MPEG......................................... 54

Figura 22 - Função Base da DCT-II em 2D ........................................................................ 58

Figura 23 - Exemplo da quantização de um bloco de imagem de 8x8 pixels. O processo de codificação é mostrado na parte superior da imagem e o de decodificação na parte inferior. ..... 59 Figura 24 - Comparação entre DCT e DFT, a DFT tem como resultado uma matriz de coeficientes composto por números complexos, menos adequado para a aplicação de compressão que a DCT cujo resultado são coeficientes puramente reais. Aplicando um filtro passa baixa nas duas matrizes de coeficientes, o resultado é praticamente o mesmo ....................................... 60 Figura 25 - Exemplo de varredura do bloco em zigzag e do Run-Length-Coding ..................... 61 Figura 26 - Sequência de quadros de um vídeo composta por dois quadros chaves I, um quadro com predição anterior $\mathrm{P}$ e um quadro com predição bidirecional $\mathrm{B}$. Imagem retirada de (http://en.wikipedia.org/wiki/I-frame) e complementada ..................................................62 62

Figura 27 - Exemplo de alteração de canal em serviço IPTV ................................................ 65

Figura 28 - Envio de todos os canais para a ONU como proposto em [16] ............................. 67 Figura 29 - Envio de canais adjacentes proposto em [51]. A) Transporte dos canais na rede; B)

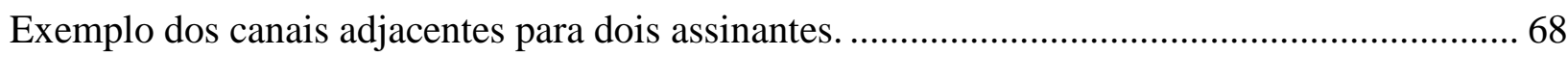

Figura 30 - Estrutura de codificação de quadros I, P e B para o Normal Stream e o Fast Channel Change Stream. Imagem extraída do artigo [52].... 69

Figura 31 - Servidor de vídeo escalável, a imagem original é codificada em quatro imagens complementares. 71

Figura 32 - Esquema simplificado do codificador de vídeo escalável em SNR com 4 stream complementares 72

Figura 33 - Divisão da matriz de quantização em quatro seguimentos para o scan .................... 72 Figura 34 - Vídeos transmitidos em stream distintos. No contexto da figura o termo "Multicast Header" significa os cabeçalhos necessários para o encaminhamento dos pacotes multicast do stream de vídeo 73

Figura 35 - Recomposição da imagem no STB reagrupando os stream disponíveis no processo de scan inverso 
Figura 36 - Esquema simplificado do decodificador de vídeo escalável em SNR com quatro

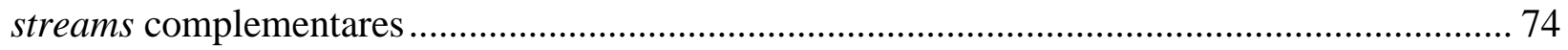

Figura 37 - Canais adjacentes solicitados pelo terminal do assinante .................................. 76

Figura 38 - Conjunto codificador/decodificador de teste ..................................................... 79

Figura 39 - Comparação da qualidade dos vídeos gerados em quatro formatos: A) usando o stream V1; B) usando os stream $\mathrm{V} 1+\mathrm{V} 2$; C) usando os stream $\mathrm{V} 1+\mathrm{V} 2+\mathrm{V} 3$; D) usando os stream

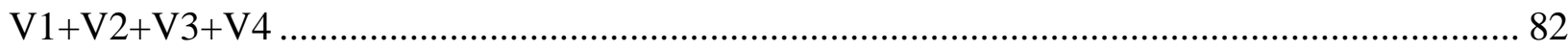

Figura 40 - Banda necessária no sistema: A) Banda para cada um dos streams que compõem o vídeo. B) Comparação entre a banda necessária para o transporte do vídeo em um único stream com o transporte do vídeo em quatro streams ..... 83

Figura 41 - Diversas resoluções sendo transmitidas pela rede GPON dependendo da necessidade do assinante e disponibilidade da rede 84 Figura 42 - Análise de alguns casos de entrada de canal onde o instante 1 do gráfico é o momento da mudança do canal. A) Mudança única de canal; B) Mudança dupla de canal com intervalo de 1 segundo. 85 Figura 43 - Comparação de banda média utilizada por assinante na rede GPON. Simulação com grades de 100, 200 e 500 canais transmitidos de forma padrão e em vídeo escalável conforme proposto neste documento: A) Grade com 100 canais; B) Grade com 200 canais; C) Grade com 500 canais; D) Banda total ocupada para IPTV com 200 canais. 87 


\section{Lista de Tabelas}

Tabela 1 - Comparação entre os padrões GPON e EPON empregados em redes PON atuais. ... 29

Tabela 2 - Recomendação de QoE para serviço de IPTV ...................................................... 65

Tabela 3 - Priorização dos stream na rede ............................................................................. 76

Tabela 4 - Valor médio das qualidades de vídeo composto pelas combinações dos streams e BW

(Bandwidth) média necessária para cada stream .................................................................. 83 


\section{Lista de Siglas}

\begin{tabular}{|c|c|}
\hline ADSL & - Asymmetric Digital Subscriber Line \\
\hline $\mathrm{AE}$ & - Advanced Ethernet \\
\hline AES & - Advanced Encryption Standard \\
\hline AVC & - Attribute Value Change \\
\hline BPON & - Broadband Passive Optical Network \\
\hline BridgeID & - Bridge Identification \\
\hline BW & - Bandwidth \\
\hline CATV & - Community Antenna Television \\
\hline CES & - Circuit Emulation Service \\
\hline $\mathrm{CO}$ & - Central Office \\
\hline CPU & - Central Processing Unit \\
\hline $\mathrm{CRC}$ & - Cyclic Redundancy Check (or polynomial code checksum) \\
\hline DA & - Destination Address \\
\hline DBRu & - Dynamic Bandwidth Report Upstream \\
\hline DC & - Direct Current \\
\hline DCT & - Discrete Cosine Transform \\
\hline DFT & - Discrete Fourier transform \\
\hline DHCP & - Dynamic Host Configuration Protocol \\
\hline DS & - Down Stream \\
\hline DSL & - Digital Subscriber Line \\
\hline EDFA & - Erbium-Doped Fiber Amplifier \\
\hline EOB & - End Of Block \\
\hline EPON & - Ethernet Passive Optical Network \\
\hline FGS & - Fine Grain Scalability \\
\hline FIFO & - First In First Out \\
\hline FPGA & - Flip-chip Pin Grid Array \\
\hline FTTB & - Fiber to the Business \\
\hline FTTC & - Fiber to the Cabinet \\
\hline FTTH & - Fiber to the Home \\
\hline FTTP & - Fiber to the Premises \\
\hline GEM & - GPON Encapsulation Method \\
\hline GI & - Gerência Integrada \\
\hline GMII & - Gigabit Media Independent Interface \\
\hline GOP & - Group Of Pictures \\
\hline GPON & - Gigabit-capable Passive Optical Networks \\
\hline GEPON & - Gigabit-capable Ethernet Passive Optical Networks \\
\hline $\mathrm{HD}$ & - High Definition \\
\hline HDMI & - High-Definition Multimedia Interface \\
\hline HDTV & - High-Definition Television \\
\hline HEC & - Header Error Control/Check \\
\hline
\end{tabular}




\begin{tabular}{|c|c|}
\hline HFC & - Hybrid Fiber-Coaxial \\
\hline ICMP & - Internet Control Message Protocol \\
\hline IDCT & - Inverse Discrete Cosine Transform \\
\hline IEEE & - Institute of Electrical and Electronics Engineers \\
\hline IETF & - Internet Engineering Task Force \\
\hline IGMP & - Internet Group Management Protocol \\
\hline IP & - Internet Protocol \\
\hline IPV4 & - Internet Protocol Version 4 \\
\hline IPV6 & - Internet Protocol Version 6 \\
\hline IPTV & - Internet Protocol Television \\
\hline ITU-T & - International Telecommunication Union - Telecommunication Standardization \\
\hline Sector & \\
\hline JPEG & - Joint Photographic Experts Group \\
\hline LAN & - Local Area Network \\
\hline LRTV & - Low Resolution Television \\
\hline MAC & - Media Access Control \\
\hline MAN & - Metropolitan Area Network \\
\hline MLD & - Multicast Listener Discovery \\
\hline MPEG & - Moving Picture Experts Group \\
\hline MSE & - Mean Square Error \\
\hline OAM & - Operation, Administration and Maintenance \\
\hline OLT & - Optical Line Termination \\
\hline OMCI & - ONU Management and Control Interface \\
\hline ONU & - Optical Network Unit \\
\hline ONT & - Optical Network Termination \\
\hline $\mathrm{PC}$ & - Personal Computer \\
\hline PCBd & - Physical Control Block Downstream \\
\hline PDA & - Personal digital assistants \\
\hline PIM & - Protocol Independent Multicast \\
\hline PIP & - Picture In Picture \\
\hline PLI & - Payload Length Indicator \\
\hline PLOAM & - Physical Layer OAM \\
\hline PON & - Passive Optical Network \\
\hline PortID & - Port Identification \\
\hline PPTV & - Picture In Picture Television \\
\hline PSNR & - Peak Signal-to-Noise Ratio \\
\hline PTI & - Payload Type Indicator \\
\hline QAM & - Quadrature Amplitude Modulation \\
\hline QoE & - Quality of Experience \\
\hline QoS & - Quality of Service \\
\hline RF & - Radio Frequency \\
\hline RFC & - Request for Comments \\
\hline RGB & - Red, Green and Blue \\
\hline RxGEM & - Receive GPON Encapsulation Method \\
\hline RTCP & - Real-Time Transport Control Protocol \\
\hline RTP & - Real-Time Protocol \\
\hline
\end{tabular}




$\begin{array}{ll}\text { RTSP } & \text { - Real-Time Streaming Protocol } \\ \text { SA } & \text { - Source Address } \\ \text { SD } & \text { - Standard Definition (used for image quality 640x480) } \\ \text { SDTV } & \text { - Standard Television } \\ \text { SNR } & \text { - Signal Noise Ratio } \\ \text { SSM } & \text { - Source-Specific Multicast } \\ \text { STB } & \text { - Set Top Box } \\ \text { STM } & \text { - Synchronous Transport Module } \\ \text { TCONT } & \text { - Transmission Containers } \\ \text { TDM } & \text { - Time Division Multiplexing } \\ \text { TDMA } & \text { - Time Division Multiple Access } \\ \text { TxGEM } & \text { - Transceiver GPON Encapsulation Method } \\ \text { UDP } & \text { - User Datagram Protocol } \\ \text { US } & \text { - Up Stream } \\ \text { VDSL } & \text { - Very-high-bit-rate Digital Subscriber Line } \\ \text { VGA } & \text { - Video Graphics Array } \\ \text { VLAN } & \text { - Virtual Local Area Network } \\ \text { VLANID } & \text { - Virtual Local Area Network Identification } \\ \text { VoD } & \text { - Video on Demand } \\ \text { VoIP } & \text {-Voice over Internet Protocol } \\ \text { VoTDM } & \text { - Voice over Time Division Multiplexing } \\ \text { WAN } & \text { - Wide Area Network } \\ \text { WDM } & \text { - Wavelength-Division Multiplexing } \\ \text { WiMax } & \text { - Worldwide Interoperability for Microwave Access } \\ \text { xDSL } & \text { - Variations of Digital Subscriber Line }\end{array}$




\section{Lista de Símbolos}

\begin{tabular}{|c|c|}
\hline B & - Componente azul do pixel da imagem \\
\hline BufferSize & - Tamanho máximo que deve ser reservado para o buffer da imagem \\
\hline $\mathrm{Cb}$ & - Crominância azul do pixel da imagem \\
\hline $\mathrm{Cr}$ & - Crominância vermelha do pixel da imagem \\
\hline $\mathrm{DCT}^{\mathrm{Cl}}()$ & - Matriz de coeficientes calculados pela DCT-I \\
\hline $\mathrm{DCT}^{\mathrm{C}}()$ & - Matriz de coeficientes calculados pela DCT-II \\
\hline $\mathrm{DCT}^{\mathrm{C} 3}()$ & - Matriz de coeficientes calculados pela DCT-III \\
\hline $\mathrm{DCT}^{\mathrm{C} 4}()$ & - Matriz de coeficientes calculados pela DCT-IV \\
\hline $\mathrm{f}()$ & - Matriz com os valores dos pixels da imagem \\
\hline G & - Componente verde do pixel da imagem \\
\hline $\mathrm{I}()$ & - Matriz com os valores dos pixels da imagem I \\
\hline $\mathrm{K}()$ & - Matriz com os valores dos pixels da imagem $\mathrm{K}$ \\
\hline $\mathrm{K}_{\mathrm{u}}$ & - Constante para o cálculo da DCT associada ao índice dos coeficientes da DCT \\
\hline $\mathrm{K}_{\mathrm{v}}$ & - Constante para o cálculo da DCT associada ao índice dos coeficientes da DCT \\
\hline $\begin{array}{l}\mathrm{K}_{\mathrm{x}} \\
\text { imagem }\end{array}$ & - Constante para o cálculo da DCT associada ao índice da primeira dimensão da \\
\hline $\begin{array}{l}\mathrm{K}_{\mathrm{y}} \\
\text { imagem }\end{array}$ & - Constan \\
\hline M & - Dimensão total da segunda dimensão da imagem ou bloco da imagem \\
\hline MAX $_{I}$ & - Valor máximo que o pixel da imagem I pode atingir (normalmente 255) \\
\hline MaxInterval & - Intervalo máximo entre frames I no GOV \\
\hline MinDejitter & - Menor buffer dimensionado para eliminação de Jitter \\
\hline MSE & - Erro médio quadrático entre duas imagens \\
\hline $\mathrm{N}$ & - Dimensão total da primeira dimensão da imagem ou bloco da imagem \\
\hline PSNR & - Relação sinal ruído entr \\
\hline $\mathrm{R}$ & - Componente vermelha do pixel da imagem \\
\hline . & - Índice da primeira dimensão dos coeficientes da DCT \\
\hline $\mathrm{v}$ & - Índice da segunda dimensão dos coeficientes da DCT \\
\hline V1 & - Stream de vídeo comprimido contendo apenas a resolução \\
\hline V16vga & - Imagem de vídeo recuperada com o primeiro stream de vídeo V1 \\
\hline $\mathrm{V} 2$ & - Stream de vídeo comprimido contendo apenas o complemento da resolução mais \\
\hline \multicolumn{2}{|c|}{ baixa para a baixa } \\
\hline \multicolumn{2}{|c|}{ baixa para a média } \\
\hline $\begin{array}{l}\text { V4 } \\
\text { média para a }\end{array}$ & $\begin{array}{l}\text { - Stream de vídeo comprimido contendo apenas o complemento da resolução } \\
\text { lta }\end{array}$ \\
\hline V4vga & - Imagem de vídeo recuperada com os 2 primeiros streams de vídeo $(\mathrm{V} 1+\mathrm{V} 2)$ \\
\hline Vvga & - Imagem de vídeo recuperada com os 3 primeiros streams de vídeo $(\mathrm{V} 1+\mathrm{V} 2+\mathrm{V} 3)$ \\
\hline $\mathrm{Vf}$ & - Imagem de vídeo recuperada com todos os 4 streams de vídeo (V1+V2+V3+V4) \\
\hline $\mathrm{x}$ & - Índice da primeira dimensão da imagem \\
\hline $\mathrm{y}$ & - Índice da segunda dimensão da imagem \\
\hline Y & - Luminância do pixel da imagem \\
\hline
\end{tabular}





\section{CAPÍTULO 1 - INTRODUÇÃO}

As redes de computadores foram divididas em três grandes grupos, as redes de âmbito global (WAN - Wide Area Network), as redes metropolitanas (MAN - metropolitan area network) e as redes locais (LAN - local area network). Esta divisão foi proposta devido às características particulares de cada uma delas. As WAN são redes que devem atingir grandes distâncias, de dezenas de quilômetros nas ligações entre cidades vizinhas a até milhares de quilômetros nas redes intercontinentais. Estas redes utilizam links em fibra ótica dedicada, com capacidade atual de tráfego na ordem de centenas de Gbit/s.

As redes LAN fornecem a infra-estrutura de comunicações internas nos prédios, empresas e residências. Padronizadas pelo IEEE 802.1 [1] as redes LAN contam com bandas de 10Mbit/s, 100Mbit/s, 1Gbit/s e em fase de padronização 10Gbit/s. Nos últimos anos, o padrão IEEE 802.11[2], conhecido como $\mathrm{WiFi}$, também se tornou um importante padrão propiciando mobilidade para as redes LAN, na versão IEEE 802.11a atende usuários a até 300m com banda máxima de 54Mbit/s.

Por fim, as redes MAN, também conhecidas como redes de acesso ou última milha, compreendem a porção da rede que liga as operadoras de telecomunicações (redes MANs) aos seus assinantes (redes LANs). As redes de acesso foram e ainda continuam sendo o grande gargalo nos sistemas de telecomunicações, principalmente por compreender a porção mais cara tanto na instalação quanto na operação e manutenção.

A utilização de fibras óticas nas redes de acesso, denominada FTTP (fiber to the premises), foi proposta há mais de 20 anos, visando atender ao contínuo aumento na demanda por banda pelos usuários das redes de telecomunicações. Com a padronização das redes óticas de acesso passivas (PON - passive optical network), em particular a GPON (gigabit-capable passive optical network) [3] - [6], que tornaram estas redes viáveis [7], uma nova gama de serviços com necessidades especiais de largura de banda, atraso e jitter (variação do atraso) como, vídeo sob demanda, jogos on-line (já viáveis nas redes DSL (digital subscriber line) e cable, mas melhorados com as redes PON) e IPTV (Internet protocol television) passaram a ser impulsionados. Estes serviços, por sua vez, justificam o investimento nesta nova rede [8]. 
Segundo estimativas [9], a demanda por largura de banda tem crescido por um fator superior a $50 \%$ ao ano, nos últimos anos.

Dentre estes serviços, o IPTV é considerado o de maior apelo comercial por possibilitar que um número maior de canais em alta definição seja entregue aos assinantes quando comparado com os sistemas CATV (community antenna television). Em ambos os sistemas, a banda disponível é limitada, porém, em IPTV, somente os canais assistidos são enviados para os assinantes enquanto que no CATV todos os canais estão sempre presentes no STB (set top box) (ocupando banda da rede).

Tanto na compressão em MPEG-2 (Moving Picture Experts Group) [10] quanto em MPEG-4 [11], a qualidade do vídeo entregue é função de alguns fatores como, codec utilizado, taxa de compressão, banda ocupada (quanto maior a compressão, menor a banda e menor a qualidade) e da diversidade da imagem (vídeos com maiores ou menores frequências espaciais e temporais). De forma genérica, executando ajustes nas tabelas de quantização, os codificadores usados nos sistemas de TV digital, entregam o vídeo com uma banda constante, alterando constantemente a qualidade da imagem. Por este motivo, vídeos de alta frequência, por exemplo, cachoeiras ou shows com luzes piscando, têm sua qualidade degradada ao ponto de percebermos a quadriculação causada pelos blocos de compressão. Diferente dos sistemas de CATV que possuem banda passante constante por canal [12], em IPTV a banda pode ser adaptada à necessidade do canal em tempo real, o que significa que o codificador pode possuir certa flexibilidade no corte da banda de saída evitando quedas muito acentuadas na qualidade do vídeo.

Outra característica importante do IPTV é que os canais podem trafegar por praticamente qualquer rede que aceite os protocolos IP. Desta forma, os assinantes podem assistir aos canais não apenas em um aparelho de televisão ligado a um STB, mas também em computadores, PDAs (personal digital assistants) e telefones celulares.

Por outro lado, o grande inconveniente dos sistemas que provêem TV digital, que é acentuado nos sistemas IPTV, é o tempo necessário para a troca de canal (channel zapping delay). Como foi mostrado em [14] este atraso pode chegar a 10 segundos enquanto que o limite empírico considerado aceitável é abaixo de 2 segundos. Este atraso é composto por um conjunto de atrasos 
que podem ser agrupados em três grupos: os atrasos da rede, o atraso de buffer de dejittering ${ }^{1}$ e o atraso de descompressão causado pelo aguardo de um quadro âncora "I" [15].

A fim de resolver este problema, algumas propostas têm sido defendidas. Por exemplo, em [16] é proposto um sistema limitado a 100 canais de $10 \mathrm{Mbit} / \mathrm{s}$ cada totalizando um stream de $1 \mathrm{Gbit} / \mathrm{s}$ que deve ser transportado na íntegra até o STB. Segundo o sistema proposto é possível selecionar o canal em 10ms, porém atrasos por buffer e descompressão não foram levados em conta. Este processo tem grande custo de banda da rede, e não apresenta vantagens significativas sobre os sistemas atuais de CATV.

Procurando encontrar uma forma inovadora que permita um atraso abaixo de 2 segundos com um crescimento reduzido da banda necessária para IPTV por assinante, estamos propondo neste trabalho um processo de codificação e transmissão de IPTV em redes GPON que reduz o tempo de zapping, iniciando com imagens de baixa resolução, no instante da mudança do canal, que melhora a qualidade progressivamente no decorrer dos primeiros segundos. No momento da mudança de canal, o assinante pretende decidir, o mais breve possível, se permanecerá no novo canal ou não. Para este fim, uma imagem de vídeo de baixa qualidade, pode resolver o problema. Uma vez que o assinante permaneça no canal, a qualidade deve aumentar para a máxima limitada por seu sistema.

A proposta está baseada na codificação escalável em SNR (signal noise ratio) do padrão MPEG2 e pode ser portado para os padrões de codificação FGS (fine grain scalability) do MPEG-4 [17] [18]. O codificador de vídeo proposto gera, para cada canal, quatro fluxos de vídeo complementares, o primeiro com a imagem em baixa resolução. Somando o segundo fluxo ao primeiro, a qualidade melhora, e assim sucessivamente até atingir a melhor qualidade com a soma dos quatro fluxos. Cada um destes fluxos é transportado do servidor de vídeo até o assinante usando os protocolos multicast IP e as características multicast e filtros do GPON.

O Transporte de vídeos escaláveis nas redes IP é empregado atualmente com a finalidade de melhorar a qualidade em caso de perda de pacotes [19] - [23]. Neste documento é defendido que além desta melhoria na qualidade, o STB pode antecipar o próximo canal a ser assistido pelo

\footnotetext{
${ }^{1}$ Buffer de Dejittering é uma fila do tipo FIFO (First In First Out) onde um número de quadros é armazenado antes do inicio da exibição, com a finalidade de evitar interrupções na exibição da imagem, caso um quadro demore um pouco mais para chegar ao STB do que os outros, fenômeno conhecido como Jitter da rede.
} 
assinante e solicitar este canal em baixa resolução. Desta forma, quando o assinante comandar a mudança do canal, ele já estará disponível em baixa resolução podendo ser exibido no próximo quadro. $\mathrm{O}$ assinante poderá, então, decidir se permanece ou não neste canal e, enquanto isto, o STB solicita os fluxos complementares do canal para que ele passe para a máxima resolução.

Esta dissertação está organizada da seguinte forma: no capítulo 2 é apresentada a rede GPON, que constitui a infra-estrutura de transporte para o sistema, nele é mostrado como o GPON funciona, como os fluxos, tanto unicast quanto multicast, são criados e qual a vantagem de se usar IPTV no GPON no lugar de sistemas convencionais de CATV. No capítulo 3 são apresentados os conceitos de IPTV, incluindo o processo de codificação MPEG-2 que será usado como base para a proposta. Tanto no capítulo 2 quanto no capítulo 3 é exposto o estado atual das tecnologias GPON e IPTV. No capítulo 4 a proposta do novo sistema de codificação e transporte é apresentada, discutindo como ele é feito, quais as vantagens e dificuldades deste novo sistema. No capítulo 5 são apresentados os resultados dos testes executados usando este novo sistema provando sua eficiência na melhoria do tempo de zapping em sistemas IPTV sobre GPON. Por fim, no capítulo 6 é apresentada uma conclusão do trabalho, juntamente com sugestões para trabalhos futuros sobre o assunto. 


\section{CAPÍTULO 2 - AS REDES GPON}

Neste capítulo é feito o embasamento teórico referente às redes de acesso GPON. Inicialmente é feita uma descrição da rede em comparação com outras tecnologias de acesso, tanto em cabo metálico (HFC (hybrid fiber-coaxial) e DSL) quanto em fibra ótica (AE (advanced Ethernet) e EPON (Ethernet passive optical network)). Por fim, é abordada a criação de fluxos de serviços no sistema GPON, tanto unicast quanto multicast e as duas formas de prover o serviço de TV usando esta rede.

\subsection{CONCEITOS BÁSICOS}

A utilização de FTTP atende a uma série de requisitos para a evolução das redes de acesso, quando comparado com outras tecnologias [24] como HFC e xDSL (variações de digital subscriber line). Dentre os diversos requisitos, os que mais se destacam são:

- Capacidade potencial de Gbit/s por distâncias de até dezenas de quilômetros;

- Facilidade de instalação e atualização;

- Possibilidade de serviços simétricos;

- Baixo custo de operação e manutenção, confiabilidade, imunidade a interferências eletromagnéticas;

- Cabos mais leves e mais compactos;

- Oferecer serviços triple-play (voz, vídeo e dados), o que implica em um controle robusto de qualidade de serviço;

- Atender a clientes variados (residências, condomínios, empresas) compartilhando a mesma infra-estrutura, cada qual com seus requisitos no que tange à relação custo por qualidade de serviço;

- Instalação de equipamentos em ambiente não controlado (fora de estações). Elementos intermediários na rede devem ser, sempre que possível, passivos;

- Exigência de baixo custo (infra-estrutura de rede compartilhada entre usuários) e

- Expectativa de alta confiabilidade dos serviços pelo cliente. 
Entretanto, até recentemente os equipamentos necessários para a implantação desta tecnologia apresentavam custos superiores aos de outras tecnologias e a demanda por banda não era suficiente para justificar o investimento nesta tecnologia [8].

O gráfico da Figura 1 mostra uma comparação da largura de banda, entre os principais tipos de rede de acesso, na relação banda por distância entre a central e o assinante. Observe que, para curtas distância (abaixo de 10km) as redes óticas possuem a banda constante.

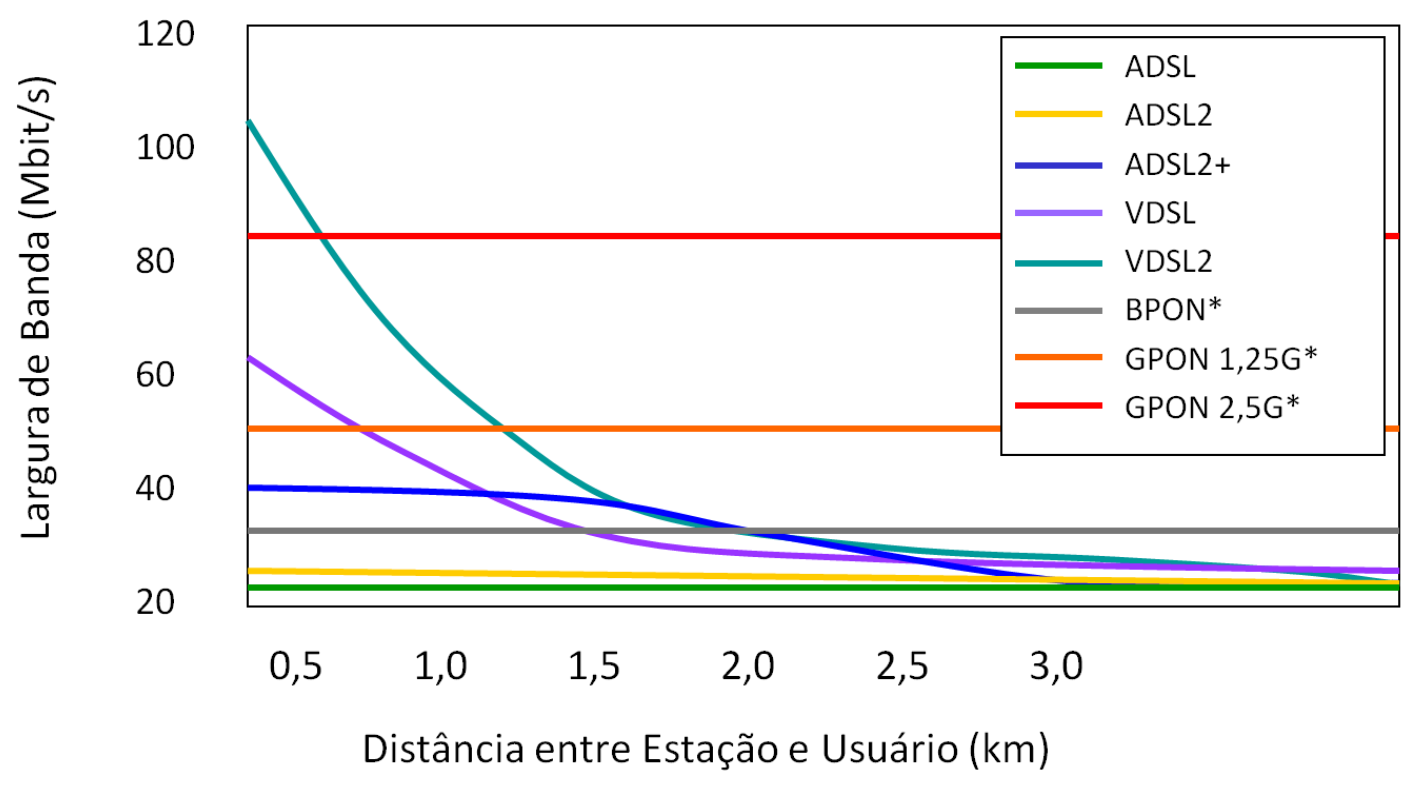

Figura 1 - Comparação entre as diversas redes de acesso na relação banda por distância. 32 usuários por link As redes HFCs, largamente empregadas nos sistemas de CATV, são bastante eficientes na transmissão dos canais de TV em broadcast para os assinantes, porém, o canal de subida possui uma taxa de 39Mbit/s por banda de 6MHz para modulação 64QAM (quadrature amplitude modulation). Esta banda é compartilhada entre os assinantes que são atendidos pelo mesmo cabo. Estas redes também necessitam de vários estágios de amplificação nos cabos metálicos, o que aumenta os custos de implantação e manutenção, além de aumentar o nível de ruído no canal de subida, reduzindo a banda para $27 \mathrm{Mbit} / \mathrm{s}$ por $6 \mathrm{MHz}$.

O ADSL2+ (asymmetric digital subscriber line), largamente empregado pelas empresas de telecomunicações que possuem par metálico como rede de acesso, atinge uma banda máxima de descida de 24Mbit/s e 1Mbit/s para subida, com um alcance máximo de $1 \mathrm{~km}$. Com o aumento da distância entre a central e o assinante e com a redução da qualidade dos cabos instalados 
(exemplo: unidade, grande número de emendas e interferências eletromagnéticas) a taxa cai significativamente.

Das três arquiteturas básicas de redes óticas de acesso, ponto-a-ponto, estrela passiva e pontomultiponto [24], mostradas na Figura 2, a grande maioria das redes de acesso sendo instaladas são ponto-multiponto ou redes óticas passivas PON (letra c da Figura 2), em função da redução nos custos de operação e manutenção quando comparado com as outras arquiteturas.

A arquitetura ponto-multiponto usa um ou mais níveis de acopladores ópticos passivos para distribuir o sinal aos clientes.

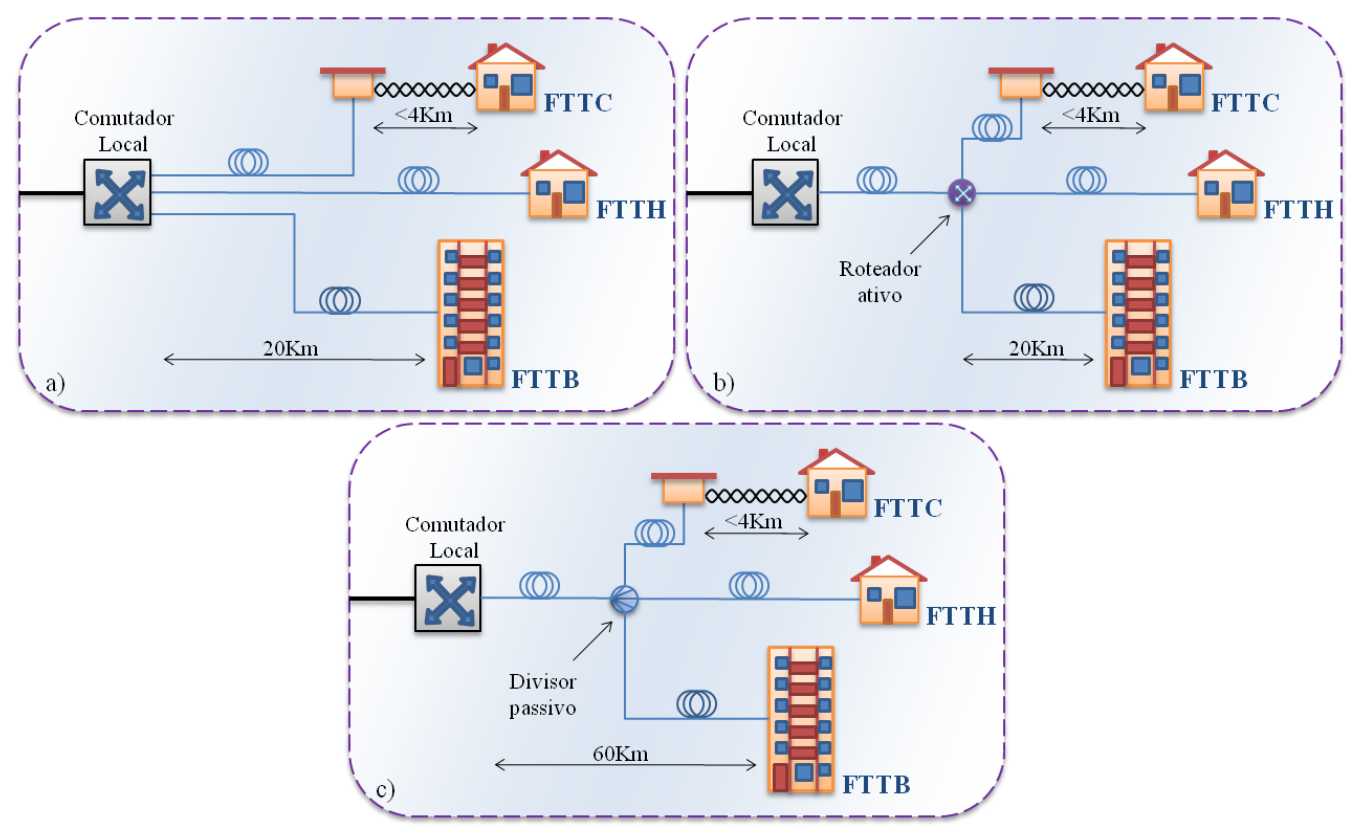

Figura 2 - Comparação entre as três tecnologias de acesso, a) acesso ponto-a-ponto, b) acesso pontomultiponto com nó ativo e c) acesso ponto-multiponto com nó passive (PON)

Para o tráfego de descida, o comutador local, neste caso uma OLT (optical line termination), possui um conjunto de portas, cada qual alocada em uma fração de tempo para cada frame conforme Figura 3. As ONUs (optical network unit) são programadas para filtrar todas as portas que não pertençam a ela, entregando ao assinante, apenas o tráfego que lhe pertence. Para garantir o sigilo, o tráfego de descida é criptografado. No cabeçalho GEM (GPON encapsulation method), que é o método de controle da camada física da rede GPON, a OLT define quando cada ONU poderá transmitir - esta multiplexação no tempo (TDMA - time division multiple access) evita colisões nos acopladores ópticos. 


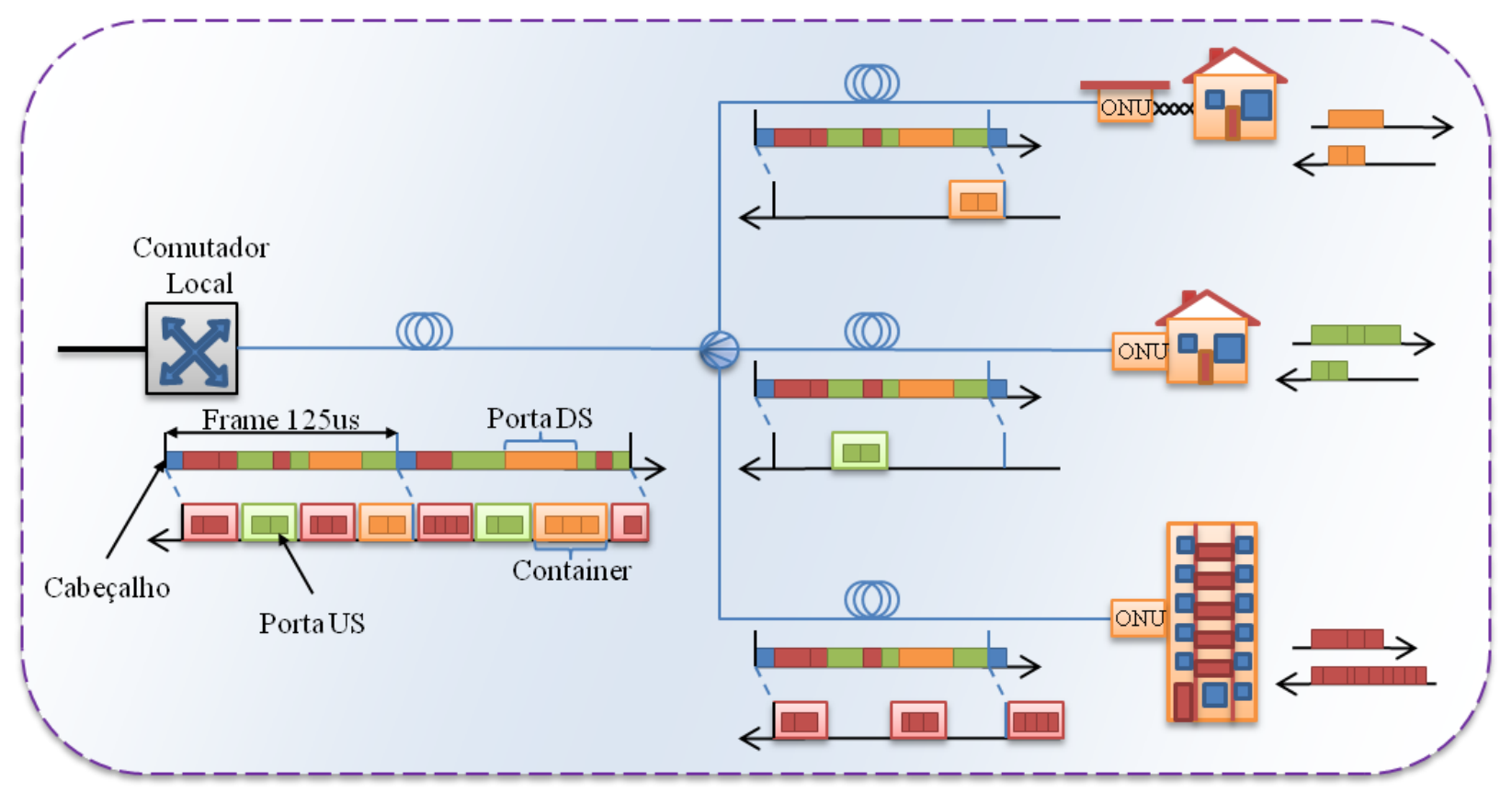

Figura 3 - Multiplexação no tempo (TDMA) dos dados na rede PON evitando colisão nos acopladores ópticos para o tráfego de subida e distribuindo corretamente o tráfego de descida

Existem duas tecnologias de redes óticas passivas sendo instaladas: PON com capacidade de gigabit, GPON, padronizada pela ITU-T G.984 e Ethernet PON, EPON, padronizada pela IEEE 802.34h. O padrão GPON foi desenvolvido pelas operadoras de telecomunicações e oferece algumas vantagens técnicas sobre o EPON, como maiores taxas de tráfego descendente e ascendente, maior eficiência de banda, maior variedade de serviços, suporte a OAM (operation, administration and maintenance) e serviços TDM (time division multiplexing). Entretanto, o padrão EPON apresenta custos menores e é uma tecnologia em estágio de maturidade mais adiantado do que a tecnologia GPON. A Tabela 1 traz uma comparação entre estas duas tecnologias.

Muitos países estão realizando testes de campo e instalações de produtos de acesso ópticos lançados recentemente [25], sendo que em 2010 o número de usuários conectados por fibra no mundo já ultrapassa 30 milhões. No Japão, a maior parte das implantações, cerca de 10 milhões, usam EPON, com bandas oferecidas entre 1,5 e $40 \mathrm{Mb} / \mathrm{s}$ [26]. Nos Estados Unidos e na Europa, a maior parte das operadoras selecionou a tecnologia GPON para suas redes FTTP [27]. 
Tabela 1 - Comparação entre os padrões GPON e EPON empregados em redes PON atuais.

\begin{tabular}{|c|c|c|}
\hline Característica & EPON (GEPON) & GPON \\
\hline Taxa de descida & $1 \mathrm{Gbit} / \mathrm{s}$ & 1,25 a $2,5 \mathrm{Gbit} / \mathrm{s}$ \\
\hline Taxa de subida & $1 \mathrm{Gbit} / \mathrm{s}$ & $155 \mathrm{Mbit} / \mathrm{s}$ a $1,25 \mathrm{Gbit} / \mathrm{s}$ \\
\hline Voz & $\begin{array}{c}\text { VoIP (CES - circuit emulation } \\
\text { service })\end{array}$ & VoIP (CES) ou VoTDM \\
\hline Vídeo & Vídeo IP & Vídeo RF e/ou Vídeo IP \\
\hline Outros & -- & TDM (T1/E1, OC-3) \\
\hline QoS (quality of service) & Ethernet (VLAN) & GEM (Ethernet/IP, TDM) \\
\hline $\begin{array}{l}\text { Eficiência de uso da largura de } \\
\text { banda* }\end{array}$ & $70 \%$ & $93 \%$ \\
\hline Número de usuários & 16 ou 32 por fibra & 32,64 ou 128 por fibra \\
\hline Alcance máximo & $20 \mathrm{~km}$ & $\begin{array}{l}60 \mathrm{~km} \text {, com diferença lógica } \\
\text { máxima de } 20 \mathrm{~km} \text { entre a ONU } \\
\text { mais próxima e a mais distante }\end{array}$ \\
\hline Banda média por usuário** & $\begin{array}{l}24 \mathrm{Mbit} / \mathrm{s} \text { (DS) } \\
18 \mathrm{Mbit} / \mathrm{s} \text { (US) }\end{array}$ & $\begin{array}{l}73 \mathrm{Mbit} / \mathrm{s} \text { (DS) } \\
35 \mathrm{Mbit} / \mathrm{s} \text { (US) }\end{array}$ \\
\hline Segurança na descida & Aberto & $\begin{array}{c}\text { AES (advanced encryption } \\
\text { standard })\end{array}$ \\
\hline OAM & Ethernet OAM & $\begin{array}{c}\text { PLOAM (physical layer OAM) + } \\
\text { OMCI }(\text { ONU management and } \\
\text { control interface })\end{array}$ \\
\hline
\end{tabular}

* valor aproximado com variação entre subida e descida;

** assumindo 32 usuários por link; DS - downstream; US - upstream.

Em novembro de 2005, três grandes operadoras de telecomunicações norte-americanas, Verizon, Bell South e SBC Communications (as duas últimas recentemente unidas e renomeadas AT\&T) lançaram um edital para a instalação de redes GPON. Em abril de 2007, já havia um milhão e trezentos mil de usuários FTTH (fiber to the home), sendo metade destes com a Verizon [28]. No Brasil algumas operadoras estão realizando testes de campo da tecnologia GPON e desde 2008 planejam a instalação de centenas de milhares de usuários [29]. 


\subsection{OS FLUXOS DE SERVIÇOS NAS REDES GPON}

Os sistemas GPON são compostos por, no mínimo, uma OLT, uma ONU e um switch de camada 2 que são os blocos em azul escuro mostrados na Figura 4.

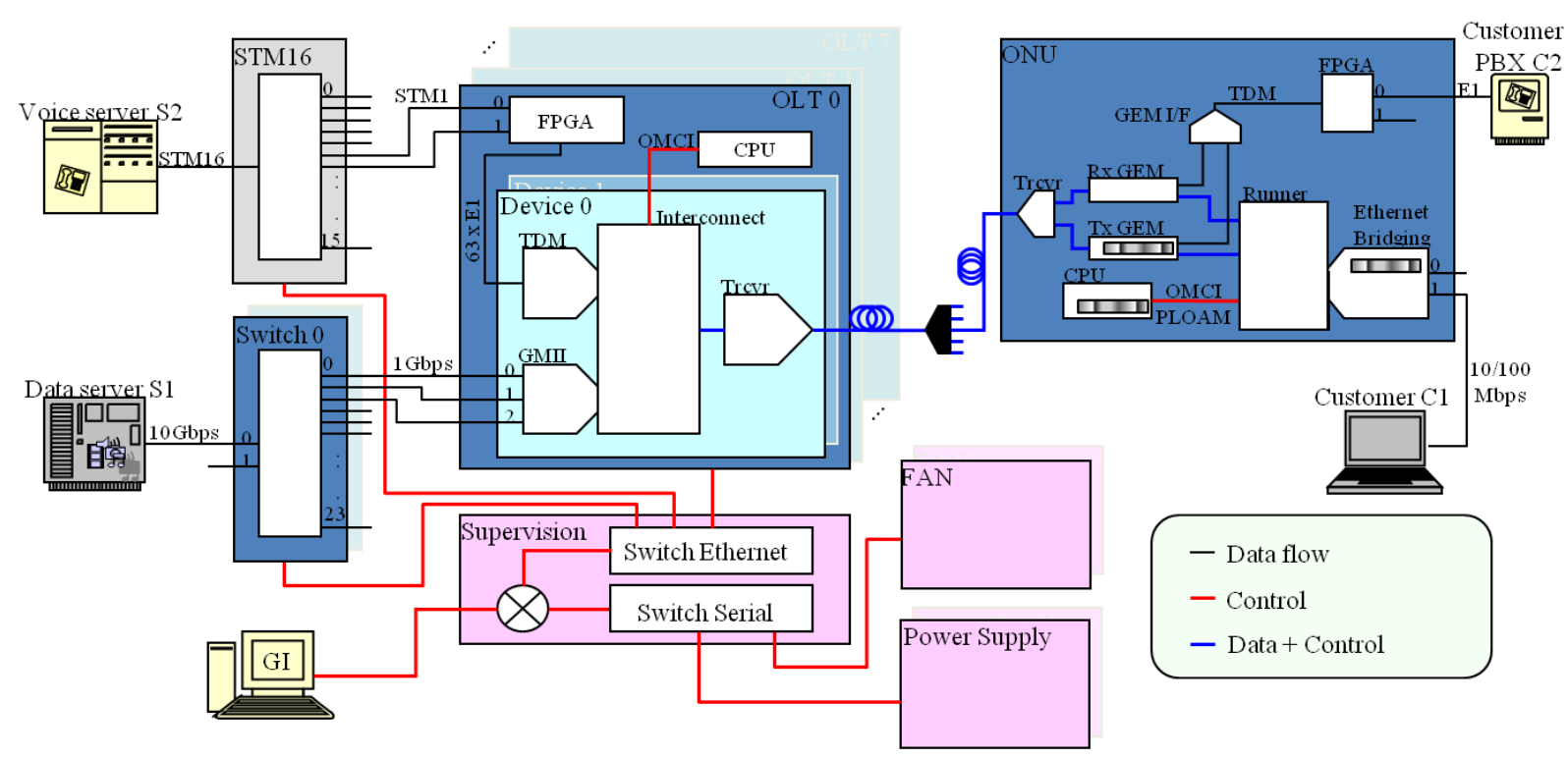

Figura 4 - Composição mínima de um sistema GPON, com um Switch, uma OLT e uma ONU

\subsubsection{Fluxo de descida}

O estabelecimento do fluxo de descida pode ser feito totalmente independente do fluxo de subida, neste caso, supondo que um pacote seja transmitido do servidor S1 para o cliente C1, empregando encaminhamento por VLAN (virtual local area network) [30]. O operador deve estabelecer o fluxo tanto físico (Figura 5) quanto lógico (Figura 6) para esta conexão.

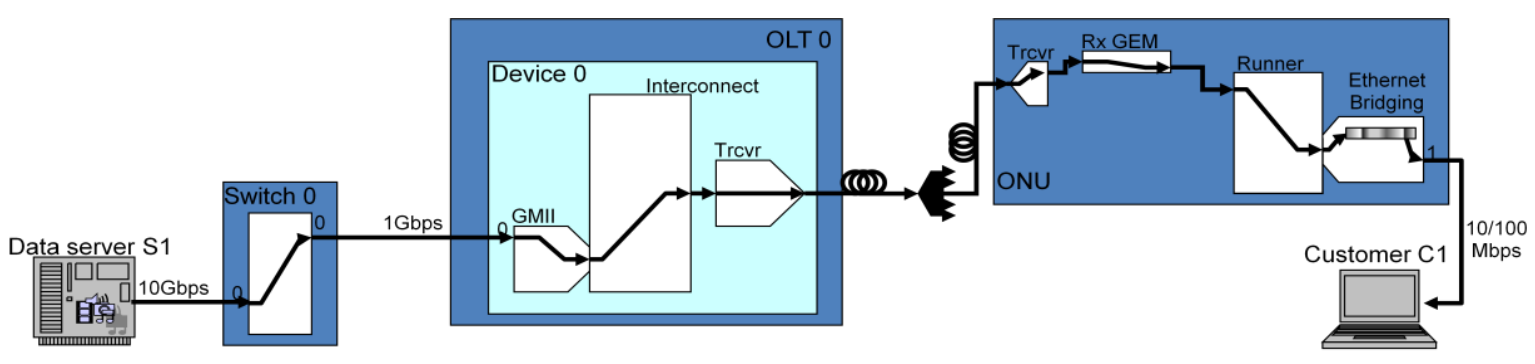

Figura 5 - Conexão física para fluxo de dados de descida do servidor S1 para o cliente C1

No switch 0 uma VLAN deve criar o caminho entre a porta física de entrada (onde o servidor está conectado), com a porta física de saída (onde a OLT está conectada). A OLT pode contar com uma ou mais portas Ethernet de entrada (portas GMII - gigabit media independent 
interface), quando existe mais de uma elas são concatenadas e, por isto, independente de qual porta de estrada seja usada, os fluxos serão encaminhados para o Interconnect, que é responsável pela operação lógica e será detalhado a seguir. Por fim os dados são enviados para o transceiver óptico, que transmite efetivamente os bits para a ONU.

Na ONU, após a conversão dos bits de óptico para elétrico no transceiver, o RxGEM (receive GPON encapsulation method), identificando que é um pacote Ethernet, chaveia o frame GEM para o Runner que possui um caminho pré-programado entre a sua porta física de entrada a de saída (no caso da Figura 4 Eth0 ou Eth1). Cada porta física possui um conjunto de filas de prioridades, cada porta de saída do Runner deve ser conectado a uma das filas do bloco Priority.

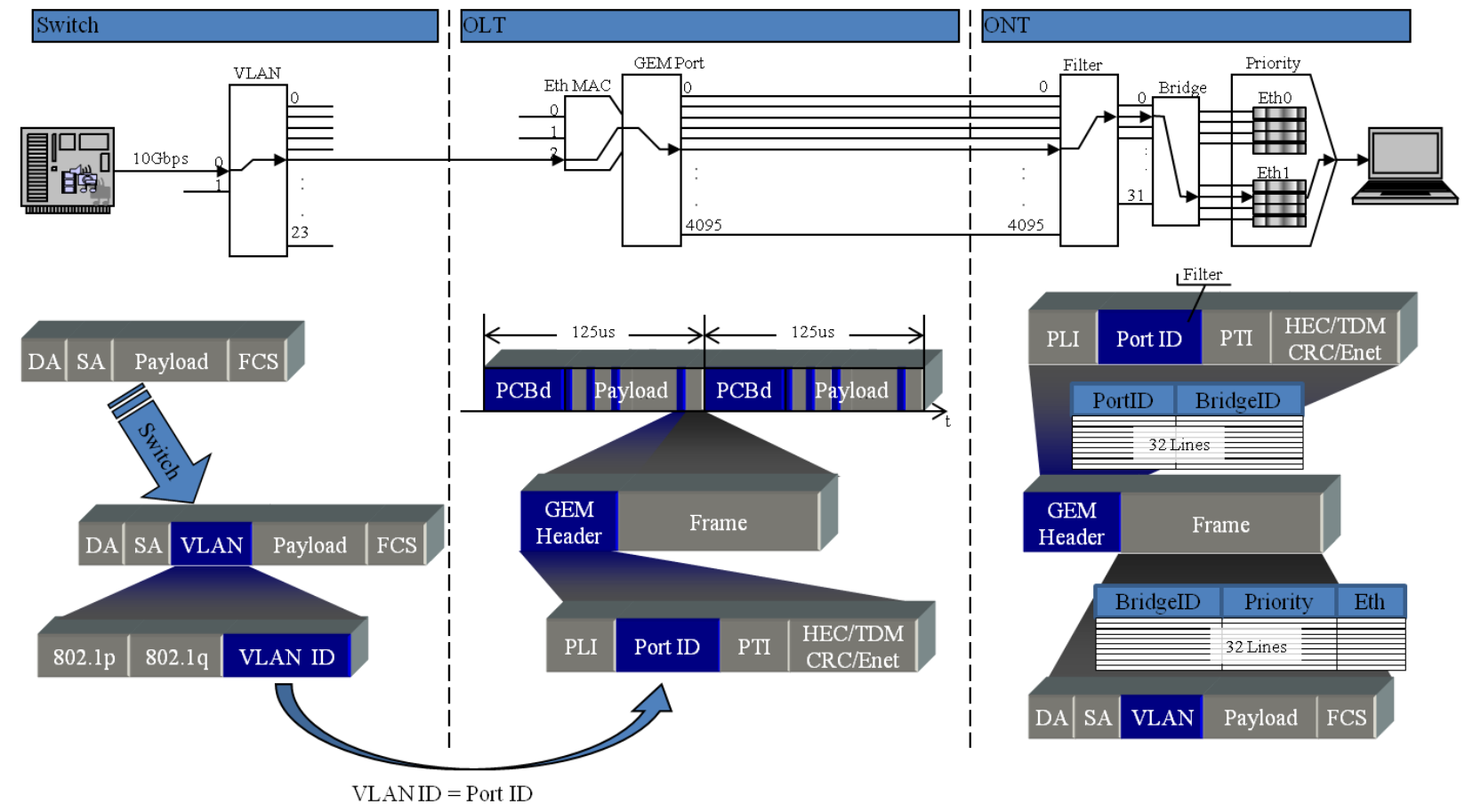

Figura 6 - Conexão lógica para fluxo de dados de descida do servidor S1 para o cliente C1

A conexão lógica de descida inicia no switch que, usando uma programação prévia, identifica o destino do pacote e introduz o tag VLANID (virtual local area network identification). A escolha da VLAN pelo switch é, normalmente, feita por MAC (media access control) de destino em camada 2, ou por IP de destino em camada 3. No bloco Interconnect da OLT, o frame Ethernet é empacotado em um frame GEM. Por padrão, o número da porta lógica usada para este fluxo, ou seja, o PortID (port identification), é o mesmo do VLANID como mostra a Figura 6. 
A ONU recebe o frame com todas as portas, um filtro na entrada é programado para que ela deixe passar apenas as portas cujo PortID lhe pertença. Na ONU exemplificada na Figura 4, o Runner é do tipo bridge, ou seja, os dados serão encaminhados da entrada para a saída sem processamentos de camadas mais elevadas. Uma tabela faz a relação entre o PortID e a porta de entrada da Bridge e outra tabela faz a relação entre a porta de entrada e de saída da Bridge. Na saída Ethernet da ONU o tag VALNID pode ou não ser retirado, dependendo da programação. Além disto, um conjunto de filas pode ser usado para classificação dos pacotes.

\subsubsection{Fluxo de subida}

No sentido oposto, também é necessário o estabelecimento de uma rota física e uma lógica.

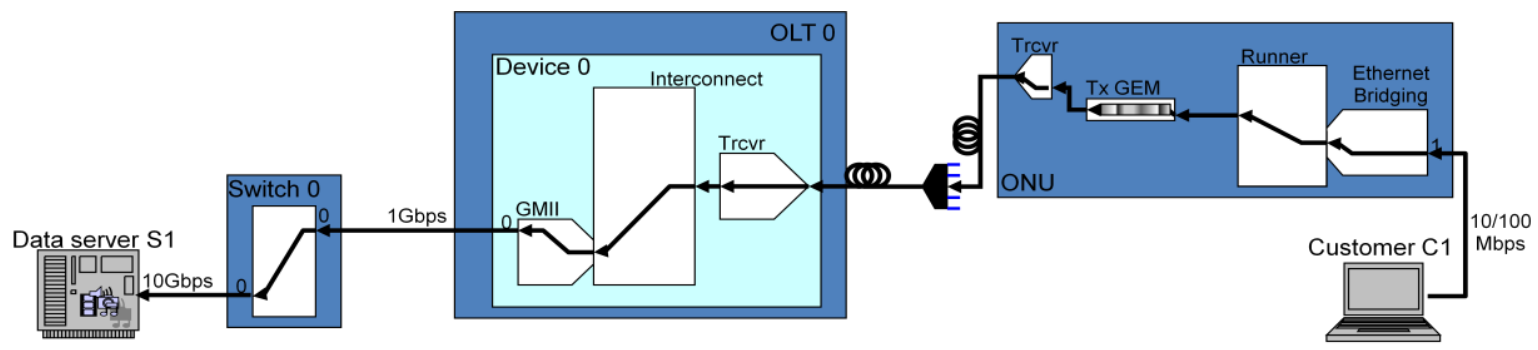

Figura 7 - Conexão física para fluxo de dados de subida do cliente C1 para o Servidor S1

Conforme esquema da Figura 7 os dados entram na ONU via porta Ethernet, neste caso ele é encaminhado para o Runner e dele para o TxGEM (transceiver GPON encapsulation method). $\mathrm{O}$ transceiver converte de elétrico para óptico e transmite pela fibra ótica. Todas as ONUs de um link estão ligadas no mesmo receptor da OLT através de divisores ópticos. A colisão é evitada logicamente por divisão no tempo (TDMA). No Interconnect os frames são chaveados para a porta Ethernet correta de saída. No Switch o caminho físico de subida é o mesmo programado para a descida.

Pelo endereço MAC de destino do frame que chegou pela Ethernet em uma ONU (Figura 8), a Bridge sabe para qual porta lógica este frame deve ser enviado e, consequentemente, para qual PortID. Diferente do tráfego de descida, o tráfego de subida não é realizado diretamente em portas, mas sim em contêineres.

Os contêineres são entidades que agregam portas. Uma tabela na ONU identifica para cada porta, a qual contêiner ela pertence e qual fila de prioridade ela deve usar. Todo o controle de QoS 
(quality of service) do tráfego de subida no sistema GPON é feito por contêiner, então, duas portas que ocupam o mesmo contêiner possuem o mesmo QoS, as portas apenas definem sua prioridade de entrada no contêiner.

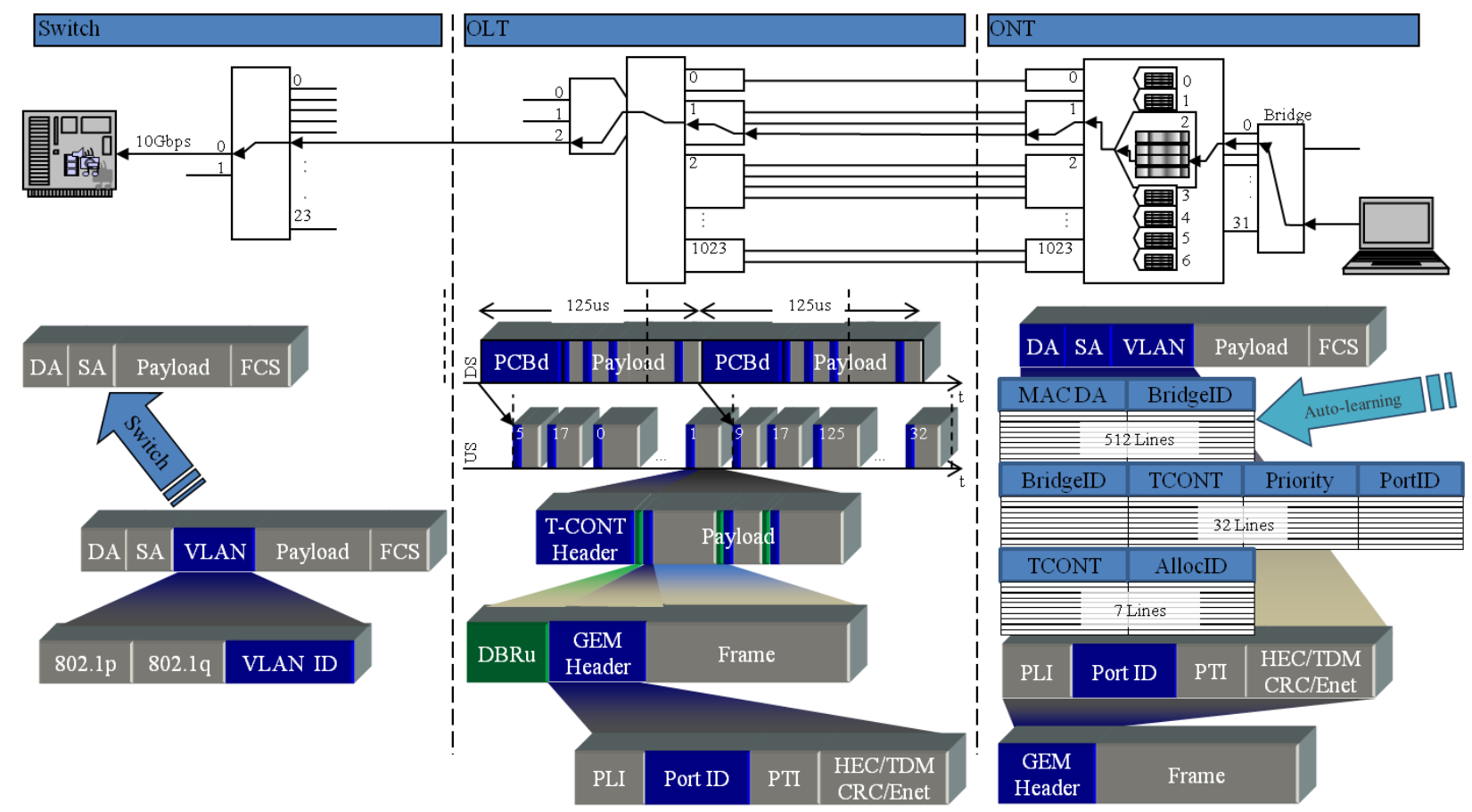

Figura 8 - Conexão lógica para fluxo de dados de subida do cliente C1 para o Servidor S1

Chegando à OLT os contêineres são abertos e os frames voltam a ser encaminhados por portas. O Interconnect retira o frame Ethernet de dentro do frame GEM e o encaminha para a porta Ethernet correta de saída da OLT. Quando necessário o switch usa o tag VLANID e o retira, ou não, antes de encaminhar os dados para o servidor S1. As referências [3] - [6] apresentam uma explicação detalhada sobre o estabelecimento de fluxos nos sistema GPON.

\subsubsection{Fluxo Multicast}

É possível observar no item 2.2.1 que em momento algum durante o fluxo de descida a OLT informa qual ONU deve receber os pacotes, existe uma relação indireta, onde a OLT informa qual a Porta de um fluxo e informa à ONU quais as Portas que devem ser filtradas e quais devem ser repassadas para o assinante. Neste caso, duas ou mais ONUs podem ser programadas para receber o fluxo de uma mesma porta, como é mostrado na Figura 9, onde as três ONUs possuem a Porta 03 em suas tabelas de repasse. Neste caso, a Porta 3 está enviando em multicast para as três ONUs. 


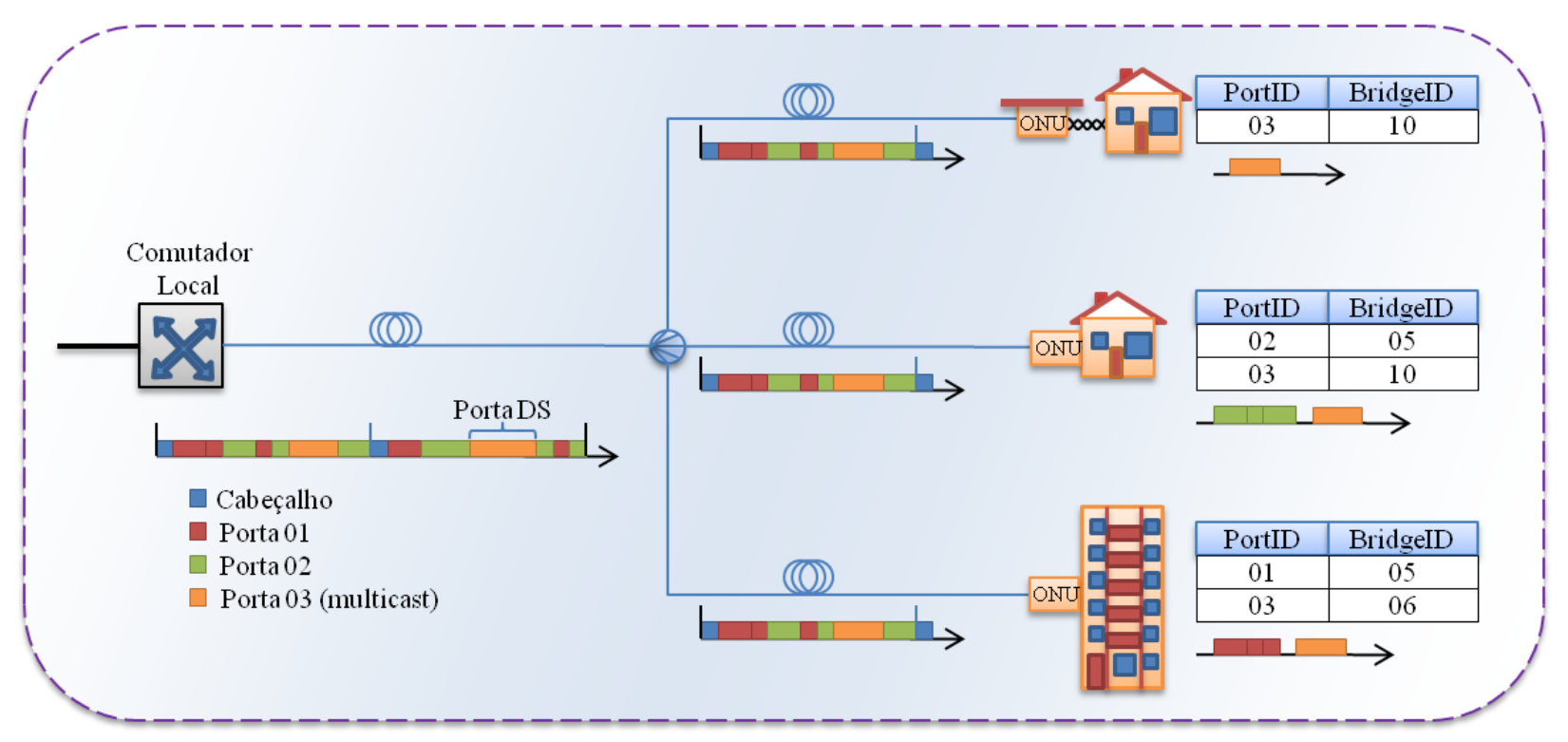

Figura 9 - Fluxo multicast de descida, as 3 ONUs recebem o conteúdo da porta 03

Uma vez que no sistema GPON, os fluxos de descida são criptografados usando o número serial da ONU, não é possível usar criptografia em fluxos multicast. Portanto, qualquer segurança necessária deve ser feita nas camadas superiores pelo provedor do serviço que trafega na forma multicast.

\subsection{TRANSMISSÃO DE TV EM SISTEMAS GPON}

Uma vez que as operadoras de telefonia ainda não conseguiram se posicionar como provedoras de serviços triple-play ${ }^{2}$ (devido ao sinal de vídeo, uma vez que elas já lideram nos serviços de voz e dados), prover vídeo se tornou a aplicação chave que deve justificar a adoção das redes GPON. O vídeo pode ser sob demanda, neste caso é estabelecida uma comunicação ponto-aponto entre o provedor de vídeo e o assinante. Ou em broadcast, neste caso o provedor estabelece uma comunicação ponto-multiponto com os diversos assinantes que estão assistindo ao vídeo [31].

Observe na Figura 10 que no $\mathrm{VoD}$ (video on demand), mesmo que os assinantes estejam assistindo ao mesmo vídeo e no mesmo momento, estes são enviados separadamente, ocupando banda para cada assinante, já o vídeo broadcast é enviado em um único fluxo ocupando uma

\footnotetext{
${ }^{2}$ Serviços triple-play: É o conjunto de serviços de telecomunicações composto por telefonia, dados e vídeo, neste caso o vídeo pode ser sob demanda, em broadcast ou ambos.
} 
única banda. O VoD tem sua aplicação para serviços onde o assinante deseja ter total controle sobre a escolha do conteúdo e o momento em que este será exibido. Já os serviços broadcast devem ser adotados na substituição dos sistemas CATV, onde o conteúdo e o momento de sua exibição em cada um dos canais são ditados pela operadora e o assinante apenas decide o canal ao qual vai assistir em cada momento.

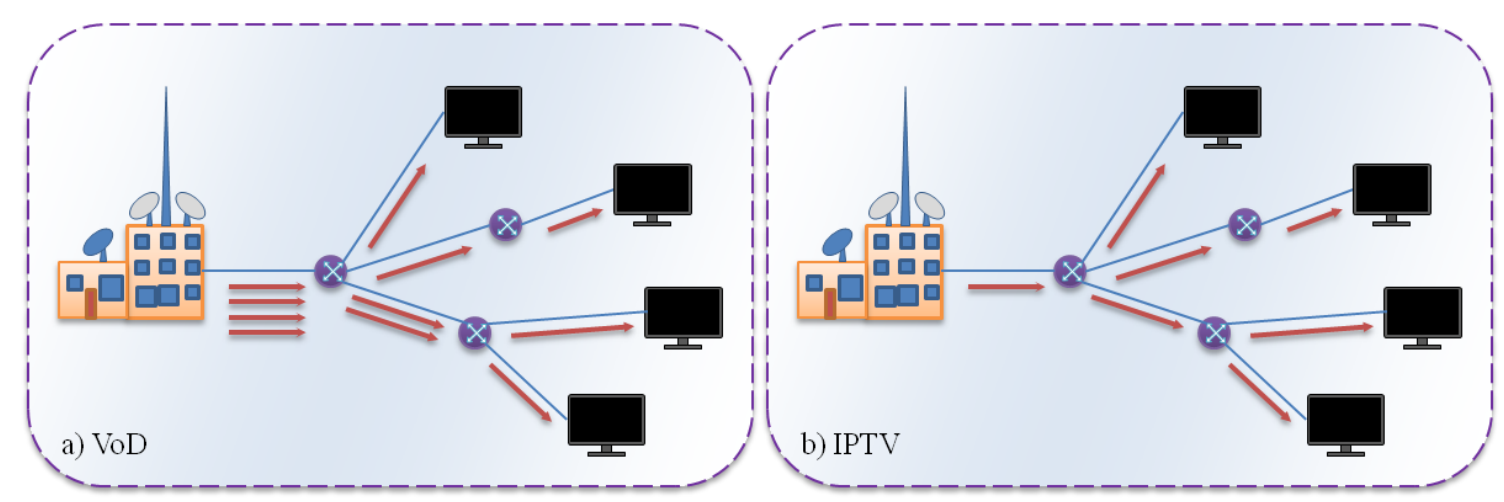

Figura 10 - Comparação da utilização da banda por sistema VoD e Broadcast. Em VoD cada assinante ocupa um fluxo independente de vários assinantes estarem assistindo ao mesmo vídeo ou não. Em IPTV (broadcast) um único fluxo atende a todos os assinantes que estão assistindo ao mesmo canal.

Dois sistemas de transmissão de vídeo foram previstos na norma GPON, o Radio Frequency Overlay ou Video Overlay onde o canal de vídeo é transportado na mesma rede PON, porém em um comprimento de onda diferente do GPON; e o IP Video (IPTV) onde o canal de vídeo é codificado e empacotado usando IP que é transmitido via GPON. Estes dois sistemas serão detalhados a seguir.

\subsubsection{Video Overlay}

Este sistema foi pensado para prover o serviço semelhante ao CATV, porém usando uma rede PON, ele transporta tanto vídeo analógico quanto vídeos digitais SDTV (standard television) e HDTV (high-definition television), todos em broadcasting. VoD pode ser transportado em Video Overlay também, porém não é o mais adequado.

A grande vantagem deste sistema é que as operadoras de CATV podem utilizá-lo sem ter que executar grandes alterações em seus Headend. Do ponto de vista do assinante, o sistema se comporta como os sistemas convencionais de CATV. Como desvantagem, este sistema possui as mesmas restrições de número de canais e banda por canal que as redes HFC. A Figura 11 mostra um sistema típico de Video Overlay em rede GPON. 


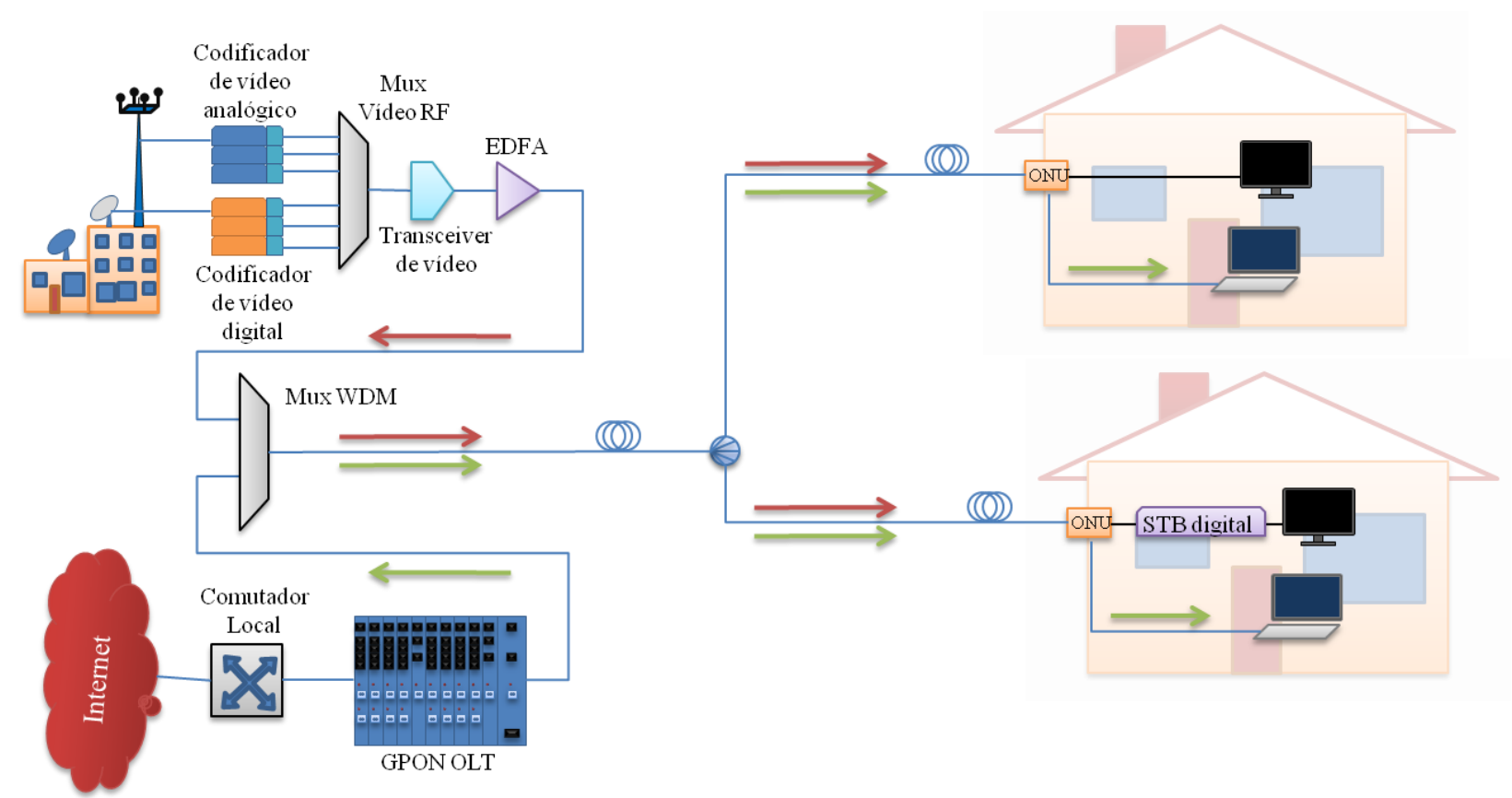

Figura 11 - Exemplo de Video Overlay em sistema GPON

Este modelo usa um headend de vídeo idêntico aos usados em HFC para CATV. O sinal de vídeo é transportado via fibra até o CO (central office) onde um amplificador EDFA (erbiumdoped fiber amplifier) passa o sinal para 1550nm (norma) e amplifica o sinal. Um Mux WDM (wavelength-division multiplexing) combina este comprimento de onda com o de 1490nm gerado pela OLT GPON. Ambos os comprimentos de onda são enviados para as ONUs conectadas à rede PON.

A ONU separa os dois comprimentos de onda. O comprimento de onda destinado ao vídeo, analógico ou digital, é repassado para o conjunto STB/TV que exibirá o vídeo. O comprimento de onda destinado ao GPON é convertido em Ethernet na própria ONU e enviado via rede LAN até o computador do assinante.

Para sinal de vídeo analógico, o cabo coaxial pode sair da ONU e ser conectado diretamente à televisão. No caso de vídeo digital, um STB deve ser empregado a fim de converter o sinal de vídeo em algum padrão aceito pelo equipamento de televisão.

Neste sistema o canal do sistema de TV de subida é feito em 1310nm via GPON. Neste caso, uma conexão entre os dois sistemas pode prover as funcionalidades de interatividade nos canais de televisão. 


\subsubsection{IPTV em sistemas GPON}

Apesar da facilidade de adoção do Video Overlay pelas operadoras que já possuem HFC, o IPTV apresenta a melhor solução de longo prazo para as operadoras que desejam entrar neste mercado por oferecer diferenciais sobre o CATV como, maior flexibilidade de banda por canal e maior número de canais. $\mathrm{O}$ ponto chave é que dados e vídeo usam o mesmo mecanismo de transporte via IP e trafegam sobre a mesma rede e mesmo comprimento de onda na fibra. Um sistema típico de IPTV é mostrado na Figura 12.

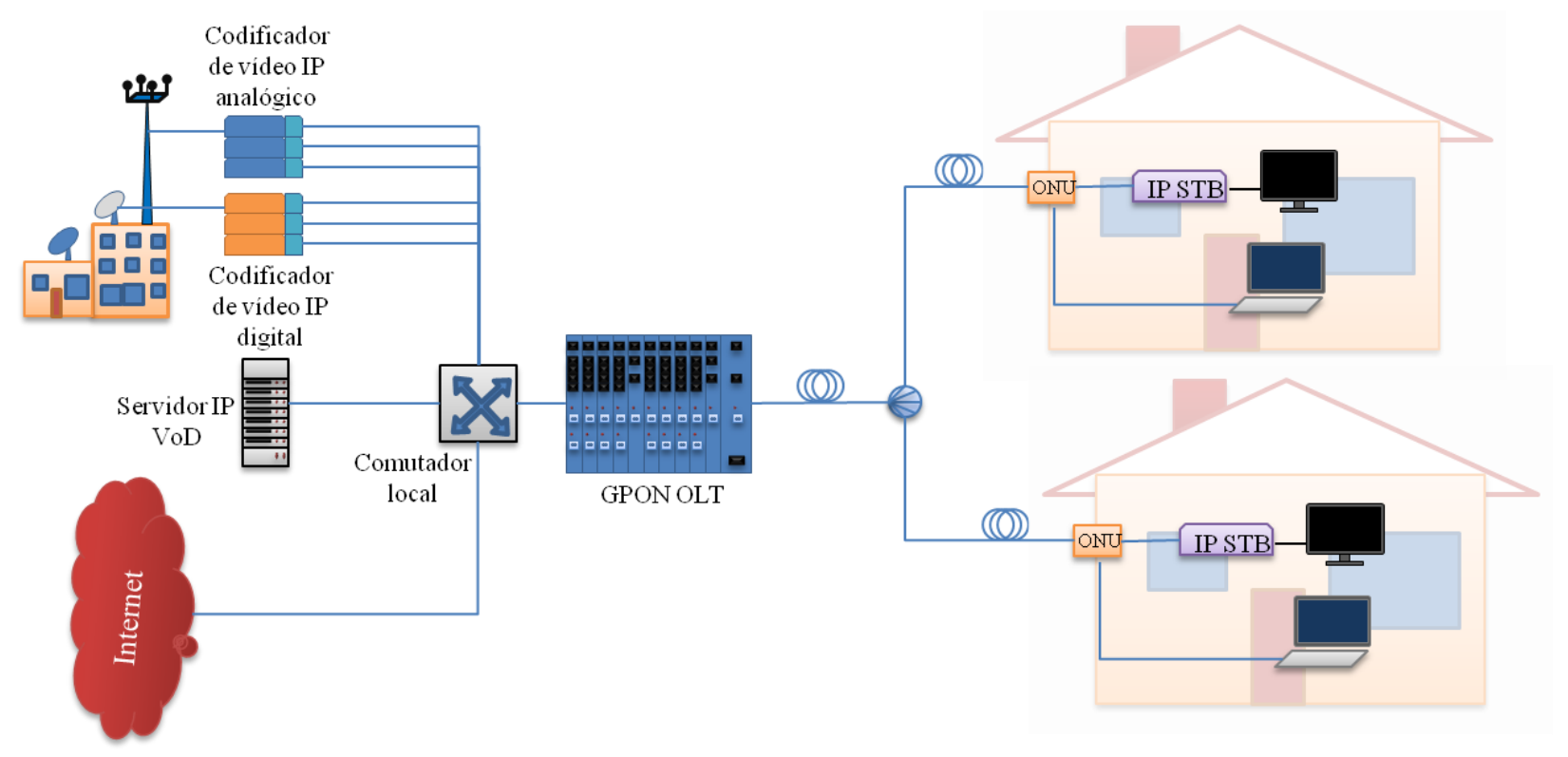

Figura 12 - Exemplo de serviço IPTV em sistema GPON

Neste modelo, é criado um headend IP onde os vídeos, analógicos ou digitais, são convertidos em streams de dados IP. Os canais de vídeo IP são agregados aos dados e aos vídeos gerados pelo sistema de VoD. Como todos são IP, eles trafegam pela mesma rede e são entregues à OLT para que sejam enviados para os assinantes. A OLT prioriza o tráfego e envia para um ou mais assinantes usando os fluxos descritos anteriormente.

$\mathrm{Na}$ residência, após a ONU, todos os pacotes, sejam eles dados ou vídeo, vão para uma rede local. Um STB que decodifica pacotes de vídeo sobre IP, conectado à rede, converte os pacotes de vídeo sobre IP, em sinal de vídeo que será entregue à televisão. 


\section{CAPÍTULO 3 - IPTV}

Como mostrado no capítulo anterior, existem diversas formas de transmitir vídeo para os assinantes de uma rede GPON. Este capítulo tem como foco o sistema IPTV e seu funcionamento. Serão apresentados os principais protocolos que envolvem o transporte de vídeo com ênfase nos que estão diretamente relacionados ao tema deste trabalho. Também será apresentada uma revisão do MPEG-2 e o processo de escalabilidade proposto nele. Por fim será discutido o problema do atraso na mudança de canal e quais as soluções mais recentes que tentam resolvê-lo.

\subsection{VISÃO GERAL DO SISTEMA IPTV}

IPTV é o nome dado ao sistema que provê um conjunto de canais de televisão, no mesmo formato dos sistemas CATV, porém empregando redes de dados baseadas no protocolo IP. Do ponto de vista do assinante, o serviço IPTV deve se comportar como o CATV, ou seja, ele deseja ter um conjunto de canais, que pode assistir trocando-os por meio de um controle remoto. Funções como 'pausa', 'avanço', 'recuo', 'iniciar' e 'finalizar' um filme não fazem parte do escopo de IPTV, elas se encaixam em outros serviços que completam o IPTV como o VoD.

As grandes vantagens do IPTV sobre o CATV para o assinante são, o aumento do número de canais, que teoricamente pode ser infinito, a melhora da qualidade de vídeo dos canais devido a flexibilidade da banda, suportando inclusive vídeos estéreos para exibição em 3D ou qualidades superiores a Full HD para expansão futura, além de ser mais adequada para serviços interativos.

$\mathrm{Na}$ rede de acesso, os sistemas CATV empregam o envio dos canais em broadcast e o canal escolhido é decodificado somente no STB. No sistema IPTV, somente o canal assistido é entregue ao assinante, todos os outros são filtrados em camadas superiores da rede, normalmente um roteador com capacidade de processamento de comandos multicast (IGMP Proxy - Internet Group Management Protocol). Esta diferença é representada na Figura 13. 
Rede de acesso para CATV

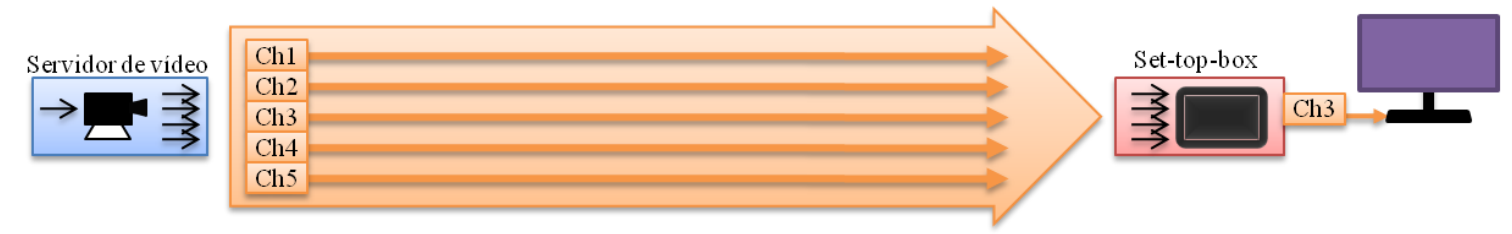

Rede de acesso para IPTV

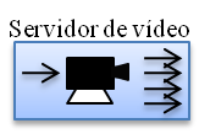

\begin{tabular}{|l|}
\hline Ch1 \\
\hline Ch2 \\
\hline Ch 3 \\
\hline Ch4 \\
\hline Ch5 \\
\hline
\end{tabular}

Roteador local

multicast

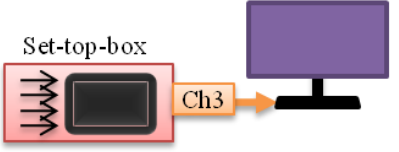

Figura 13 - Diferença do transporte dos canais na rede de acesso para um sistema CATV e para um sistema IPTV

\subsection{TOPOLOGIA DA REDE PARA PROVER SERVIÇO IPTV EM REDE}

\section{GPON}

A Figura 14 ilustra uma rede GPON para prover o serviço IPTV. O sistema conta com dois tipos de servidores, o 'Servidor IPTV', responsável pelas informações sobre os canais, incluindo o endereço multicast para onde o STB enviará as mensagens IGMP Join e Leave, e o 'Servidor de vídeo’, responsável por prover os streamings de vídeo.

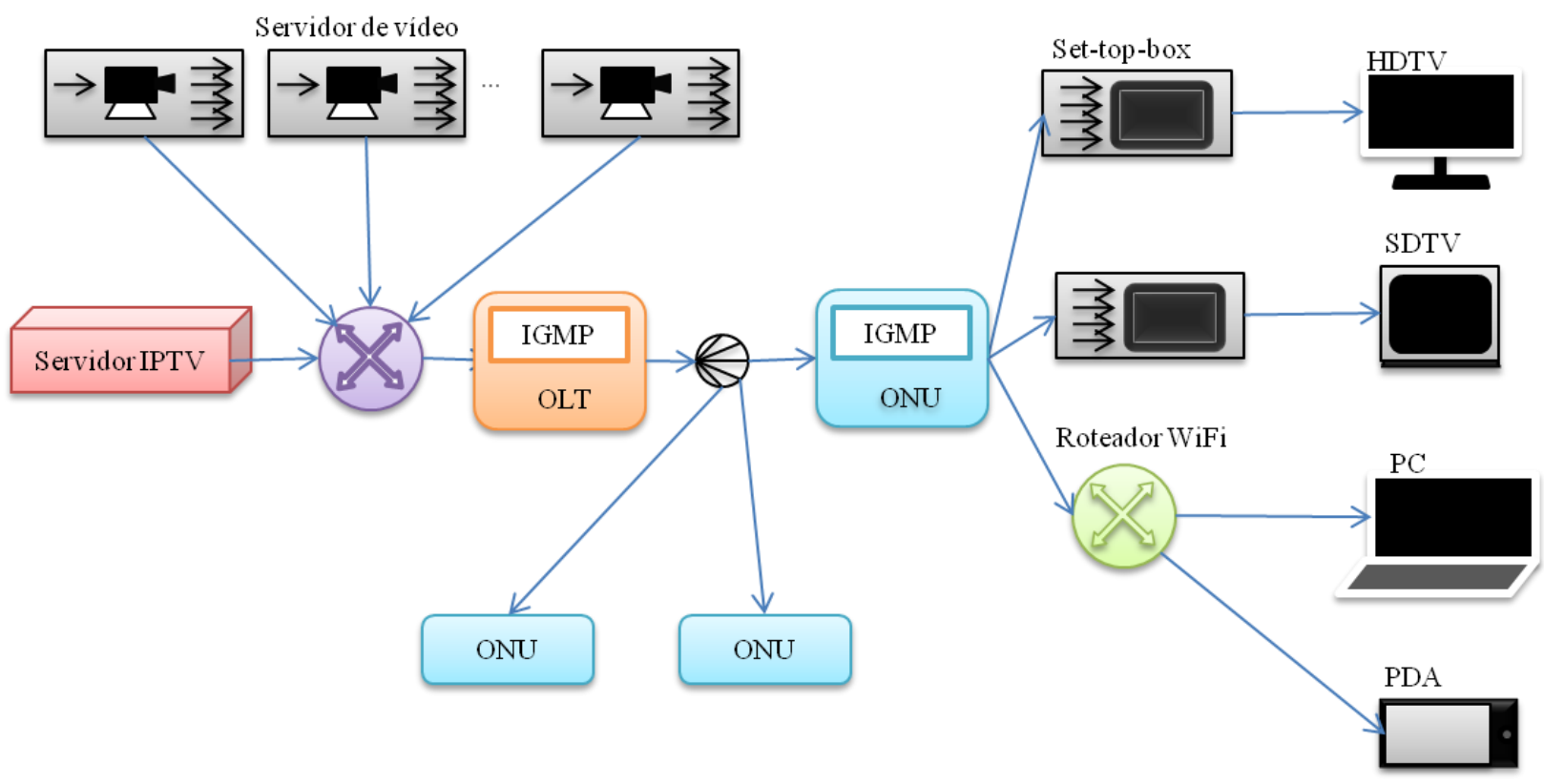

Figura 14 - Modelo básico de rede para serviço IPTV sobre rede GPON 
Ambos os servidores estão conectados à OLT, localizada no CO, através de um agregador que pode ser composto por um ou mais switches ou roteadores. Através de uma rede ótica passiva, cada OLT pode se conectar a até 128 ONUs (localizadas nas dependências dos assinantes). Tanto na ONU quanto na OLT, existem filtros IGMP permitindo que apenas os canais necessários passem para o próximo estágio da rede. Conectados à ONU estão os terminais do assinante que podem ser, entre outros, STBs, computadores pessoais e PDAs (de forma genérica os terminais do assinante serão referidos neste trabalho como STB).

No protocolo GEM [3] - [6], os pacotes de descida não são endereçados para uma ONU, mas sim para um PortID (número de 0 a 4095 que corresponde a uma porta). Cada ONU possui uma tabela com os seus PortIDs e filtra para si apenas os pacotes cujo PortID estiver nesta tabela. Duas ou mais ONUs podem possuir o mesmo PortID em sua tabela, neste caso, os pacotes enviados para este PortID serão recebidos por todas elas caracterizando assim um tráfego multicast de descida.

Uma das formas de endereçar um PortID é através da criação de VLANs [30] no agregador. Todos os tráfegos que possuírem o mesmo VLANID serão colocados no mesmo PortID. Então, conforme ilustrado na Figura 15, todos os tráfegos IPTV utilizam o mesmo PortID e são separados internamente por seus endereços multicast.

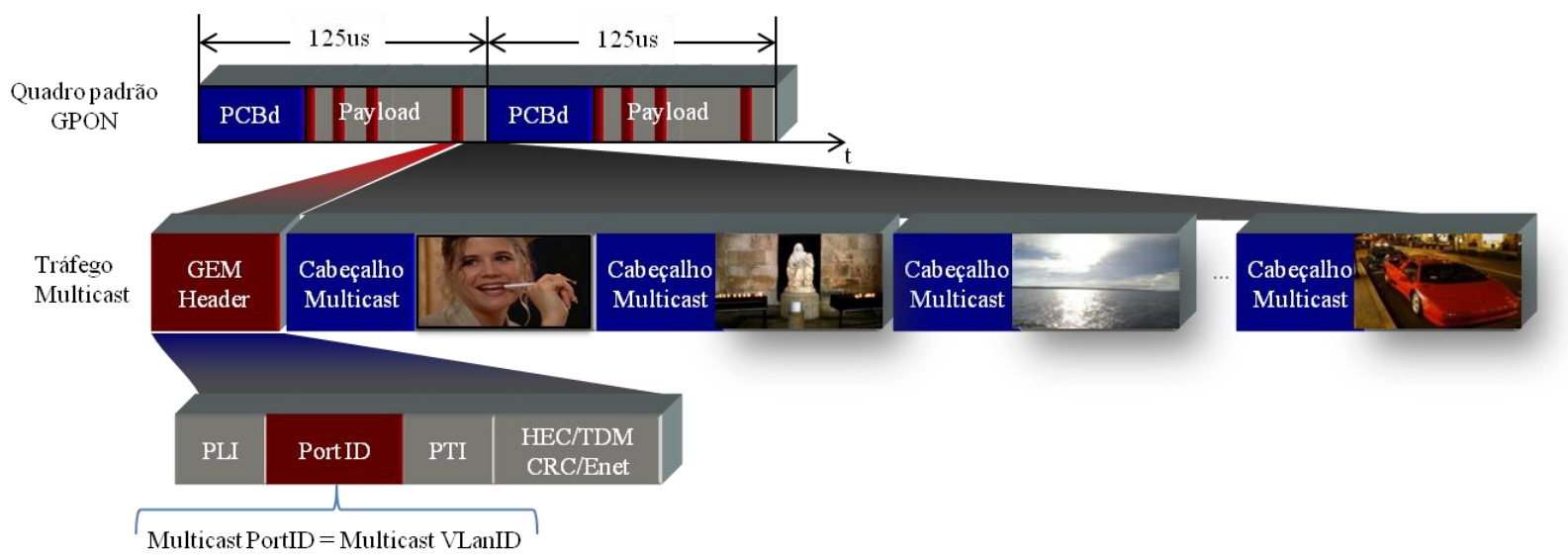

Figura 15 - Tráfego multicast no protocolo GEM. No contexto da figura o termo "Cabeçalho Multicast" significa os cabeçalhos necessários para o encaminhamento dos pacotes multicast do stream de vídeo

Mesmo que, em uma OLT, vários streams estejam chegando, apenas aqueles com tags VLANID correspondentes a um PortID válido serão encaminhados para a rede GPON. Esta decisão é normalmente tomada pelo agregador, que antecede a OLT e analisa as mensagens IGMP Join e 
Leave que trafegam na rede. Ao chegar na ONU, o frame GEM é aberto e através do endereço multicast, apenas os canais que receberam Join de um dos STBs conectados a esta ONU serão encaminhados.

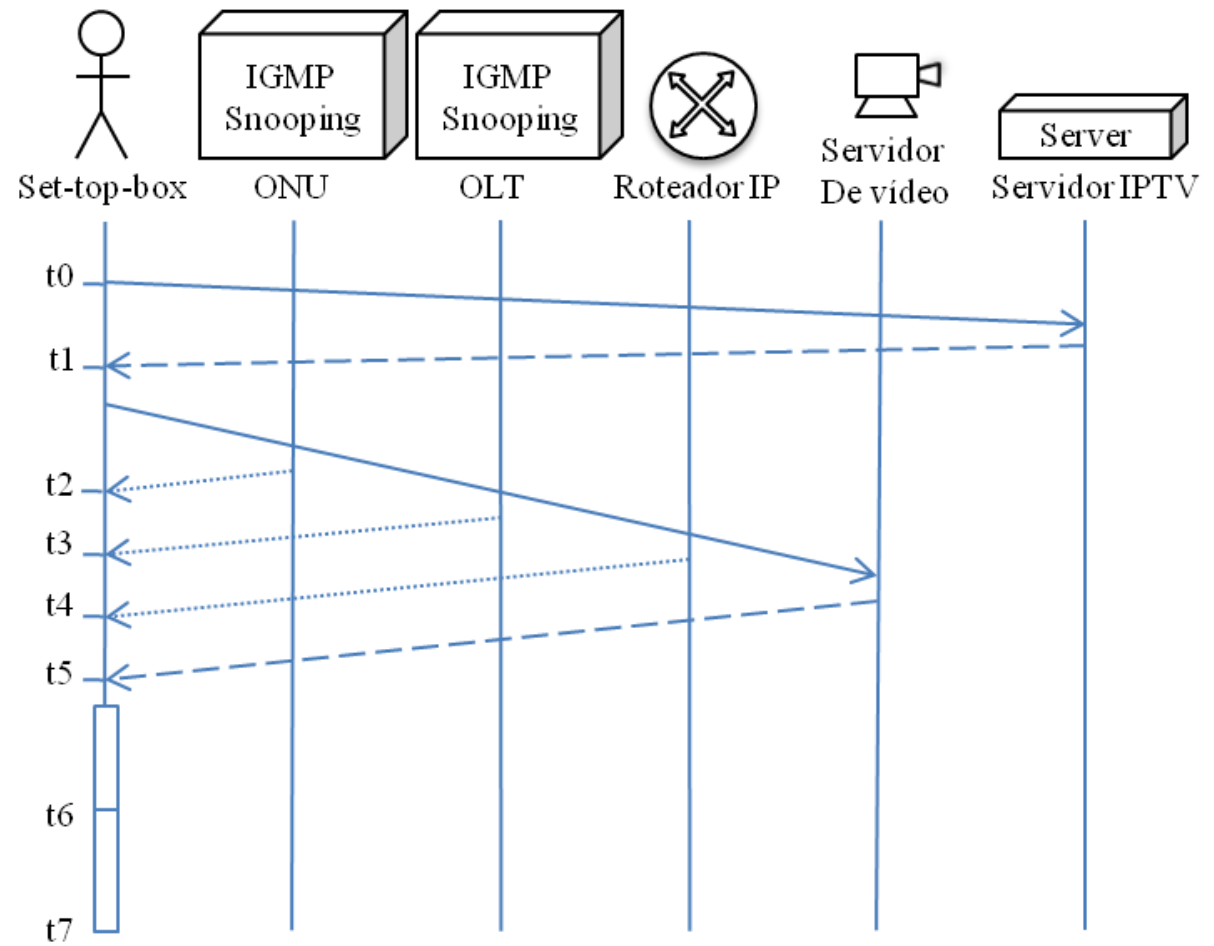

Figura 16 - Diagrama de sequência da exibição de um novo canal

Para que um canal seja exibido, o STB deve consultar o 'Servidor IPTV' para saber qual o endereço multicast do canal (t1), em seguida, enviar um Join que deve ser processado pelos diversos nós da rede (t2 à t5). Ao receber os quadros, o STB aguarda a chegada do primeiro quadro I (t6) e o coloca num buffer um conjunto de quadros (t7) antes de iniciar a exibição do vídeo para evitar ruídos devido ao jitter na rede (Figura 16).

\subsection{MULTICAST NA REDE IP}

O endereçamento multicast é uma tecnologia de rede empregada no envio de uma informação para um grupo de destinatários simultaneamente. Ele emprega a melhor estratégia de forma a ocupar a menor banda possível, enviando uma única vez cada pacote em cada seguimento da rede, mesmo que este tenha vários destinatários. 
Nos sistemas IPTV, a palavra "multicast" é usada para referir ao IP multicast, que é o sistema multicast que ocorre na camada IP, onde os roteadores criam, em tempo real, o melhor caminho para a distribuição dos datagramas. Nas redes IPs o que difere o tipo de tráfego é o grupo de endereços ao qual ele pertence, que pode ser Unicast, Broadcast, Multicast e Anycast.

\subsubsection{Endereços na rede IP}

Existem quatro grupos de endereços IPs, cada um com suas propriedades únicas:

- Unicast: É o grupo de endereços mais comum na rede. Está associado a um único remetente e um único destinatário, podem ser empregados para comunicações em ambas as direções, não importando quem iniciou a comunicação. Usualmente, um único endereço é atribuído ao remetente e ao destinatário, porém, em alguns casos um único host pode conter mais de um endereço unicast. Na comunicação unicast os datagramas percorrem sempre um caminho ponto a ponto, no caso de uma comunicação ponto multiponto, o remetente deve criar várias cópias da informação, uma para cada endereço de destino.

- Broadcast: O endereço IP 255.255.255.255 é empregado no envio de datagramas a todos os destinatários possíveis (all-host broadcast). Isto permite que um remetente envie o pacote apenas uma vez e todos os destinatários retirem uma cópia dele.

- Multicast: O endereço multicast está associado a um conjunto de destinatários alvo. De acordo com [32], os endereços 224.0.0.0 até 239.255.255.255, conhecidos como endereços de classe D, são designados como endereços de multicast no IPV4 (Internet protocol version 4). Neste, o remetente envia apenas um datagrama para o endereço multicast. Os roteadores intermediários cuidam para que cópias sejam feitas para todas as suas redes, onde destinatários tenham registrado o interesse nos dados destinados ao endereço multicast. A comunicação multicast é sempre unidirecional, ou seja, sempre um servidor envia dados para vários clientes e nunca um cliente envia dados para o servidor.

- Anycast: Assim como no broadcast e no multicast, o anycast é uma tecnologia de roteamento ponto-multiponto. Porém, o datagrama não é copiado para todas as redes, o roteador envia o dado apenas para o destinatário, que ele julga estar mais "próximo" na rede. 


\subsubsection{Protocolos Multicast}

Por se caracterizar uma transmissão diferente do unicast, apenas um conjunto de protocolos, desenvolvidos para comunicação multicast, pode ser empregado neste tipo de comunicação.

A maioria das aplicações multicast emprega o protocolo UDP (user datagram protocol) [33] na camada de transporte e o RTP (real-time protocol) [34], RTCP (real-time transport control protocol) [35] e RTSP (real-time streaming protocol) [36] no controle de frames, quando se trata de conteúdos multimídia, como os vídeos providos por IPTV.

Nas redes locais, o controle dos tráfegos multicast é feito pelo IGMP [37] [38] para o IPV4 e o MLD (multicast listener discovery) [39] [40] para IPV6 (Internet protocol version 6). O IGMP tem grande relevância neste trabalho, e será detalhado a seguir. Uma vez que ele também pode ser empregado para controle deste tipo de fluxo nos equipamentos GPON, os exemplos aqui apresentados se baseiam nele.

\subsubsection{O protocolo IGMP}

Em uma rede com serviço IPTV, os canais de televisão são distribuídos via multicast IP. IGMP é o mecanismo de controle usado para controlar a entrega do tráfego multicast para os assinantes interessados e que possuem autorização para o conteúdo do vídeo.

IGMP é o protocolo que gerencia a entrada e saída de membros de um grupo multicast em uma rede IP [41]. Ele é usado pelos servidores de multicast e agregadores (roteadores e switches) da rede para estabelecer as associações do grupo multicast.

Assim como o ICMP (internet control message protocol) [42] o IGMP é parte integrante da camada IP e trafega sobre a camada de rede (no caso Ethernet). Ele é empregado para entrega de vídeo e para alguns jogos, porém é um protocolo vulnerável [43] [44] e deve ser usado com cautela.

Atualmente o IETF define três versões para o IGMP:

- IGMPv1: Definição original do protocolo. A RFC-1112 define a mensagem de 'Join', que um determinado host usa para se juntar a um grupo multicast IP. Todavia, a versão 1 não define uma forma do host deixar o grupo. Neste caso, os roteadores empregam um 
temporizador para definir quando um host deve deixar o grupo. Esta versão não é empregada em sistemas IPTV.

- IGMPv2: A RFC-2236 define a mensagem 'Leave', que permite que um host force sua saída de um grupo, evitando a ocupação desnecessária de banda no intervalo de tempo, entre o momento em que ele não pretende mais receber os datagramas deste grupo, e os temporizadores nos roteadores espirarem.

- IGMPv3: A RFC-3376 é a versão mais atual. Nesta versão, no lugar do modelo onde um transmite e muitos recebem das versões 1 e 2, os hosts que utilizam a versão 3 podem especificar um lista de transmissores que serão ouvidos. A versão 3 também melhora a segurança do sistema empregando o SSM (source-specific multicast), que diferencia o tráfego multicast não só pelo endereço do grupo multicast, mas também pelo IP de origem do datagrama. O IGMPv3 é retro-compatível com o IGMPv2.

Em uma operação básica IGMP, dois membros da rede são envolvidos:

- IGMP host: É o equipamento do assinante para o qual o tráfego multicast se destina. Ele comando o ingresso (Join) e a saída (Leave) de um grupo multicast. Também é responsável por responder as requisições (Query) do roteador sobre seus tráfegos multicast. Na Figura 17 o IGMP host é o STB.

- IGMP router: É responsável por tratar as mensagens de 'Join' e 'Leave' enviadas pelo host, e determinar quais canais serão repassados para ele. De forma periódica, ele solicita informações (Query), dos grupos usados pelo host para evitar erros, por exemplo, no caso do host sair da rede sem ter enviado os 'Leaves', isto manteria os fluxos ativos na rede sem necessidade. Na Figura 17 o IGMP router é o "Roteador local multicast".

A arquitetura do protocolo IGMP pode ser compreendida partindo da Figura 17. Neste caso, o objetivo é transportar o streaming de vídeo, gerado no "servidor de vídeo" através dos roteadores e switches da rede, até chegar ao STB que decodificará o vídeo, mostrando-o na televisão. 


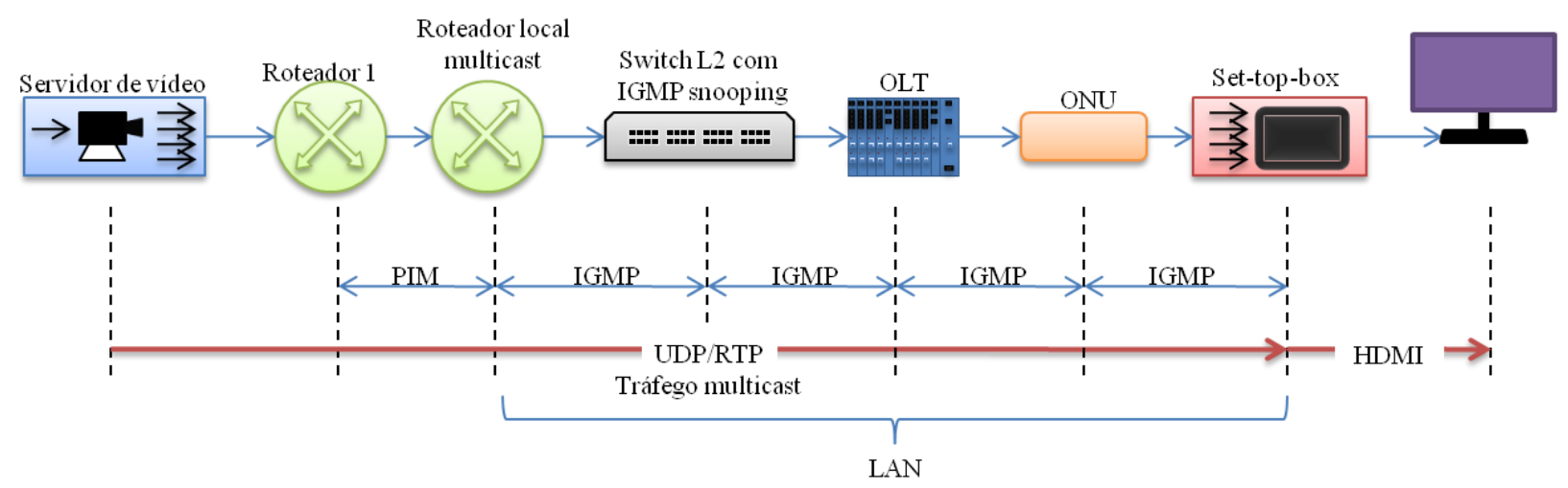

Figura 17 - Arquitetura para tráfego de stream de vídeo usando o protocolo IGMP

A versão 2 do IGMP conta com um conjunto de quatro comandos, são eles:

- Join: O host envia um comando Join para o roteador local sempre que deseja ingressar em um grupo multicast.

- Leave: O host envia um comando Leave para o roteador local sempre que deseja deixar um grupo multicast.

- Query: O roteador local, de tempos em tempos, envia uma solicitação Query para o host, conferindo se o host continua ativo e em quais grupos ele ainda deseja permanecer.

- Membership Report: Em resposta a uma solicitação Query, o host deve enviar um Report com as informações solicitadas, sobre os grupos multicast que ele permanece ou não como membro.

Para assistir a um canal, o STB envia um comando Join no grupo multicast ao qual o canal está associado, este comando passa por todos os elementos de rede de camada dois, sem sofrer qualquer alteração chegando até o roteador local de multicast. $\mathrm{O}$ roteador local executa a operação chamada de IGMP Proxy, toma para si o pacote IGMP e com isto liberando o canal para o assinante, caso o canal não esteja disponível na sua entrada, o roteador local envia um comando parecido com o IGMP, chamado PIM (protocol independent multicast) [45] para o "Roteador 1" acima dele, que por sua vez processa e repassa até chegar no servidor de vídeo propriamente dito. O servidor pode enviar constantemente o vídeo para o "Roteador 1" em uma operação chamada de flush, ou esperar os comandos PIM ou IGMP para isto.

Os elementos de camada 2 podem ignorar o conteúdo dos pacotes IGMP, desta forma, todo tráfego multicast opera como broadcast nestes elementos. A fim de melhorar o aproveitamento 
dos recursos da rede, estes elementos podem “espionar" os pacotes IGMP e desta forma ativar filtros, para que somente as portas que necessitam do vídeo recebam eles, isto é feito empregando IGMP snooping [46].

A referência [47] contém mais informações sobre IGMP e outros protocolos multicast IP.

\subsection{O CODIFICADOR DE VÍDEO MPEG-2}

Os vídeos são sequências de imagens que, quando não comprimidos, necessitam de um grande espaço de memória para armazenagem e grande largura de banda para transmissão. Um vídeo colorido VGA (video graphics array) com dimensões de 640 x 480 pixels, quantificado com 24 bits por pixel e 30 quadros por segundo, requer:

$640 \times 480=307.200$ pixels

para 24 bits, são necessários 3 bytes por pixel

$307.200 \times 3=921.600$ bytes $=900 \mathrm{kbytes}$

para 30 quadros por segundo

$900 \mathrm{k}$ x $30 \approx 26 \mathrm{Mbyte} / \mathrm{s}$

que corresponde a uma banda aproximada de 210Mbit/s para ser transmitido. Até pouco tempo atrás, tal banda era difícil de ser alcançada, mesmo em redes locais [48].

Na década de 80 foi fundado um grupo de pesquisa chamado de Moving Picture Experts Group ou MPEG, tendo como objetivo principal criar padrões internacionais para compressão, descompressão e representação codificada de áudio e vídeo. Os principais padrões criados por este grupo foram o MPEG-1 em 1993, MPEG-2 em 1995 e o MPEG-4 em 1998, atualmente apenas o MPEG-2 e o MPEG-4 são empregados.

No padrão MPEG-2 o mesmo vídeo, citado acima, ocupa uma banda aproximada de 600kbits/s (este valor pode variar, dependendo da compressão, do vídeo que está sendo comprimido e da qualidade que se deseja após a recuperação). 


\subsubsection{A técnica de compressão}

Todas as técnicas de compressão de vídeo são baseadas em três fatores:

- Redundância espacial: Em um quadro de vídeo, cada pixel possui relação com seus vizinhos, por exemplo, em um céu azul, todos os pixels possuem aproximadamente o mesmo valor. Neste caso é possível agrupar conjuntos de pixels, informando o quão parecido eles são e desta forma comprimir a imagem.

- Redundância temporal: Em uma sequência de quadros de um vídeo, cada quadro possui relação com o seu antecessor e com seu sucessor. Por exemplo, uma imagem de 30 segundos de uma paisagem, onde os pixels localizados em uma determinada região em um quadro se parecerão com os mesmo pixels do quadro seguinte. Desta forma, a compressão pode ser realizada tomando-se apenas as diferenças entre os quadros.

- Redundância psico-visual: $\mathrm{O}$ olho humano possui limitações, não conseguindo identificar certas alterações na imagem. Por exemplo, se todos os pixels de uma imagem de alta frequência (cachoeira) tiverem seus valores alterados de $0,1 \%$ um ser humano não consegue identificar este tipo de alteração. Portanto, as informações que o olho humano não consegue perceber, podem ser eliminadas na compressão.

Assim, explorando as três redundâncias acima, técnicas foram desenvolvidas e aprimoradas para a redução do tamanho dos vídeos. As técnicas que exploram os três fatores são conhecidas como compressão com perda, pois a imagem recuperada é semelhante à original, mas não idêntica. Outras formas exploram apenas as redundâncias espacial e temporal. Desta forma, se a imagem recuperada é idêntica à original, estas compressões são chamadas de sem perda. No caso do MPEG, a compressão é com perda.

\subsubsection{Uma visão geral do codificador MPEG-2}

Não existe um diagrama único para os codificadores MPEG e um possível diagrama pode ser visto na Figura 18. Este diagrama é uma simplificação que se assemelha ao MPEG-2. No caso do MPEG-4 são necessários mais alguns blocos e alguns deles são bem mais complexos. 


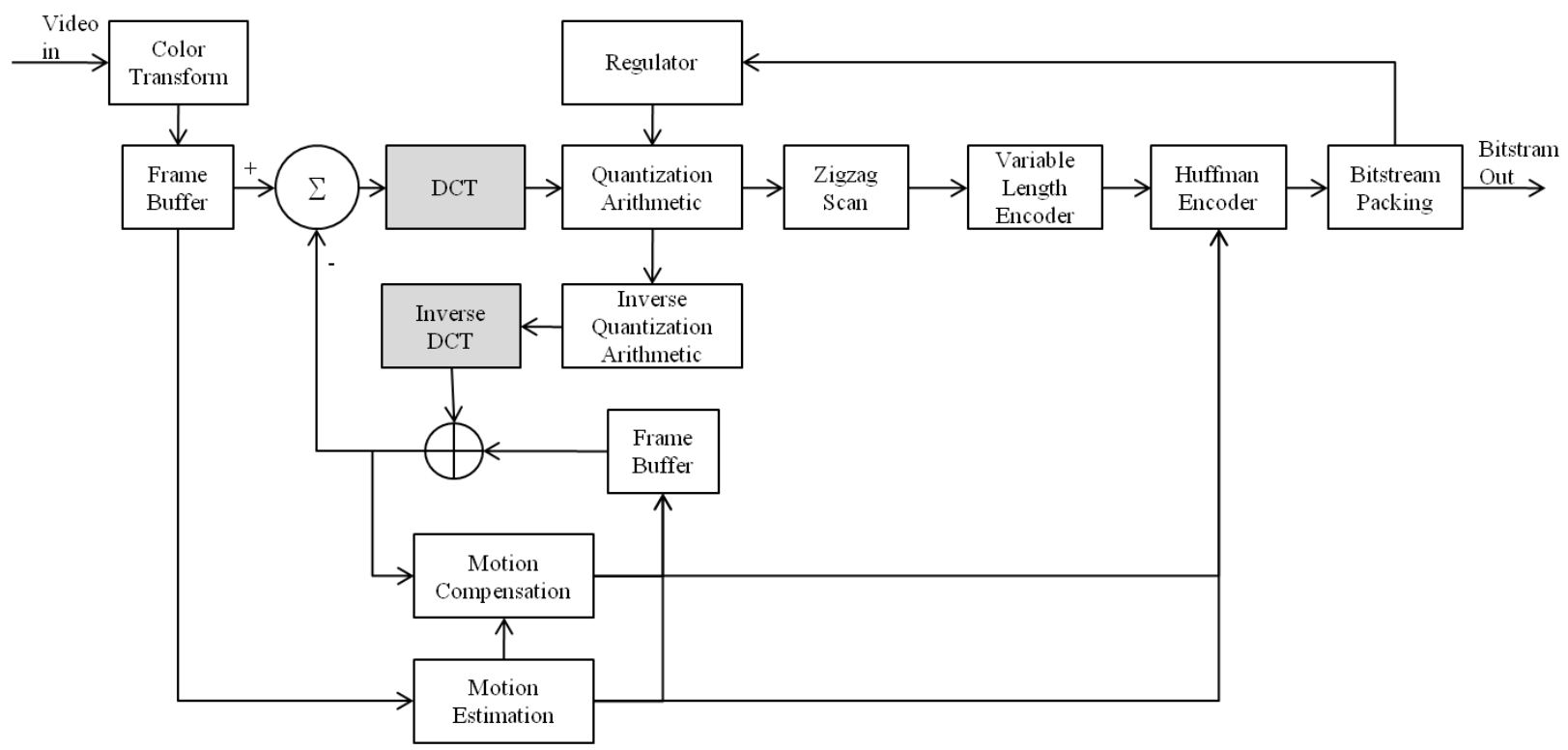

Figura 18 - Diagrama de blocos simplificado para um codificador MPEG

O vídeo é formado por uma sequência de quadros no padrão RGB (red, green and blue). Conforme será detalhado a seguir, este formato não propicia a maior compressão [49], então ele deve ser convertido para o padrão YCbCr e isto é feito no bloco Color Transform. O quadro é então armazenado em um Frame Buffer $e$, este bloco armazena o quadro atual para ser comparado com o próximo na sequência e, assim, retirar as redundâncias temporais. O somador localizado antes da DCT (discrete cosine transform) é responsável por retirar as redundâncias temporais.

A DCT é uma transformada que agrupa a energia da imagem (onde se encontra a informação importante em termos de visualização humana) nos coeficientes dispostos no canto superior esquerdo e isto faz com que as redundâncias espaciais e psico-visuais possam ser eliminadas no bloco Quantization Arithmetic. Após a quantização, boa parte dos coeficientes da DCT serão zerados. O conjunto Zigzag scan, Variable Length Encoder executam a redução propriamente dita da imagem, agrupando e eliminando os grandes seguimentos de números idênticos (em especial os que contêm o valor 0) e por fim o Huffman Encoder codifica o conjunto de bytes restantes usando a arvore de codificação de Huffman [13].

Para eliminar as redundâncias temporais, é necessário que o codificador tenha uma cópia de uma imagem que se aproxime ao máximo da recuperada no decodificador. Para isto, no codificador são colocados dois blocos do decodificador, i.e. o Inverse Quantization Arithmetic e a IDCT 
(inverse discrete cosine transform). Observe que a inversão dos outros blocos não é necessária, pois eles não introduzem erro na imagem.

Os blocos Motion Estimation e Motion Compensation ajudam a reduzir ainda mais a redundância temporal fazendo com que o novo quadro seja baseado não do anterior, mas sim do anterior com correção que o aproxima mais do atual, através da compensação dos movimentos dos objetos ou da câmera.

O par Bitstream Packet e Regulator não faz parte do codificador e não existe qualquer previsão deles na norma MPEG, porém a grande maioria das implementações possuem esta realimentação. O Bitstream Packet é responsável por empacotar e, no nosso caso em IP, o stream de vídeo para ser enviado pela rede. Ele realimenta o Regulator que atua no Quantization Arithmetic alterando a tabela de quantização a fim de manter o bitstream o mais constante possível e dentro dos valores estabelecidos pela operadora do serviço.

\subsubsection{Uma visão geral do decodificador MPEG-2}

A norma [15] propõe um diagrama simplificado para a decodificação de vídeo MPEG-2. A Figura 19 apresenta um diagrama baseado no da norma.
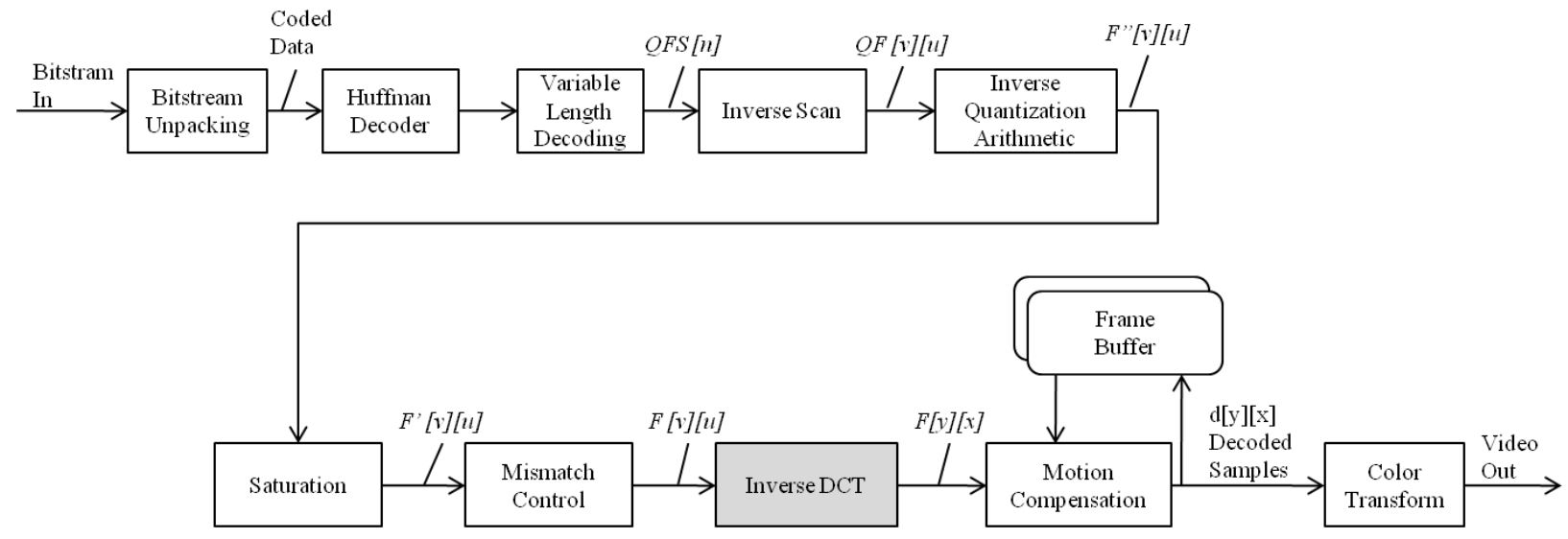

Figura 19 - Diagrama de blocos simplificado para um decodificador MPEG

Assim como no codificador, o Bitstream Unpacking não faz parte do decodificador, porém é necessário sempre que o vídeo for recebido via rede IP. O vídeo codificado deve ter sua estrutura de bits retornada ao padrão de bytes e isto é feito no Huffman Decoder. Em seguida, o Variable Length Decoding expande os grupos de valores iguais que foram agrupados na codificação, transformando os em sequências de bytes. No Inverse Scan, o stream é reposicionado nos 
macroblocos, usando um processo inverso ao do zigzag feito na codificação. Neste momento, a imagem já possui as dimensões da imagem original.

No Inverse Quantization Arithmetic a matriz de quantização, que foi empregada na codificação, é usada para retornar os valores dentro de cada bloco. Esta matriz é fornecida junto com o stream e pode alterar de quadro a quadro (como foi visto no item anterior, o codificador altera esta matriz a fim de manter a banda constante). Com a quantização, valores acima de 255 e inferiores a 0 podem aparecer, mas estes valores são ceifados no bloco Saturation.

Não existe um algoritmo único para cálculo da DCT e da IDCT definidos para o padrão MPEG. No Mismatch Control, adequações são feitas para minimizar os erros causados por eventuais incompatibilidades entre os algoritmos da DCT, empregado no codificador, e da IDCT, empregado no decodificador. Estas adequações são estatísticas e evitam principalmente erros acumulativos (de longo prazo).

A transformada inversa da DCT é calculada para cada bloco da imagem no Inverse DCT, recuperando os valores dos pixels ou de suas diferenças com os do quadro anterior.

As redundâncias temporais são eliminadas do vídeo executando-se uma comparação entre dois ou mais quadros consecutivos. Um conjunto de vetores que indicam as diferenças entre eles é construído. Estes conjuntos de vetores, chamados de vetores de movimento, são enviados do codificador para o decodificador junto com o stream de vídeo. O Motion Compensation utiliza os vetores de movimento, em conjunto com o quadro anterior armazenado no Frame Buffer, para estimar o quadro atual. As diferenças entre o quadro estimado (quadro anterior modificado segundo os vetores de movimento) e o que deve ser exibido forma uma nova imagem, chamada de imagem complementar. A imagem complementar é codificada e enviada no stream. Somando o quadro estimado a sua imagem complementar é possível recuperar o quadro total.

Desta forma, temos o quadro recuperado, porém ele ainda está em $\mathrm{YCbCr}$, padrão que será explicado na próxima seção. Por fim, o bloco Color Transform converte o quadro para RGB, para ser apresentado ao assinante.

A seguir, é feito um aprofundamento nas principais técnicas empregadas nos codificadores e decodificadores de vídeo MPEG. 


\subsubsection{O sistema de cor}

O olho humano capta as imagens usando dois tipos de células, os cones, que possuem a capacidade de reconhecer cor, e os bastonetes, com a capacidade de reconhecer luminosidade. Os cones estão divididos, na sua grande maioria, em três grupos e, cada qual corresponde a uma cor primária. Aproximadamente $65 \%$ são sensíveis à luz vermelha, $33 \%$ à luz verde e $2 \%$ à luz azul (porém, estes são mais sensíveis que os outros dois) [49]. Uma imagem codificada em RGB de 24 bits utiliza exatamente esta característica, empregando um conjunto de 8 bits para cada uma das 3 cores primárias. A luminosidade acaba sendo uma consequiência da junção das 3 cores e, desta forma, uma imagem pode ser formada sensibilizando-se não somente os cones vermelho, verde e azul, mas também os bastonetes.

Outra forma de representar esta imagem é armazenando a luminância e duas crominâncias, neste caso o padrão $\mathrm{YCbCr}$ armazena a luminância $\mathrm{Y}$ e as crominâncias azul $\mathrm{Cb}$ e vermelho $\mathrm{Cr}$. A Figura 20 mostra um bloco da imagem decomposta em RGB e em YCbCr.

Para o olho humano, a informação transportada pela luminância é mais relevante para a formação da imagem do que as de crominância ${ }^{3}$ [49]. Sendo assim, os sistemas de compressão sempre utilizam a imagem no padrão YCbCr e normalmente comprimem mais as crominâncias do que a luminância.

A conversão de uma imagem RGB em uma imagem $\mathrm{YCbCr}$ pode ser feita empregando as formulas abaixo:

$$
\begin{array}{lr}
Y=0.299 R+0.587 G+0.114 B & E q .1 \\
C b=0.168 R-0.3313 G+0.5 B+128 & E q .2 \\
C r=0.5 R-0.4187 G-0.0813 B+128 & E q .3
\end{array}
$$

Para valores de R, G e B variando de 0 a 255. A Figura 20 mostra um bloco da imagem nas codificações RGB e YCbCr. Ambos podem recompor a imagem original.

\footnotetext{
${ }^{3} \mathrm{Na}$ área total da retina, existem por volta de 7 milhões de cones e de 75 a 150 milhões de bastonetes.
} 


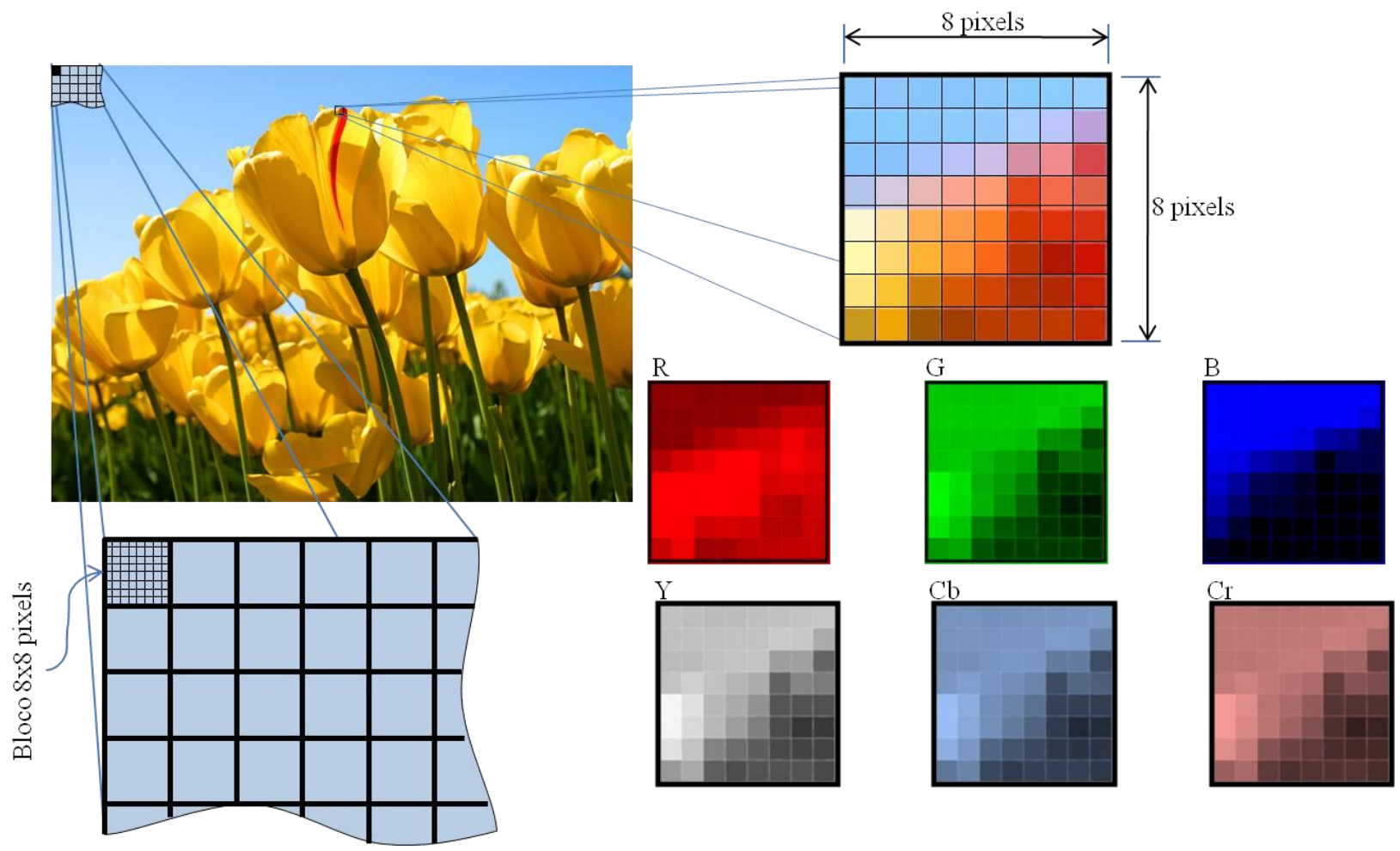

Figura 20 - Imagem dividida em blocos de 8 x 8 pixel, os blocos podem ser codificados em RGB ou YCbCr

\subsubsection{Bloco e macrobloco}

No sistema de compressão de imagem baseado nos padrões MPEG, os quadros não são codificados por inteiro, mas divididos em blocos de 8 por 8 pixels como mostra a Figura 20. Esta divisão apresenta várias vantagens. Por exemplo, o custo computacional de calcular a DCT em vários blocos $8 \times 8$ é muito menor do que o de executar um único cálculo para a imagem como um todo. Como visto no item anterior, para imagem colorida, cada bloco é composto por 3 imagens no padrão monocromático $\mathrm{YCbCr}$.

Agrupamentos de blocos formam os macroblocos. Cada macrobloco representa uma área de $16 \mathrm{x}$ 16 pixels da imagem original e com as 3 componentes juntas $\mathrm{Y}, \mathrm{Cb}$ e Cr. O MPEG prevê três formas de agrupar os blocos em macroblocos, o 4:2:0 formado por 6 blocos, o 4:2:2 formado por 8 blocos e o 4:4:4 formado por 12 blocos, conforme mostra a Figura 21. Os formatos 4:2:0 e 4:2:2 levam em consideração que a luminância é mais relevante que as crominâncias para o olho humano. Em ambos os caso a imagem recuperada terá perda quando comparada com a original. 


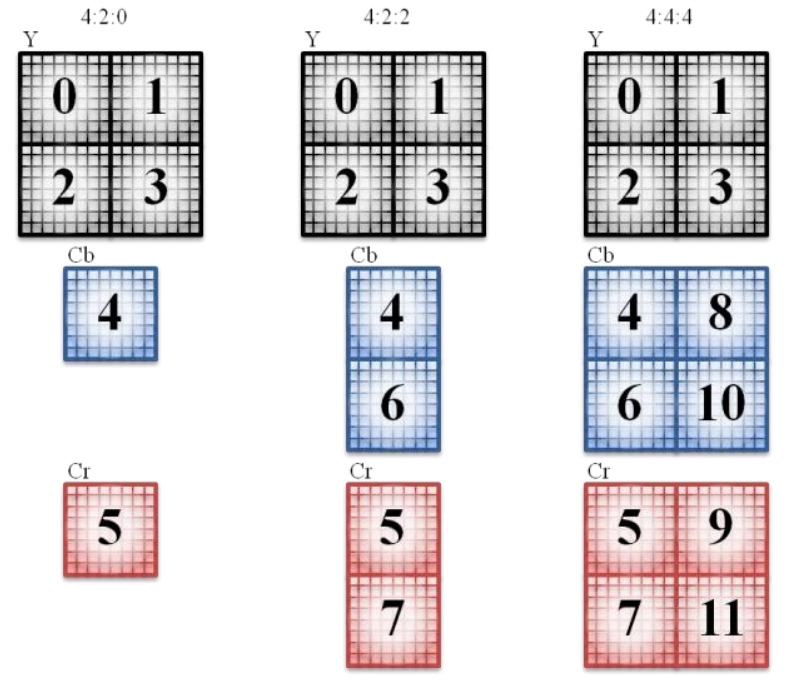

Figura 21 - Três tipos de macroblocos previstos no padrão MPEG

As componentes $\mathrm{Cb}$ e $\mathrm{Cr}$ dos macroblocos 4:2:0 e 4:2:2 são geradas a partir da média dos pixels que estão sendo agrupados.

\subsubsection{A transformada DCT}

A Transformada Discreta do Cosseno ou DCT é uma variação da Transformada de Fourier que apresenta apenas cossenos em suas componentes. Ela tem particular interesse na compressão de imagem e é largamente empregada, não só para vídeo nos padrões MPEG, mas também para imagem no padrão JPEG (Joint Photographic Experts Group). Por ser uma particularização da DFT (discrete Fourier transform), todas as propriedades da DFT podem ser usadas na DCT.

Existem quatro tipos de DCT, cada qual com sua transformada inversa ou IDCT, as equações de cada uma delas é mostrada a seguir.

\subsubsection{Transformada DCT-I}

Equação da transformada direta

$$
\operatorname{DCT}^{c 1}(u)=\sqrt{\frac{2}{N}} K_{u} \sum_{x=0}^{N} K_{x} f(x) \cos \left(\frac{u x \pi}{N}\right)
$$

Equação da transformada inversa

$$
f(x)=\sqrt{\frac{2}{N}} K_{x} \sum_{u=0}^{N} K_{u} D C T^{c 1}(u) \cos \left(\frac{u x \pi}{N}\right)
$$


para

$$
\begin{gathered}
K_{u} \text { ou } K_{x}=\left\{\begin{array}{ccc}
\frac{1}{\sqrt{2}} & \text { se } & u, x=0 \quad \text { e } \\
1 & \text { outros }
\end{array}, N=N\right. \\
x=0,1, \ldots, N \quad u=0,1, \ldots, N
\end{gathered}
$$

onde
$\mathrm{DCT}^{\mathrm{C} 1}() \quad$ - Matriz de coeficientes calculados pela DCT-I
$\mathrm{u} \quad$ - Índice dos coeficientes da DCT
$\mathrm{K}_{\mathrm{u}} \quad$ - Constante para o cálculo da DCT associada ao coeficiente da DCT
$\mathrm{x} \quad$ - Índice dos pixels da imagem
$\mathrm{N}$ - Dimensão total da imagem ou bloco da imagem
$\mathrm{K}_{\mathrm{x}} \quad$ - Constante para o cálculo da DCT associada ao índice da imagem
f() - Matriz com os valores dos pixels da imagem

\subsubsection{Transformada DCT-II}

Equação da transformada direta

$$
\operatorname{DCT}^{c 2}(u)=\sqrt{\frac{2}{N}} K_{u} \sum_{x=0}^{N-1} f(x) \cos \left(\frac{(2 x+1) u \pi}{2 N}\right)
$$

Equação da transformada inversa

$$
f(x)=\sqrt{\frac{2}{N}} \sum_{u=0}^{N-1} K_{u} D C T^{c 2}(u) \cos \left(\frac{(2 x+1) u \pi}{2 N}\right)
$$

para

$$
\begin{aligned}
& K_{u}=\left\{\begin{array}{c}
\frac{1}{\sqrt{2}} \text { se } u=0 \\
1 \quad \text { outros }
\end{array}\right. \\
& x=0,1, \ldots, N-1 \quad u=0,1, \ldots, N-1
\end{aligned}
$$

onde

$$
\begin{array}{ll}
\mathrm{DCT}^{\mathrm{C} 2}() & \text { - Matriz de coeficientes calculados pela DCT-II } \\
\mathrm{u} & \text { - Índice dos coeficientes da DCT-I } \\
\mathrm{K}_{\mathrm{u}} & \text { - Constante para o cálculo da DCT associada ao coeficiente da DCT } \\
\mathrm{x} & \text { - Índice dos pixels da imagem }
\end{array}
$$


N $\quad$ - Dimensão total da imagem ou bloco da imagem

f() - Matriz com os valores dos pixels da imagem

\subsubsection{Transformada DCT-III}

Equação da transformada direta

$$
\operatorname{DCT}^{c 3}(u)=\sqrt{\frac{2}{N}} \sum_{x=0}^{N-1} K_{x} f(x) \cos \left(\frac{x(2 u+1) \pi}{2 N}\right)
$$

Eq. 8

Equação da transformada inversa

$$
f(x)=\sqrt{\frac{2}{N}} K_{x} \sum_{u=0}^{N-1} D C T^{c 3}(u) \cos \left(\frac{x(2 u+1) \pi}{2 N}\right)
$$

para

$$
\begin{aligned}
& K_{x}=\left\{\begin{array}{cc}
\frac{1}{\sqrt{2}} & \text { se } \quad x=0 \\
1 & \text { outros }
\end{array}\right. \\
& x=0,1, \ldots, N-1 \quad u=0,1, \ldots, N-1
\end{aligned}
$$

onde

$$
\begin{array}{ll}
\mathrm{DCT}^{\mathrm{C} 3}() & \text { - Matriz de coeficientes calculados pela DCT-III } \\
\mathrm{u} & \text { - Índice dos coeficientes da DCT } \\
\mathrm{x} & \text { - Îndice dos pixels da imagem } \\
\mathrm{N} & \text { - Dimensão total da imagem ou bloco da imagem } \\
\mathrm{K}_{\mathrm{x}} & \text { - Constante para o cálculo da DCT associada ao índice da imagem } \\
\mathrm{f}() & \text { - Matriz com os valores dos pixels da imagem }
\end{array}
$$

\subsubsection{Transformada DCT-IV}

Equação da transformada direta

$$
\operatorname{DCT}^{c 4}(u)=\sqrt{\frac{2}{N}} \sum_{x=0}^{N-1} f(x) \cos \left(\frac{(2 x+1)(2 u+1) \pi}{4 N}\right)
$$

Equação da transformada inversa

$$
f(x)=\sqrt{\frac{2}{N}} \sum_{u=0}^{N-1} D C T^{c 4}(u) \cos \left(\frac{(2 x+1)(2 u+1) \pi}{4 N}\right)
$$


para

$$
x=0,1, \ldots, N-1 \quad u=0,1, \ldots, N-1
$$

onde

$$
\begin{array}{ll}
\mathrm{DCT}^{\mathrm{C} 4}() & \text { - Matriz de coeficientes calculados pela DCT-IV } \\
\mathrm{u} & \text { - Índice dos coeficientes da DCT } \\
\mathrm{X} & \text { - Índice dos pixels da imagem } \\
\mathrm{N} & \text { - Dimensão total da imagem ou bloco da imagem } \\
\mathrm{f}() & \text { - Matriz com os valores dos pixels da imagem }
\end{array}
$$

\subsubsection{Transformada DCT-II para imagem (2D)}

Dentre os quatro tipos, a mais empregada é a DCT-II. Para imagem é necessário executar o cálculo nas dimensões x e y, ou seja, é necessário aplicar a DCT em 2D. Existem duas formas de fazer isto, na primeira, como nos blocos MPEG as dimensões de x e y são idênticas (os blocos são 8 x 8), emprega-se a propriedade da DFT calculando primeiro a DCT para x e depois para $\mathrm{y}$. Na segunda, empregam-se diretamente as equações 12 e 13 que já executam o cálculo em 2D.

Equação da transformada direta em 2D

$$
D C T^{c 2}(u, v)=\sqrt{\frac{4}{N M}} K_{u} K_{v} \sum_{y=0}^{N-1} \sum_{x=0}^{M-1} f(x, y) \cos \left(\frac{(2 x+1) u \pi}{2 N}\right) \cos \left(\frac{(2 y+1) v \pi}{2 M}\right) \quad \text { Eq. } 12
$$

Equação da transformada inversa em 2D

$$
f(x, y)=\sqrt{\frac{4}{N M}} \sum_{v=0}^{N-1} \sum_{u=0}^{M-1} K_{u} K_{v} D C T^{c 2}(u, y) \cos \left(\frac{(2 x+1) u \pi}{2 N}\right) \cos \left(\frac{(2 y+1) v \pi}{2 M}\right) \quad \text { Eq. } 13
$$

para

$$
\begin{aligned}
& K_{u} \quad \text { ou } \quad K_{v}=\left\{\begin{array}{lll}
\frac{1}{\sqrt{2}} & \text { se } & u=0, v=0 \\
1 & \text { outros }
\end{array}\right. \\
& x=0,1, \ldots, N-1 \quad u=0,1, \ldots, N-1 \\
& y=0,1, \ldots, M-1 \quad v=0,1, \ldots, M-1
\end{aligned}
$$

onde

$$
\begin{array}{ll}
\mathrm{DCT}^{\mathrm{C} 2}() & \text { - Matriz de coeficientes calculados pela DCT-II } \\
\mathrm{u} & \text { - Índice da primeira dimensão dos coeficientes da DCT }
\end{array}
$$


v - Índice da segunda dimensão dos coeficientes da DCT

$\mathrm{K}_{\mathrm{u}} \quad$ - Constante de redução empregada no cálculo da DCT associada a primeira dimensão do coeficiente da DCT

$\mathrm{K}_{\mathrm{v}} \quad$ - Constante de redução empregada no cálculo da DCT associada a segunda dimensão do coeficiente da DCT

$\mathrm{x} \quad$ - Índice da primeira dimensão dos pixels da imagem

y - Índice da segunda dimensão dos pixels da imagem

$\mathrm{N}$ - Dimensão total da imagem ou bloco da imagem no eixo y

M - Dimensão total da imagem ou bloco da imagem no eixo $\mathrm{x}$

f() - Matriz com os valores dos pixels da imagem

Em termos de custo computacional, calcular as duas transformadas unidimensionais é muito mais rápido do que calcular uma bidimensional. Por exemplo, para um bloco 8 x 8, são 64 multiplicações para a bidimensional contra 16 para as duas unidimensionais.

Normalmente, o cálculo da DCT nos codificadores é feito usando-se a multiplicação de uma matriz, chamada de Função Base, pela imagem. Esta função pode ser visualizada graficamente na Figura 22. Cada ponto da DCT é obtido através da soma dos produtos de todos os pixels da imagem, pela matriz correspondente ao ponto na Função Base. A Figura 23 mostra, em termos numéricos, o resultado de uma DCT.

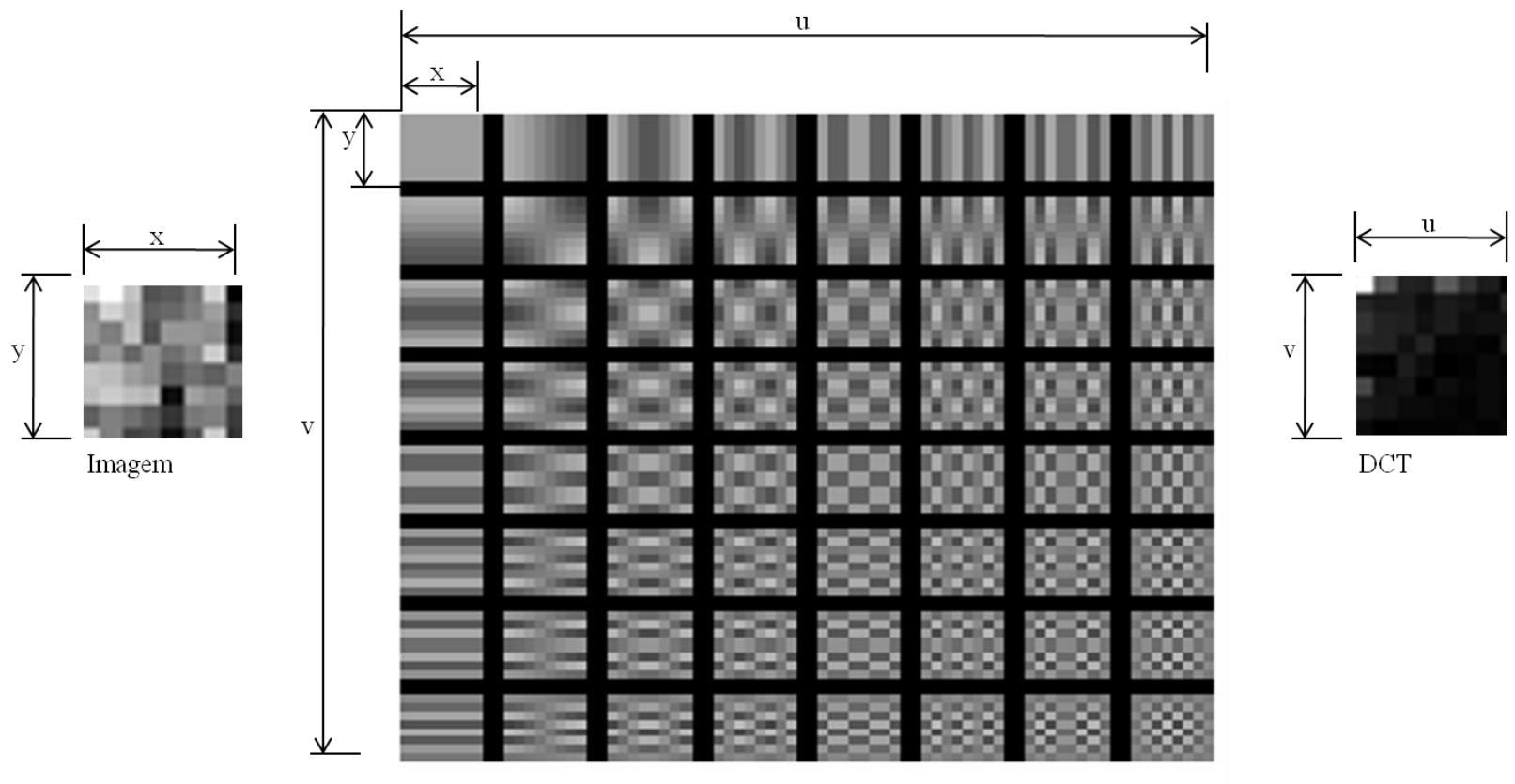

Figura 22 - Função Base da DCT-II em 2D 


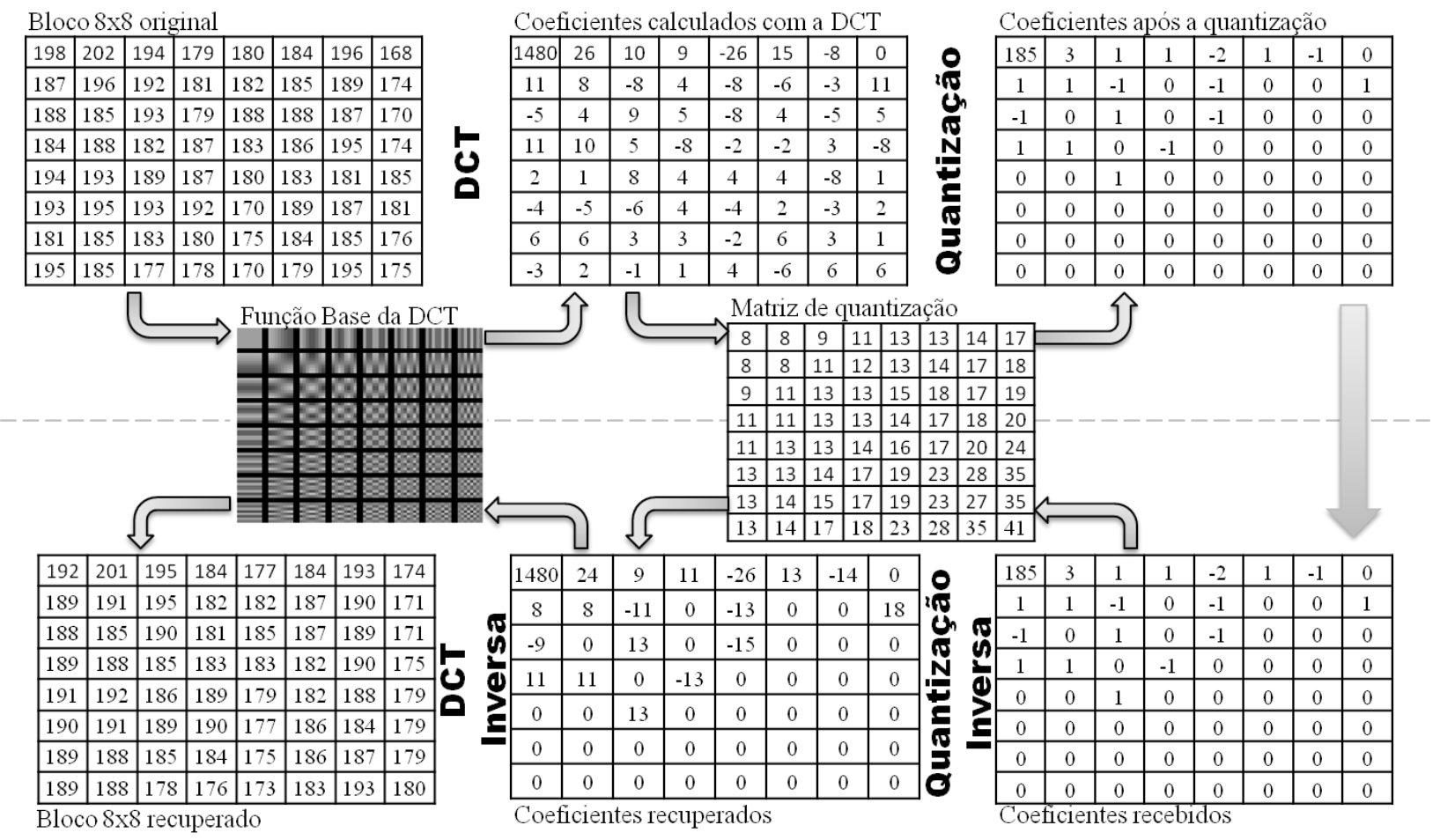

Figura 23 - Exemplo da quantização de um bloco de imagem de 8x8 pixels. O processo de codificação é mostrado na parte superior da imagem e o de decodificação na parte inferior.

Observando a Função Base é possível notar que o ponto superior esquerdo da DCT contém o valor médio dos pixels que compõem a imagem, sendo chamado de nível DC (direct current) do bloco. O nível DC possui algumas características particulares. Ele é tratado à parte pelos sistemas de codificação e este ponto também será tratado de forma particular pelo sistema proposto.

Em imagens coerentes, que possuem relação entre os pixels, a DCT concentra a maior parte da energia da imagem no canto superior esquerdo. Quando comparado com a DFT, a DCT também tem a vantagem de trabalhar com um único conjunto de coeficientes, reais, como resultado que representa tanto fase como frequência. A Figura 24 traz uma comparação visual entre estas duas transformadas, um filtro passa baixa é empregado em ambas. Na DFT, este filtro deixa passar os cantos da matriz de coeficientes da frequência e o total da matriz da fase. Já na DCT, este filtro deixa passar o canto superior esquerdo da matriz de coeficientes. Apesar desta diferença os resultados são bem próximos. 


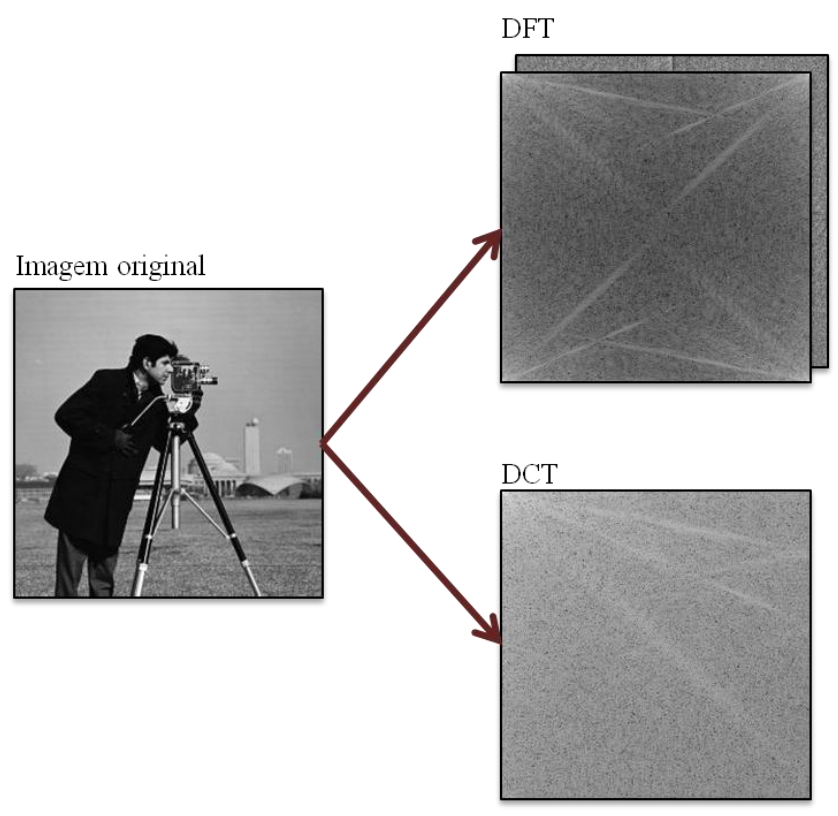

DFT filtrada
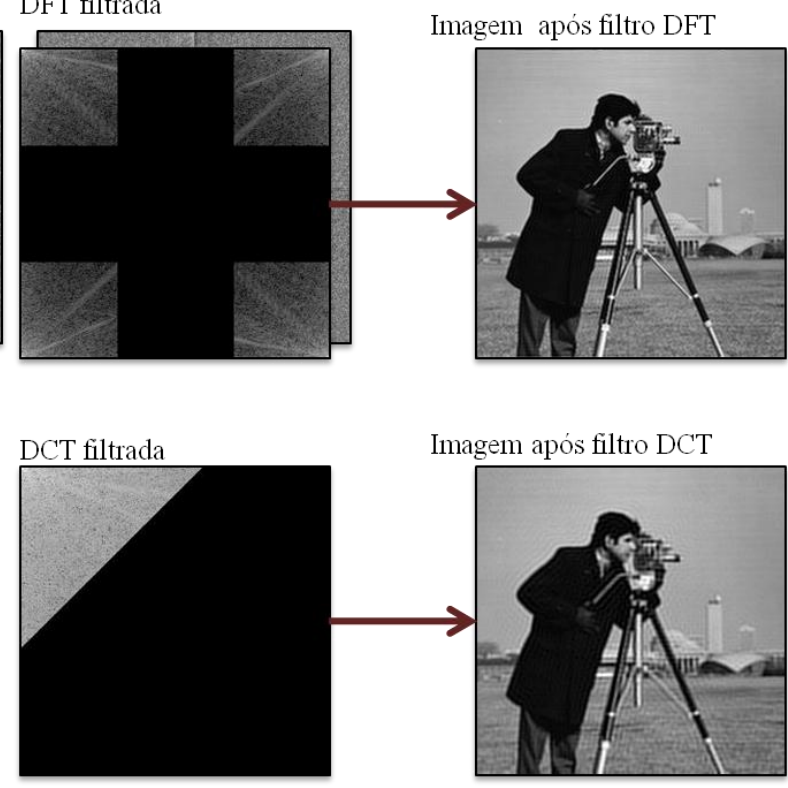

Figura 24 - Comparação entre DCT e DFT, a DFT tem como resultado uma matriz de coeficientes composto por números complexos, menos adequado para a aplicação de compressão que a DCT cujo resultado são coeficientes puramente reais. Aplicando um filtro passa baixa nas duas matrizes de coeficientes, o resultado é praticamente o mesmo

\subsubsection{Quantização da imagem}

As matrizes de coeficientes resultantes da DCT são compostas por números reais (positivos e negativos) de 32 bits, ou seja, após a aplicação da DCT a imagem cresce, pois antes cada pixel era codificado com 8 bits. A fim de reduzir o tamanho da imagem, cada matriz de coeficientes é dividida, ponto a ponto, por uma matriz de quantização e o resultado é arredondado para o inteiro de 8 bits mais próximo. Este processo faz com que a grande maioria dos coeficientes passe a ser zero como mostrado na Figura 23.

No decodificador, a mesma matriz de quantização é multiplicada pelos coeficientes recebidos, recuperando desta forma os coeficientes originais. Como na codificação houve um arredondamento dos valores, a matriz de coeficientes recuperada é parecida com a original, mas não idêntica. Através da DCT inversa os valores dos pixels são recuperados, porém, mais uma vez os valores recuperados são parecidos com os originais, mas não idênticos.

\subsubsection{A varredura em zigzag}

É possível notar, tanto na imagem da Figura 22, quanto nos valores da Figura 23, que a maior parte dos coeficientes tiveram seus valores reduzido a zero após a quantização e que a maior 
parte do que sobrou se concentra no canto superior esquerdo do bloco. Como a intenção é agrupar ao máximo as sequências de números idênticos, o processo de varredura do bloco que o transforma de bidimensional para unidimensional é feito em zigzag na diagonal, iniciando do canto superior esquerdo e indo em direção ao canto inferior direto, como mostra a Figura 25.

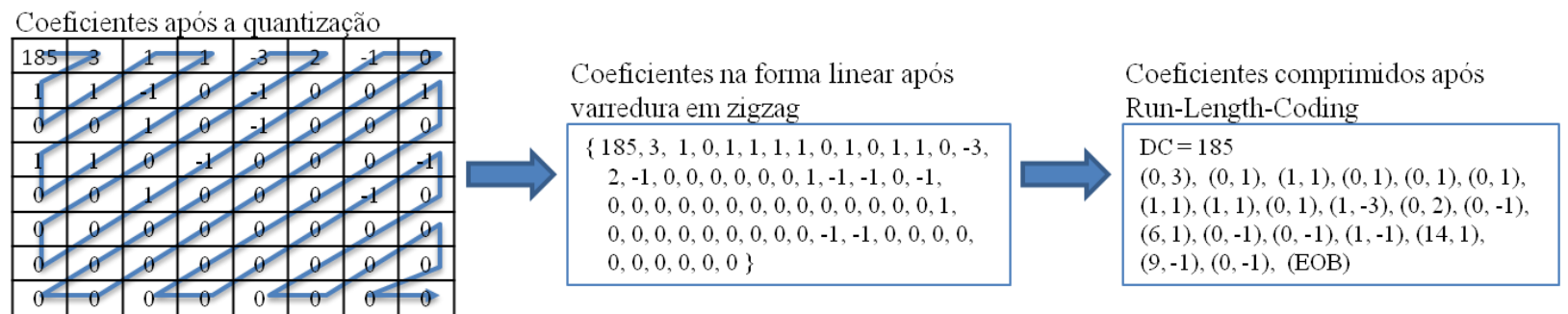

Figura 25 - Exemplo de varredura do bloco em zigzag e do Run-Length-Coding

\subsubsection{O Run-Length-Coding}

No Run-Length-Coding o número de bytes é efetivamente reduzido, agrupando sequências de valores iguais, em particular as sequências de zeros. Além disto, o nível DC (valor no canto superior esquerdo da matriz de coeficientes) é codificado à parte, devido ao fato dele ter características bastante particulares quando comparado com o resto dos coeficientes, e a última sequência de zeros não é codificada e no seu lugar um caractere especial de fim de bloco (EOB end of block) é colocado.

Para agrupar as sequências de zeros, na Figura 25, antes de cada número diferente de zero foi acrescentado quantos zeros existem antes dele, sendo estas sequências de zeros retiradas da lista.

\subsubsection{A previsão de quadros}

Para reduzir a redundância temporal do vídeo, o MPEG-2 propõe três tipos de quadros: os quadros I (I-frame ou Intra-coded frame) compostos pela imagem completa, os quadros $\mathrm{P}(P$ frame ou Predictive-coded frame) que são baseados no quadro anterior, e os quadros B (B-frame ou Bidirectional-predictive-coded frame) que são baseados no quadro anterior e no posterior (Figura 26). Tanto nos quadros $\mathrm{P}$ quanto nos quadros $\mathrm{B}$, apenas o que alterou na imagem é transmitido. 


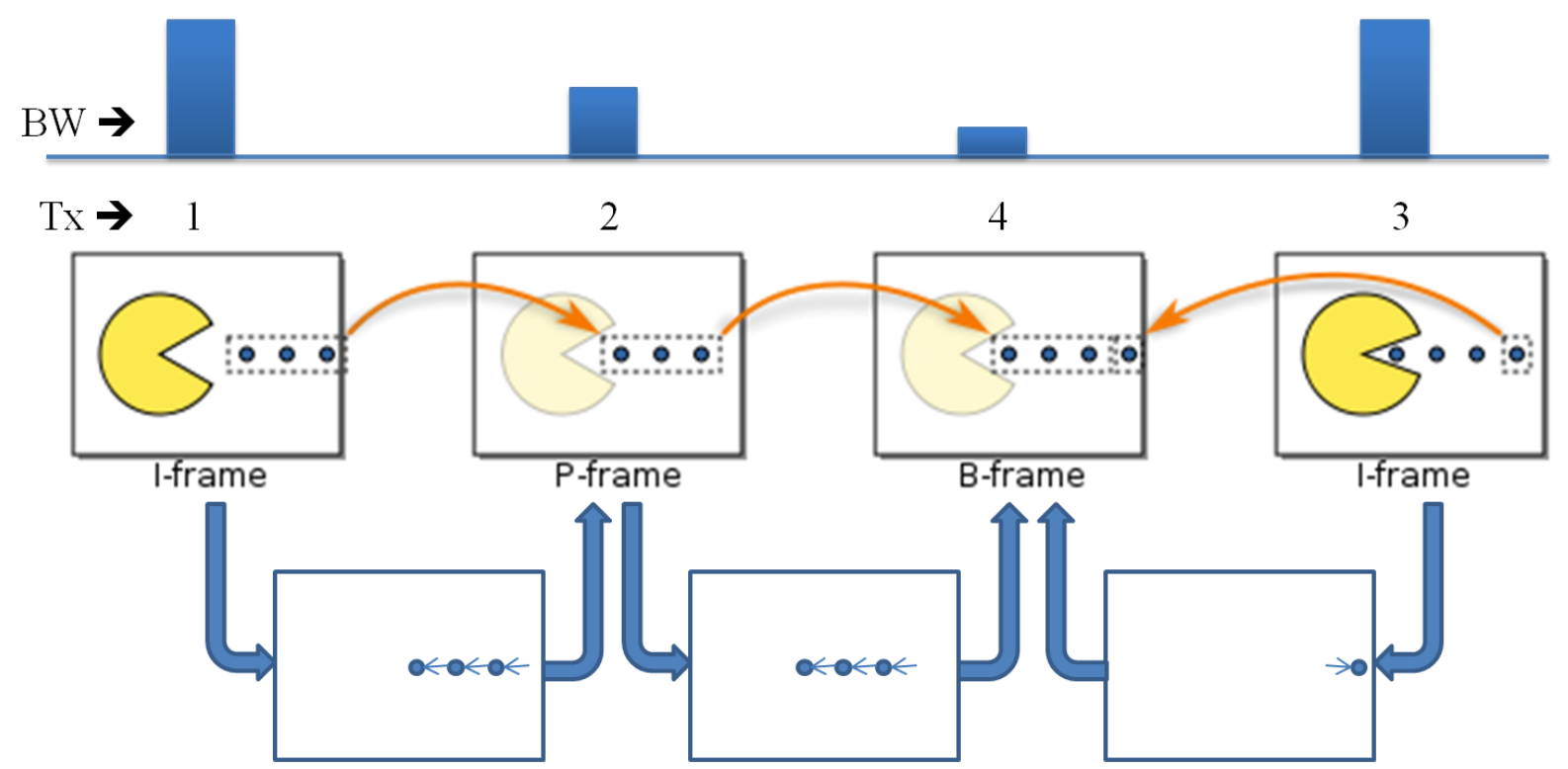

Figura 26 - Sequência de quadros de um vídeo composta por dois quadros chaves I, um quadro com predição anterior P e um quadro com predição bidirecional B. Imagem retirada de (http://en.wikipedia.org/wiki/Iframe) e complementada

A norma não obriga a utilização dos quadros $\mathrm{P}$ e B. Devido à complexidade de implementação dos quadros B, alguns codificadores só implementam quadros I e P. A sequência de quadros I, P e B também não é definida pela norma, cada quadro carrega esta informação em seu cabeçalho.

No codificador, a geração de um quadro $\mathrm{P}$ é feita através da subtração, pixel a pixel, do quadro com seu antecessor. No decodificador, após recuperar o quadro com as diferenças, este é somado ao quadro anterior gerando assim o novo quadro. O decodificador só pode iniciar a exibição de um vídeo a partir de um quadro chave I.

\subsection{MEDIDA DE QUALIDADE DE VÍDEO}

Para verificar a qualidade de uma imagem de vídeo, a medida mais aceita atualmente é o PSNR (peak signal-to-noise ratio). Neste trabalho esta medida foi realizada comparando a imagem original com a resultante após a recuperação no decodificador.

A relação sinal ruído de pico (PSNR) é o termo dado em engenharia para a relação entre a potência máxima do sinal e a potência do ruído, que degrada a fidelidade da representação final deste sinal. A representação é normalmente feita em decibéis (uma escala logarítmica), pois esta medida possui uma larga variação dinâmica. 
No caso do PSNR empregado na avaliação da qualidade de imagens, ele é uma aproximação à reação do olho humano à qualidade da imagem recebida. Esta aproximação não é ideal, mas é a melhor que se conhece atualmente. Sabe-se que em, alguns casos, uma imagem com PSNR numericamente inferior ${ }^{4}$ a outra pode ser mais 'agradável' ao olho humano. Por este motivo é preciso ser cauteloso ao se empregar esta medida. Porém, neste estudo, a comparação é válida, pois o codec empregado é o mesmo e o tipo de ruído introduzido na imagem, ocasionado pelo corte dos coeficientes da DCT, tem a mesma origem [50].

A forma mais comum para o cálculo do PSNR é através do cálculo do erro quadrático médio MSE (mean square error). Neste caso, dado duas imagens $\mathrm{I}(\mathrm{x}, \mathrm{y})$ e $\mathrm{K}(\mathrm{x}, \mathrm{y})$, onde $\mathrm{I}(\mathrm{x}, \mathrm{y})$ é a imagem original antes do codificador e $\mathrm{K}(\mathrm{x}, \mathrm{y})$ a imagem recuperada após o decodificador, o MSE pode ser definido como:

$$
M S E=\frac{1}{M N} \sum_{x=0}^{M-1} \sum_{y=0}^{N-1}[I(x, y)-K(x, y)]^{2}
$$

onde
MSE - Valor do erro quadrático médio entre as imagens I e K
$\mathrm{x} \quad$ - Índice da primeira dimensão dos pixels da imagem
y - Índice da segunda dimensão dos pixels da imagem
$\mathrm{N}$ - Dimensão total da imagem ou bloco da imagem no eixo y
M - Dimensão total da imagem ou bloco da imagem no eixo $\mathrm{x}$
I() - Matriz com os valores dos pixels da imagem I
$\mathrm{K}() \quad$ - Matriz com os valores dos pixels da imagem $\mathrm{K}$

Desta forma, define-se o PSNR como:

$$
P S N R=20 . \log _{10}\left(\frac{M A X_{I}}{\sqrt{M S E}}\right)
$$

onde

PSNR - Valor de pico da relação sinal ruído entre as imagens I e K

MSE - Valor do erro quadrático médio entre as imagens I e K

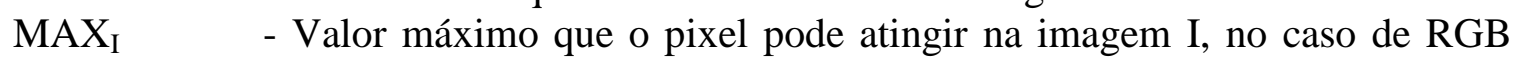
com cores codificadas em 8 bits este valor é 255 .

\footnotetext{
${ }^{4}$ Um PSNR maior indica uma reconstrução da imagem com qualidade melhor.
} 


\subsection{O ATRASO NA MUDANÇA DE CANAL}

Em 2006, o DSL fórum realizou um estudo com o objetivo de levantar os requisitos mínimos para os serviços triple-play ${ }^{5}$ fim a fim. Este estudo teve como resultado o relatório técnico apresentado em [14]. A qualidade de experiência ou QoE (quality of experience) é um requisito definido de acordo com a perspectiva do assinante. Ela está relacionada às diversas partes do sistema e às qualidades de serviços ou QoS de cada uma delas. A QoE se refere aos requisitos mínimos para uma experiência satisfatória do assinante ao usar cada serviço triple-play.

Quando se trata de transmissão de vídeo em redes, existem diversos tipos de serviços que podem ser prestados pelas operadoras, cada qual com seus requisitos únicos de QoE:

- Videoconferência: vídeo em tempo real, interativo, bidirecional e de sala a sala.

- Videofone: vídeo em tempo real, interativo, bidirecional, de pessoa a pessoa.

- TV tradicional em broadcast (IPTV): vídeo próximo de tempo real, sem interatividade e unidirecional.

- Canais especiais tipo pay-per-view: vídeo próximo de tempo real, sem interatividade e unidirecional.

- Vídeo sob demanda (VoD): vídeo em tempo real ou próximo de tempo real quando demandado, entregue sob demanda, interatividade parcial e unidirecional.

- Aplicações de segurança: vídeo em tempo real com baixa qualidade (baixo número de quadros por segundo), interatividade parcial e unidirecional.

- Stream de vídeo via Internet para PCs (personal computers), PDAs e celulares: vídeo não precisa ser em tempo real, baixa qualidade, interatividade e unidirecional.

- Colaboração de vídeo em rede: vídeo profissional de alta qualidade, não precisa ser em tempo real, bidirecional.

No caso deste estudo, o foco está nos vídeos para TV em broadcast ou IPTV e em particular no requisito de QoE, que se refere ao tempo decorrente entre o assinante solicitar a mudança do canal e a imagem ser apresentada na tela da televisão. Para conferir uma interatividade satisfatória, este tempo deve ser inferior a 2 segundos como mostra a Tabela 2 extraída de [14].

\footnotetext{
${ }^{5} \mathrm{O}$ termo serviço Triple-play se refere ao conjunto de serviços compostos por voz, dados e vídeo que devem ser entregues aos assinantes via rede de acesso. Neste caso, o desejo é que estes três serviços, apesar de características distintas, trafeguem na mesma rede.
} 
Tabela 2 - Recomendação de QoE para serviço de IPTV

\begin{tabular}{ccc}
\hline Ação do usuário & Exemplo & $\begin{array}{c}\text { Máximo atraso } \\
\text { recomendado }\end{array}$ \\
\hline $\begin{array}{c}\text { Ação na interface } \\
\text { do usuário }\end{array}$ & $\begin{array}{c}\text { Tempo entre o botão do controle remoto ser pressionado e o STB } \\
\text { dar alguma indicação de que o comando foi aceito. }\end{array}$ & $200 \mathrm{~ms}$ \\
$\begin{array}{c}\text { Mudança de } \\
\text { canal }\end{array}$ & Tempo entre o botão do controle remoto ser pressionado e o STB \\
exibir o novo canal na tela & $2 \mathrm{~s}$ \\
$\begin{array}{c}\text { Tempo de ligar o } \\
\text { equipamento }\end{array}$ & Tempo entre o STB ser ligado e o primeiro canal aparecer na tela & $10 \mathrm{~s}$ \\
\hline
\end{tabular}

\subsubsection{Origem do atraso na mudança de canal em IPTV}

O processo de alteração de canal, exemplificado na Figura 27, inicia quando o assinante pressiona o botão do controle remoto, por exemplo, a seta para cima indicando o desejo de assistir ao próximo canal da grade. O STB, ao identificar a tecla pressionada, deve tomar três providências. Primeiro, ele deve informar visualmente na tela que a tecla foi aceita, mostrando, por exemplo, as informações do próximo canal da grade. Em seguida, ele deve enviar um Join para o grupo multicast, que corresponde ao próximo canal e, por fim, um Leave para o grupo multicast que corresponde ao canal que ele estava assistindo.

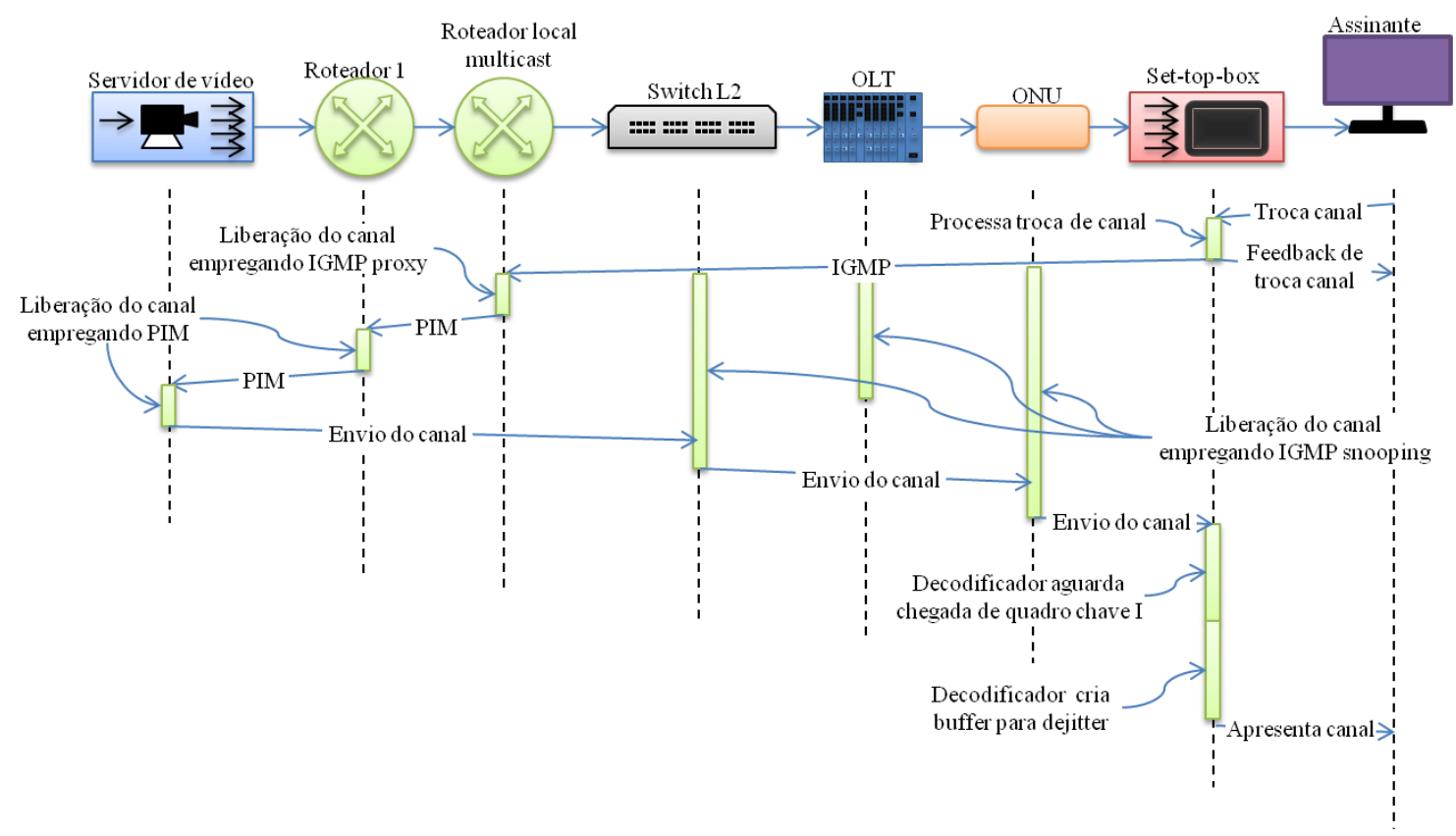

Figura 27 - Exemplo de alteração de canal em serviço IPTV 
O comando IGMP passa pela ONU, OLT e switch, todos de camada 2 e todos com IGMP snooping para melhor utilização da banda. Cada um destes dispositivos demandam um tempo para processar o comando IGMP. O vídeo só será entregue efetivamente para o STB quando todos tiverem excluídos o filtro do grupo multicast do canal.

O roteador multicast recebe o comando IGMP e o processa criando a rota para que o canal passe por ele chegando até o switch. Este roteador gera um comando PIM para o Roteador 1, que executa um tratamento semelhante enviando um PIM para o servidor de vídeo propriamente dito. No caso do exemplo, o servidor não opera em modo flush, mas sim sob demanda e o vídeo só será enviado quando o servidor processar o comando PIM.

Após todas as rotas terem sido criadas nos roteadores, e todos os filtros removidos dos equipamentos de camada 2, o stream de vídeo chega efetivamente ao STB. Antes de iniciar a decodificação do vídeo, o decodificador precisa de um quadro chave I. Em média, este tempo é 600 ms. Por fim, o STB deve armazenar alguns quadros para corrigir problemas de variação no atraso da rede que possam vir a ocorrer. O número de quadros armazenados antes da exibição varia de acordo com alguns fatores A qualidade da rede entre o STB e o servidor de vídeo é o principal deles. Este é normalmente um parâmetro configurado pela operadora.

Todo este processo introduz um atraso entre a ação do assinante de pressionar o botão e a exibição do vídeo na televisão, que pode chegar a até 10s [14]. Este problema tem sido bastante estudado, pois inviabiliza a prestação de serviço de IPTV. Testes executados por diversas operadoras tem recebido inúmeras reclamações devido a este atraso.

\subsubsection{Possíveis soluções para reduzir o atraso na mudança de canal}

Este é um tema bastante estudado atualmente e vários pesquisadores têm proposto possíveis formas de reduzir o atraso na mudança de canal. Algumas destas propostas serão analisadas a seguir.

\subsubsection{Envio de todos os canais}

Em 2007, Ikeda et al. [16] propuseram uma solução composta por duas partes que reduz drasticamente o tempo para troca de canais. Na primeira parte da solução, o servidor, que converte os canais em endereços IP multicast, deve operar como os servidores de IP dinâmicos com protocolo DHCP (dynamic host configuration protocol). Isto evita que para cada alteração 
de canal o STB tenha que consultar o IP multicast do canal, pois ele deverá possuir uma tabela interna com esta relação, que será atualizada de forma periódica pelo servidor. Na segunda parte da solução ele propõe enviar todos os canais para os assinantes que utilizam redes de acesso GPON, mostrado na Figura 28. Estes canais passam pela OLT e são enviados de forma broadcast para todas as ONUs. Conforme visto anteriormente, cada canal ocupará apenas a banda necessária para uma ONU, pois ele será colocado em uma porta que será recebida por todas as ONUs.

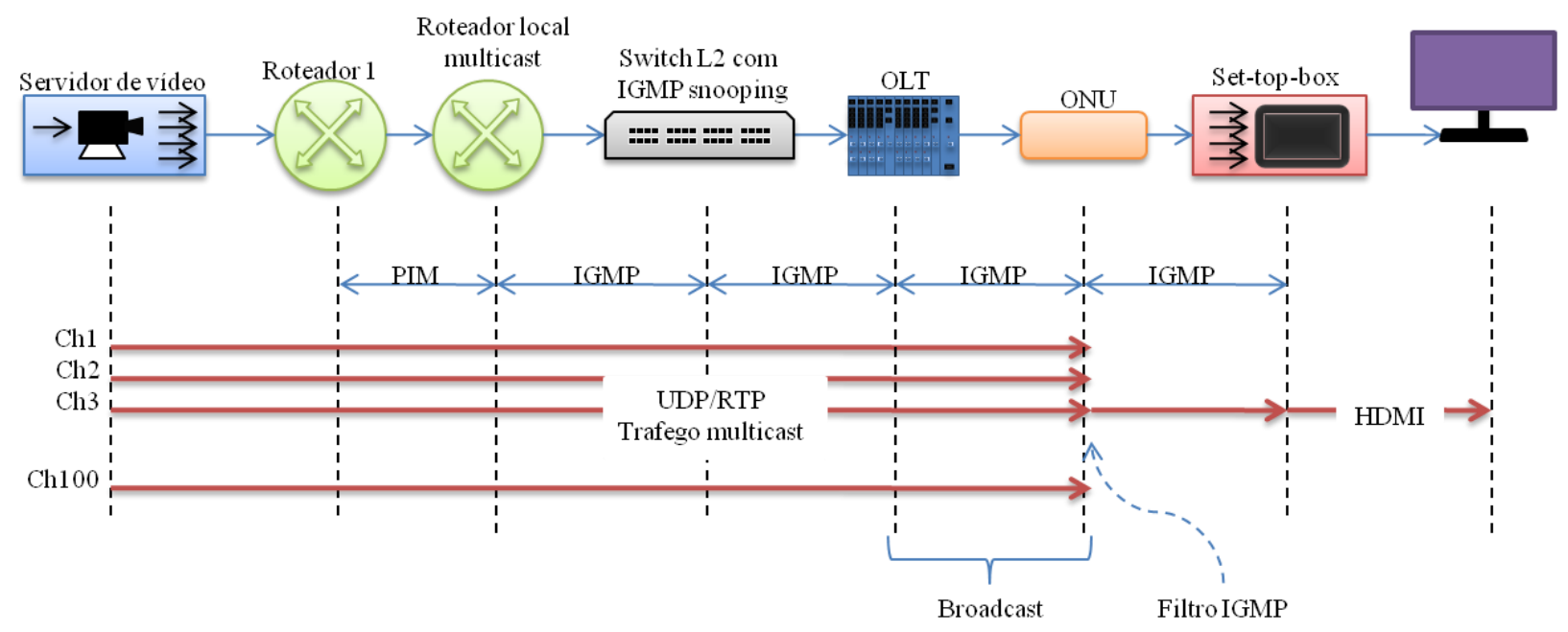

Figura 28 - Envio de todos os canais para a ONU como proposto em [16]

Segundo está proposta, se codificados em MPEG-4, cada canal pode ser limitado em 10Mbit/s de banda na rede, desta forma, para uma grade de 100 canais, a banda total na rede GPON seria de $1 \mathrm{Gbit} / \mathrm{s}$ que é menor que as 2,5Gbit/s disponíveis nos sistemas atuais.

As ONUs devem possuir a capacidade de filtrar o tráfego multicast contido neste fluxo broadcast. Isto é feito empregando o protocolo IGMP snooping em camada 2. O filtro é necessário uma vez que a banda total para entrega de todos os vídeos é superior à capacidade da porta Ethernet da ONU.

No momento da troca de canal, todos os atrasos de rede são evitados. O STB já possui o IP multicast que o assinante deseja assistir e o Join será tratado somente pela ONU uma vez que o vídeo já está presente nela. No artigo, o autor afirma que o atraso conseguido nos testes foi de 10ms, porém em nossos testes, que serão apresentados no próximo capítulo, somando os atraso 
do buffer de dejitter ( $\approx 600 \mathrm{~ms})$, ao atraso de espera pelo quadro ancora I ( $\approx 600 \mathrm{~ms})$, o atraso total ficou acima de $1.3 \mathrm{~s}$.

O primeiro inconveniente desta técnica é que mais da metade da banda disponível na rede GPON foi empregada para o tráfego dos canais de vídeo, o que torna o sistema ineficiente uma vês que muitos destes canais não serão assistidos pelos assinantes da rede. Este problema será minimizado no 10GPON desde que o número de canais não cresça. O segundo inconveniente é que o sistema não apresenta vantagens sobre o CATV ou o Video Overlay previsto na norma do GPON com relação ao limite de canais oferecidos ao assinante.

\subsubsection{Transmissão de canais adjacentes}

Em 2004, Cho C. et al.[51] propuseram um sistema para reduzir o tempo de zapping, transmitindo além do canal assistido pelo assinante, seus adjacentes. Desta forma, caso o assinante solicite um dos adjacentes ele já estará presente no STB, reduzindo o atraso na sua exibição. Este sistema é bem próximo do que é proposto nesta dissertação. Conforme veremos nos resultados obtidos, ele também pode conseguir trocas de canais com um intervalo de tempo de um frame e sempre com qualidade máxima oferecida pelo servidor.

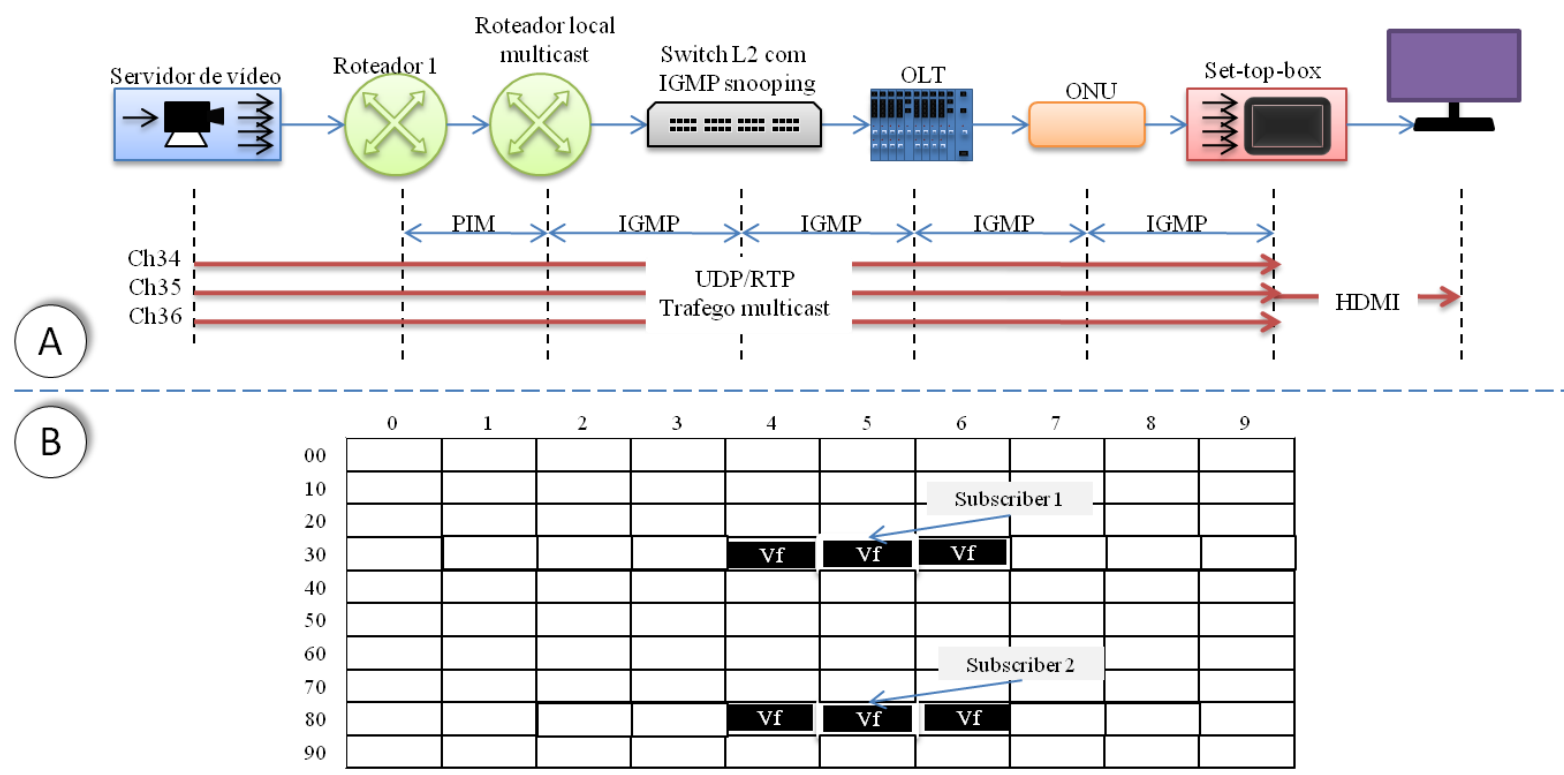

Figura 29 - Envio de canais adjacentes proposto em [51]. A) Transporte dos canais na rede; B) Exemplo dos canais adjacentes para dois assinantes.

Foram identificados alguns inconvenientes nesta proposta. O primeiro é que a banda necessária por assinante é elevada, ficando próxima da proposta neste documento para poucos assinantes, 
crescendo com o aumento de canais e assinantes, podendo chegar ao dobro da banda da proposta com vídeos escaláveis. O segundo é que se o assinante solicitar a troca muito rápida dos canais ocorrerá um intervalo sem imagem. Por exemplo, se o atraso total para troca de canal for de 5s, e o assinante solicitar duas trocas consecutivas com intervalo de 1s entre elas, ele ficará 4s sem imagem. Isto pode ser resolvido enviando 2 adjacentes, no lugar de 1, mas o custo de banda fica ainda maior.

Por fim, este artigo restringe a predição aos canais adjacentes, o que nem sempre é verdade. O sistema proposto nesta dissertação prevê que em trabalhos futuros sistemas de predição melhores (empregando redes neurais, por exemplo) possam ser empregados.

\subsubsection{Stream auxiliar para troca rápida de canal}

Joo H. et al.[52], propuseram em 2008 um sistema onde o servidor envia dois streams para cada canal, o primeiro, chamado de "Stream Normal", contém o vídeo codificado em 30 quadros por segundo com GOP (group of pictures) de 12 quadros (IBBPBBPBBPBB). O segundo, chamado de "Stream Para Troca Rápida de Canal", é composto apenas por quadros I's codificados no lugar dos quadros Ps. Neste stream os quadros Is e Bs do StreamI Normal não são codificados, como mostra a Figura 30 extraída do artigo.

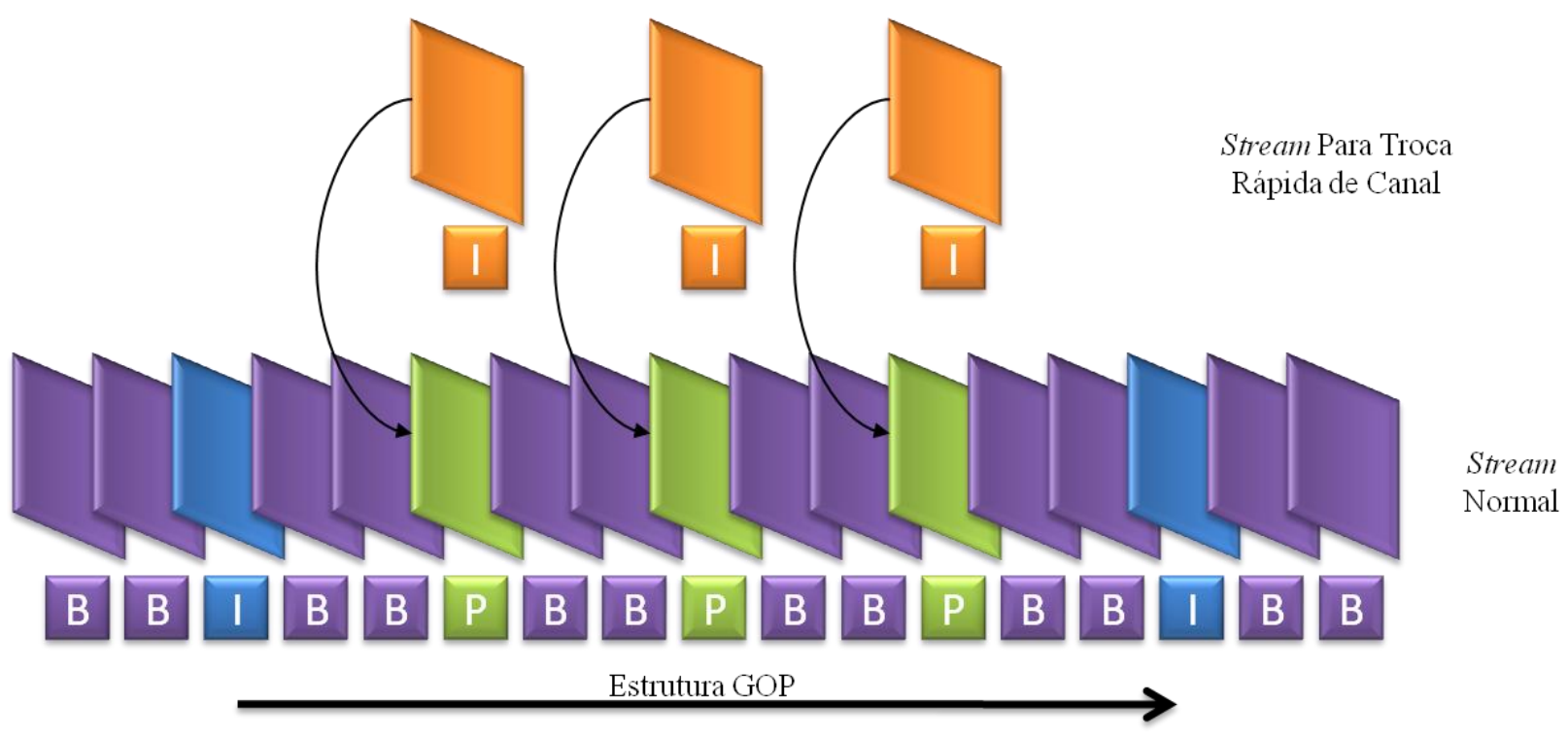

Figura 30 - Estrutura de codificação de quadros I, P e B para o Stream Normal e o Stream Para Troca Rápida de Canal. Imagem extraída do artigo [52] 
Em regime permanente, o STB recebe apenas o Stream Normal, porém, no momento da mudança de canal, o STB pode solicitar, além do Stream Normal, o Stream Para Troca Rápida de Canal. Isto acelera drasticamente a alteração do canal, uma vez que o STB não terá que aguardar a próximo quadro I de Normal Stream para iniciar a decodificação.

Assim que a decodificação for iniciada com sucesso o STB pode comandar o Leave do Stream Para Troca Rápida de Canal.

Este sistema se mostrou bastante eficiente, com um bom equilíbrio entre banda necessária para cada assinante por tempo necessário para a troca de canal. Porém, ainda resta o problema dos atrasos na rede. Para isto ele divide os canais em dois grupos, os mais assistidos, chamados de Static Channels, são mantidos em roteadores mais próximos do assinante, enquanto que os menos assistidos, chamados de Dynamic Channels, são mantidos mais distantes. Desta forma, o zapping para um Static Channel será menor que para um Dynamic Channel.

De forma estatística Joo conseguiu resultados muito bons, suas técnicas podem ser empregadas junto com a proposta nesta dissertação aprimorando ainda mais o resultado final de ambas.

Outra abordagem deste problema foi feita por Boyce, J.M. e Tourapis, A.M. em 2005 [53] que propõem a introdução periódica de quadros Is de baixa resolução junto com o stream normal de vídeo. Quando existe a troca do canal, o STB utiliza o quadro I de baixa resolução ao invés de aguardar pelo quadro I normal. Joo mostra em [52] que sua técnica é superior a de Boyce. 


\section{CAPÍTULO 4 - PROPOSTA PARA REDUÇÃO DO ATRASO NA MUDANÇA DE CANAL}

Neste capítulo será detalhada a proposta para reduzir o atraso na mudança de canal. Nele é detalhada a alteração no codificador para que quatro resoluções distintas estejam disponíveis no sistema. Também é mostrado como o STB deve prever os próximos canais acessados pelo assinante e como ele deve comandar a solicitação dos mesmos.

A fim de reduzir o tempo de espera entre a mudança de canal e a sua exibição na tela do assinante, propomos uma modificação do padrão de vídeo escalável em SNR do MPEG-2 [15], além de um sistema que mantenha alguns streams disponíveis para o assinante, mesmo que ele não esteja assistindo a todos. Esta técnica também pode ser usada em outros tipos de codificação, por exemplo, o vídeo escalável FGS [54] proposta no amendment 4 do MPEG-4 [11] [17].

\subsection{SERVIDOR DE VÍDEO ESCALÁVEL}

Diferentemente do sistema atual, os servidores de vídeo codificam cada vídeo em quatro streams distintos e complementares conforme esquematizado na Figura 31. V1 é um stream que contém o vídeo em baixa resolução, enquanto V2, V3 e V4 são complementos que melhoram o vídeo composto pela soma de seus anteriores. Desta forma, para visualizar o vídeo em resolução total é necessário somar os quatros streams.

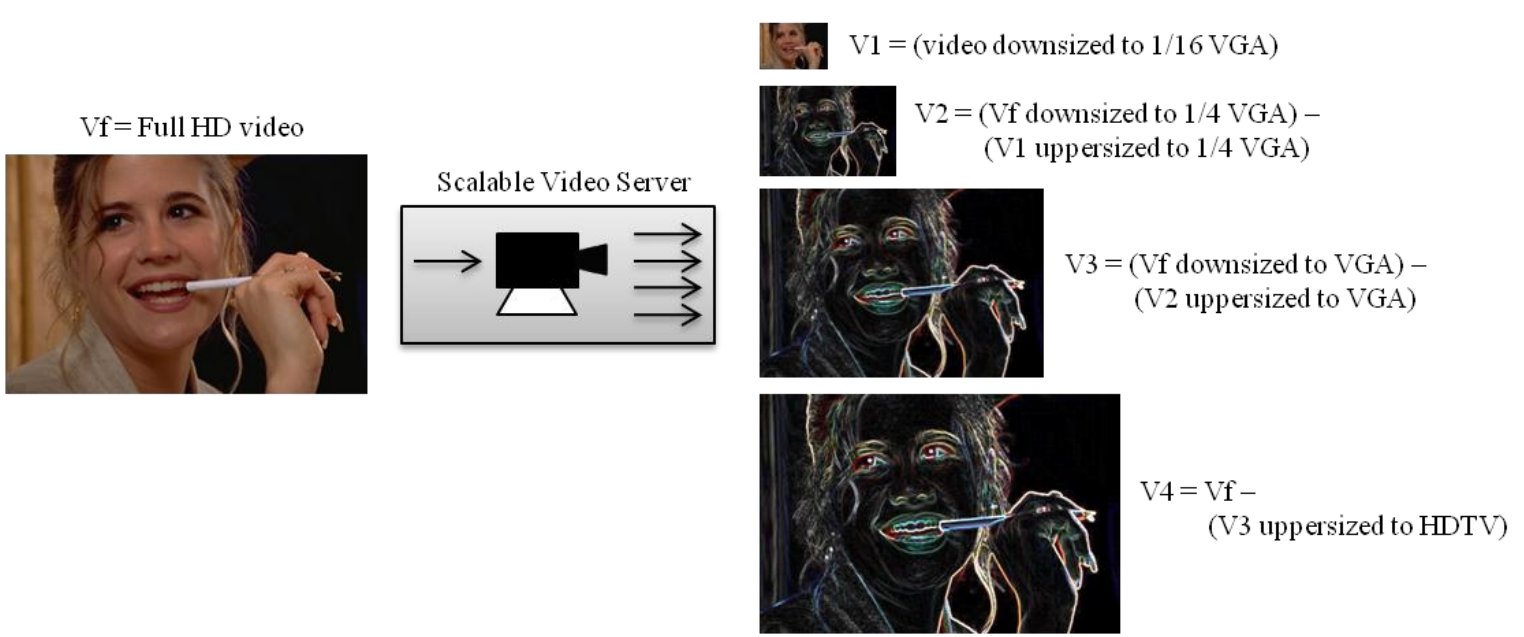

Figura 31 - Servidor de vídeo escalável, a imagem original é codificada em quatro imagens complementares. 
Expandindo o processo de codificação escalável em SNR do MPEG-2 temos o esquema básico para o codificador, mostrado na Figura 32.

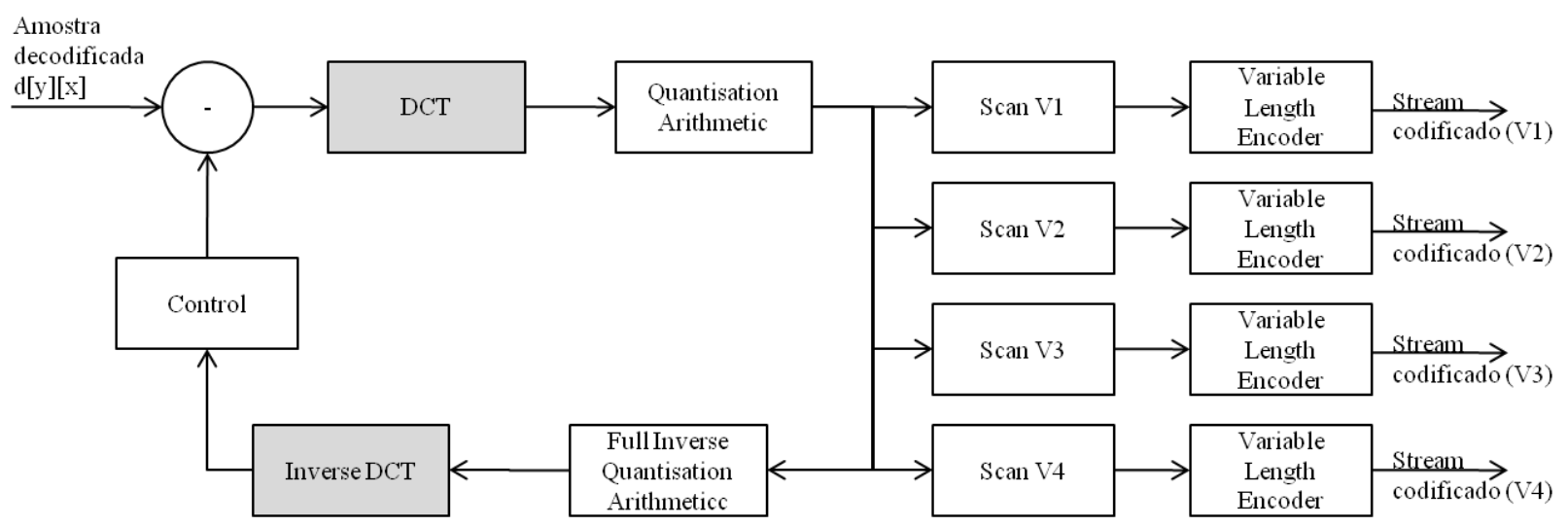

Figura 32 - Esquema simplificado do codificador de vídeo escalável em SNR com 4 stream complementares

Para que os vídeos sejam complementares, os quatro scans devem ser complementares. Além disto, para que não haja distorção nas imagens recuperadas sem os quatro streams, cada um dos scans deve ser simétrico em relação à diagonal do canto superior esquerdo para o canto inferior direito. Para V1 o scan é composto apenas pela diagonal 1, ou seja, o componente DC, V2 é composto pela diagonal 2, V3 pelas diagonais 3 e 4 e V4 pelas diagonais restantes conforme ilustra a Figura 33.

Divisão da matriz se quantização intra bloco par
expansão do vídeo escalável em SNR
(luminância e crominância)
\begin{tabular}{c|cccccccc} 
& 0 & 1 & 2 & 3 & 4 & 5 & 6 & 7 \\
\hline 0 & 8 & 16 & 19 & 22 & 26 & 27 & 29 & 34 \\
1 & 16 & 16 & 22 & 24 & 27 & 29 & 34 & 37 \\
\hline 2 & 19 & 22 & 26 & 27 & 29 & 34 & 34 & 38 \\
3 & 22 & 22 & 26 & 27 & 29 & 34 & 37 & 40 \\
4 & 22 & 26 & 27 & 29 & 32 & 35 & 40 & 48 \\
5 & 26 & 27 & 29 & 32 & 35 & 40 & 48 & 58 \\
6 & 26 & 27 & 29 & 34 & 38 & 46 & 56 & 69 \\
7 & 27 & 29 & 35 & 38 & 46 & 56 & 69 & 83
\end{tabular}

Divisão da matriz se quantização intra bloco para a expansão do vídeo escalável em SNR luminância e crominância)

8 Scan para V1
Divisão da matriz se quantização não-intra bloco para a expansão do vídeo escalável em SNR (luminância e crominância)

\begin{tabular}{c|cccccccc} 
& 0 & 1 & 2 & 3 & 4 & 5 & 6 & 7 \\
\hline 0 & 16 & 16 & 16 & 16 & 16 & 16 & 16 & 16 \\
1 & 16 & 16 & 16 & 16 & 16 & 16 & 16 & 16 \\
2 & 16 & 16 & 16 & 16 & 16 & 16 & 16 & 16 \\
3 & 16 & 16 & 16 & 16 & 16 & 16 & 16 & 16 \\
4 & 16 & 16 & 16 & 16 & 16 & 16 & 16 & 16 \\
5 & 16 & 16 & 16 & 16 & 16 & 16 & 16 & 16 \\
6 & 16 & 16 & 16 & 16 & 16 & 16 & 16 & 16 \\
7 & 16 & 16 & 16 & 16 & 16 & 16 & 16 & 16
\end{tabular}

Figura 33 - Divisão da matriz de quantização em quatro seguimentos para o scan 
É possível notar que o processo proposto é computacionalmente viável, pois tanto a DCT quanto a IDCT são executadas apenas uma vez para os quatro streams. Outro ponto importante é que um vídeo codificado em MPEG-2 pode ser facilmente convertido para os quatro streams sem a necessidade de uma nova compressão.

\subsection{TRANSPORTE DO STREAM DE VÍDEO}

Cada um dos streams será disponibilizado em um endereço multicast distinto. Desta forma, o STB poderá executar o Join e Leave nos streams que lhe convier.

Neste ponto, podemos observar uma vantagem deste processo, pois caso o vídeo seja exibido em uma tela de tamanho reduzida, como a de um celular, apenas os streams V1 e V2 são necessários, conforme visualizado na Figura 34.

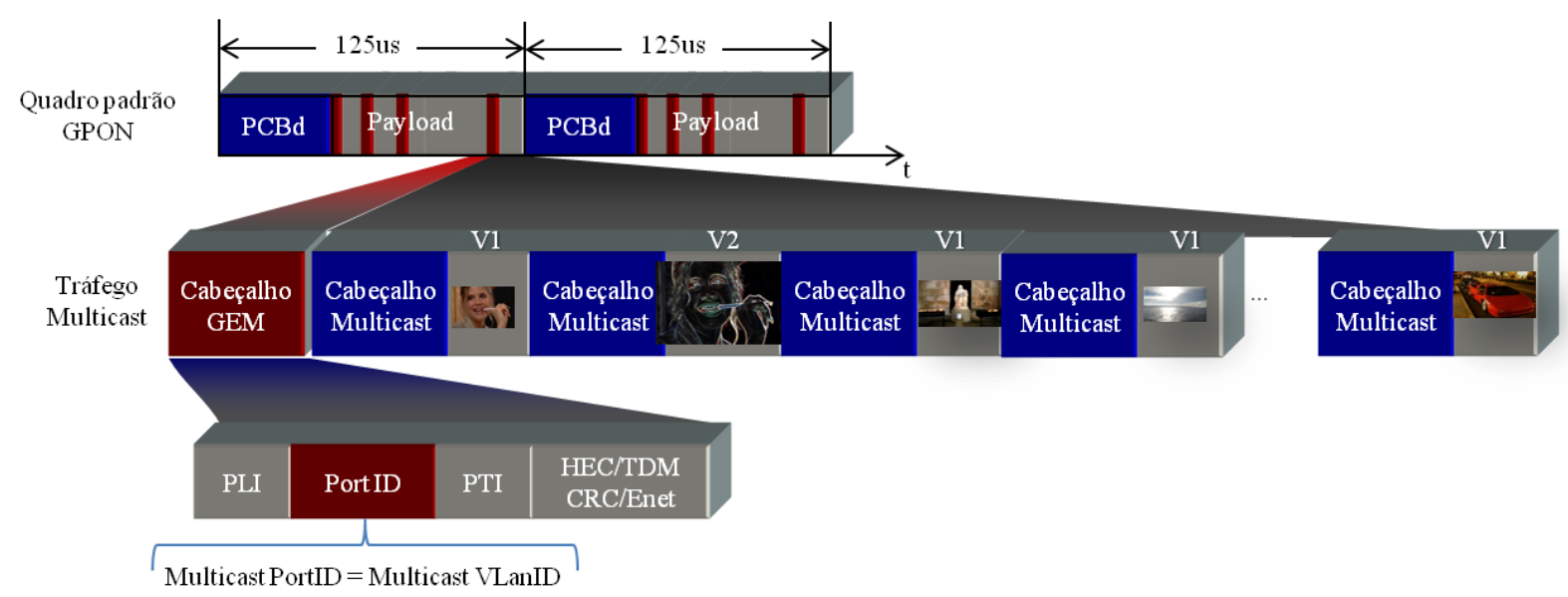

Figura 34 - Vídeos transmitidos em stream distintos. No contexto da figura o termo "Cabeçalho Multicast" significa os cabeçalhos necessários para o encaminhamento dos pacotes multicast do stream de vídeo

Prioridades diferentes podem ser adotadas para streams diferentes, como discutido em [19] para MPEG-2 e em [54] [55] para MPEG-4. Isto melhora significativamente a qualidade do vídeo quando existe perda de pacotes devido a congestionamento na rede.

\subsection{RECEPTOR DE VÍDEO ESCALÁVEL}

A recuperação do vídeo será executada no STB somando os streams disponíveis no processo de scan inverso, como mostra o diagrama simplificado da Figura 35. 


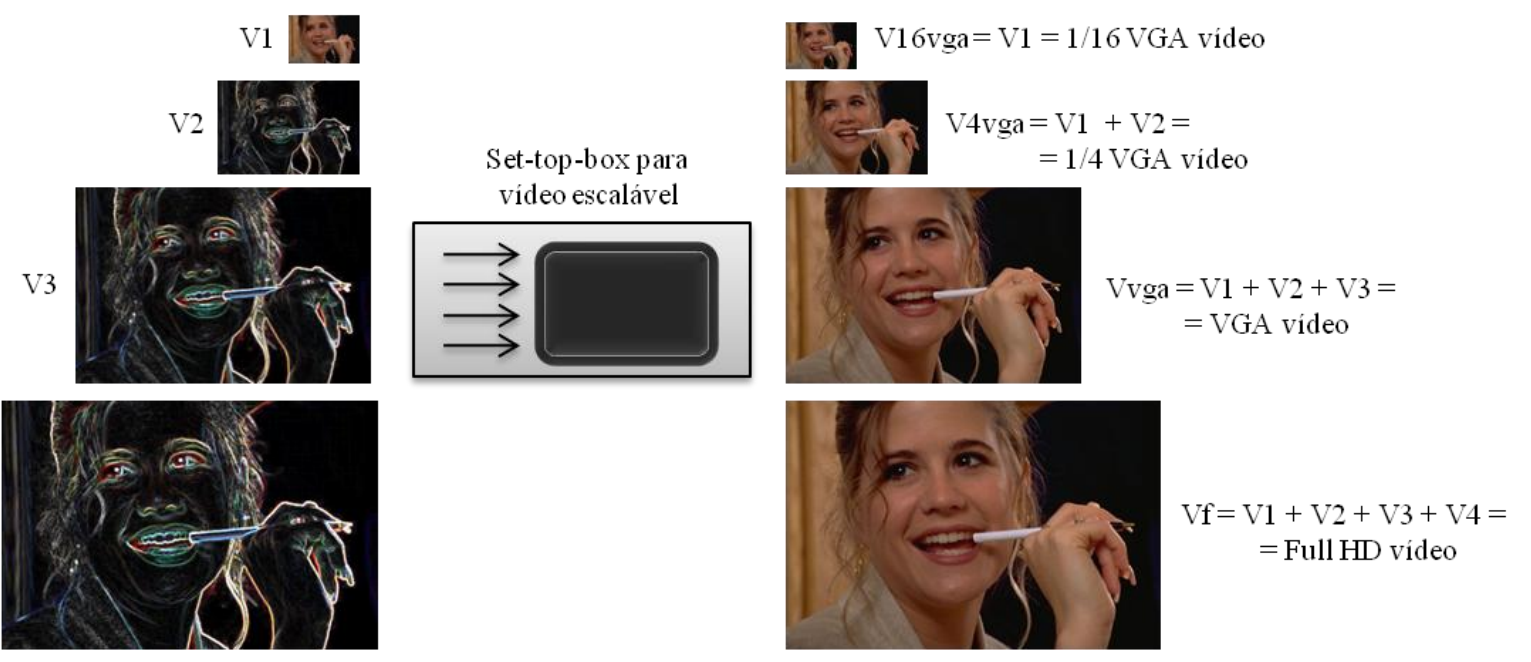

Figura 35 - Recomposição da imagem no STB reagrupando os stream disponíveis no processo de scan inverso O diagrama da Figura 36 mostra um esquema simplificado do decodificador presente no STB para decodificar o conjunto de streams.

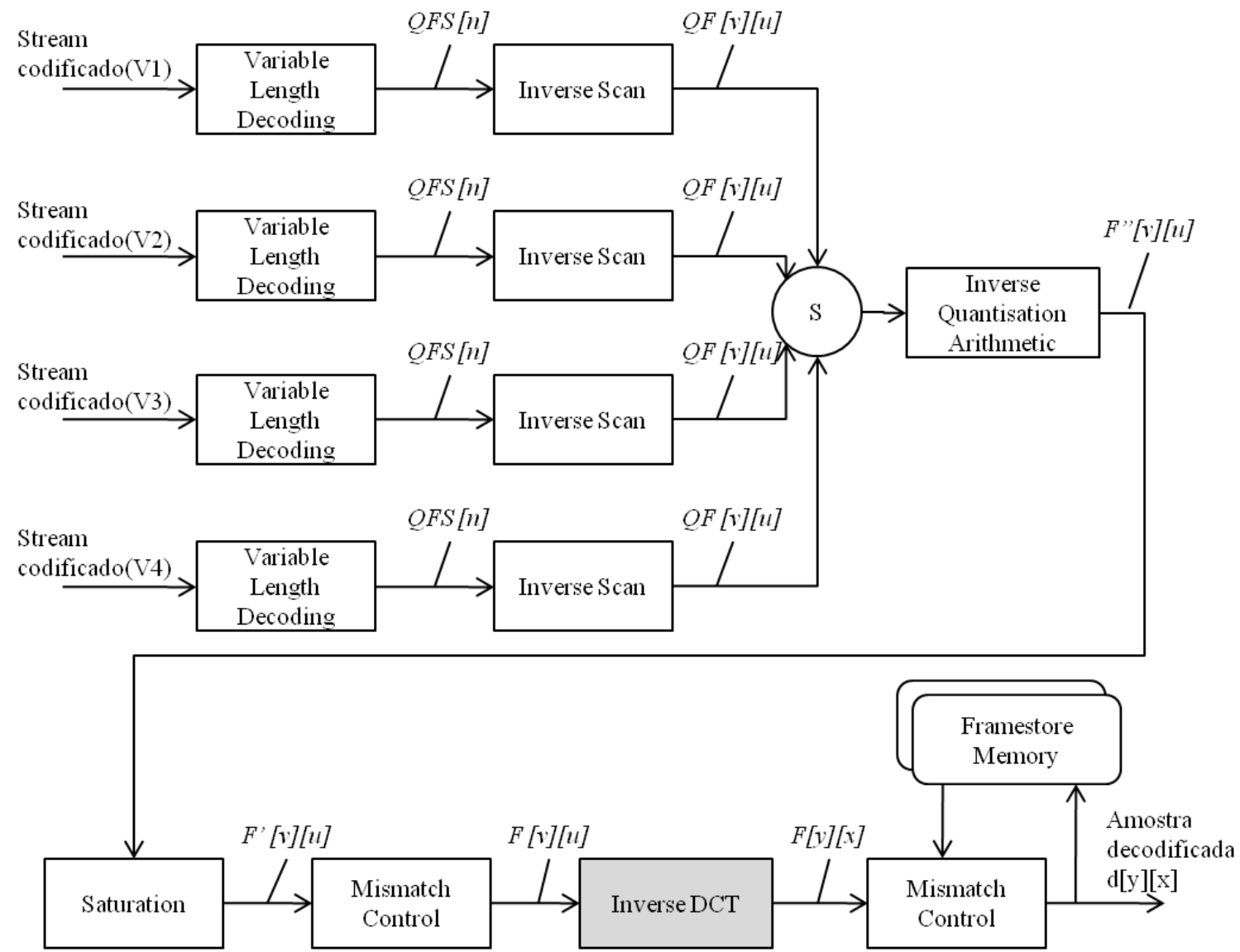

Figura 36 - Esquema simplificado do decodificador de vídeo escalável em SNR com quatro streams complementares 
Assim como na codificação, a decodificação utiliza apenas uma IDCT, o que torna o processo viável em equipamentos com processamento limitado. Não é necessário que todos os streams estejam disponíveis para que o vídeo seja decodificado. Ocorre que o PSNR melhora quanto maior o número de streams utilizados. A redução da qualidade do vídeo se dá pela perda das componentes de alta frequência uma vez que a frequência da imagem cresce da direita para a esquerda e de cima para baixo em cada bloco. A perda das altas frequências é percebida, de forma mais acentuada, em telas com resoluções superiores, pois a redução da resolução de uma imagem atua naturalmente como um filtro passa baixa.

No caso dos vídeos reconstituídos a partir apenas de V1, não existe a necessidade da IDCT. V1 já é por si só a média dos 64 pixels que compõem aquele bloco e podem ser usados diretamente após a quantização. Isto faz com que o processo de descompressão seja mais leve e possa ser executado em paralelo com a descompressão de outro vídeo para ser usado, por exemplo, em sistemas PIP (picture in picture).

Partindo de um vídeo HDTV (1920x1080), o vídeo gerado por V1 pode ser exibido com boa qualidade (PSNR acima de $36 \mathrm{~dB}$ para o nosso codificador) em telas de 240x135, que denominamos V16vga. Acrescentando V2, o vídeo pode ser exibido em 480x270, chamado de V4vga. Somando V3 à anterior temos o vídeo para telas 960x540 (normalmente convertido para SDTV), chamado de Vvga, e com a soma dos quatro streams temos o vídeo ideal para HDTV, chamado de Vf conforme será visto nos resultados apresentados no próximo capítulo.

\subsection{SOLICITAÇÃO DOS STREAMS PELO STB}

O STB pode solicitar os streams conforme sua necessidade. A fim de evitar que o assinante tenha que aguardar os atrasos da rede, de buffer e de descompressão, uma predição é empregada de tal forma que o STB receberá, além do canal assistido em HDTV, um conjunto de outros canais em baixa resolução, cujas probabilidades de serem os próximos selecionados sejam grandes. Como exemplo, em uma grade de 100 canais, os canais adjacentes ao assistido podem ser solicitados como mostra a Figura 37. 


\begin{tabular}{|c|c|c|c|c|c|c|c|c|c|c|}
\hline & 0 & 1 & 2 & 3 & 4 & 5 & 6 & 7 & 8 & 9 \\
\hline 00 & & & & & & & & & & \\
\hline 10 & & & & & & & \multirow{2}{*}{\multicolumn{2}{|c|}{ Assinante 1}} & & \\
\hline 20 & & & & & & & & & & \\
\hline 30 & & V16vga & V16vga & V16vga & V4vga & $\mathrm{Vf}$ & V4vga & V16vga & V16vga & V16vga \\
\hline 40 & & & & & & & & & & \\
\hline 50 & & & & & & & & & & \\
\hline 60 & & & & & & & \multirow{2}{*}{\multicolumn{2}{|c|}{ Assinante 2}} & & \\
\hline 70 & & & & & & & & & & \\
\hline 80 & & & V16vga & V4vga & V4vga & $\mathrm{Vf}$ & V4vga & V4vga & V16vga & \\
\hline 90 & & & & & & & & & & \\
\hline
\end{tabular}

Figura 37 - Canais adjacentes solicitados pelo terminal do assinante

O assinante 1 está assistindo ao canal 35, que é recebido em Vf. Supondo que o sistema possua quatro níveis de prioridade, a Tabela 3 ilustra como os canais podem ser solicitados para que o restante da rede consiga descartar corretamente pacotes em caso de congestionamento. Neste caso, $\mathrm{P} 0$ é a fila de maior prioridade e $\mathrm{P} 3$ a de menor.

Tabela 3 - Priorização dos stream na rede

\begin{tabular}{|c|c|c|c|c|c|c|c|c|c|}
\hline & V16vga & V16vga & V16vga & V4vga & Vf & V4vga & V16vga & V16vga & V16vga \\
\hline V4 & & & & & P1 & & & & \\
\hline V3 & & & & & P0 & & & & \\
\hline V2 & & & & P2 & P0 & P2 & & & \\
\hline V1 & P3 & P2 & P1 & P1 & P0 & P1 & P1 & P2 & P3 \\
\hline
\end{tabular}

A decisão de quais canais solicitar, em quais streams e em qual prioridade é de responsabilidade do STB baseado no comportamento do assinante. Observe que sistemas baseados em inteligência artificial (em particular as redes neurais artificiais) podem ser adotados para esta predição.

Ao receber os canais solicitados, o terminal deve armazenar todos. A fim de assegurar o menor atraso possível, o tamanho total do buffer para cada stream deve ser calculado como:

$$
\text { BufferSize }=\text { MaxIInterval }+ \text { MinDejitter }-1
$$

onde 
BufferSize - Tamanho que deve ser reservado para o buffer em número de frames MaxIInterval - Máximo intervalo entre frames I em número de frames

MinDejitter - Menor buffer dimensionado para eliminação de jitter em número de frames

No momento da mudança de canal, o terminal usará o vídeo que está no buffer. Este vídeo possui uma qualidade inferior, porém, boa o suficiente para que o assinante decida permanecer ou não no canal. Enquanto isto, o STB deve comandar os Joins e Leaves necessários para a nova posição. Ao receber os novos streams, a imagem melhora, progressivamente, para o assinante. 


\section{CAPÍTULO 5 - RESULTADOS OBTIDOS}

\subsection{SIMULADOR PARA PROVA DE CONCEITO}

Para provar o conceito proposto, implementamos um conjunto codificador/decodificador simplificado em C++ empregando o Visual Studio da Microsoft, a Figura 38 mostra o diagrama deste software incluindo dois medidores (BW e PSNR) e uma chave de teste com trigger por número de quadros. Este software abre arquivos do tipo AVI de vídeo sem compressão, executa a codificação nos quatro streams, calcula a banda necessária para o transporte de cada um deles e decodifica juntando um ou mais streams conforme o experimento desejado.

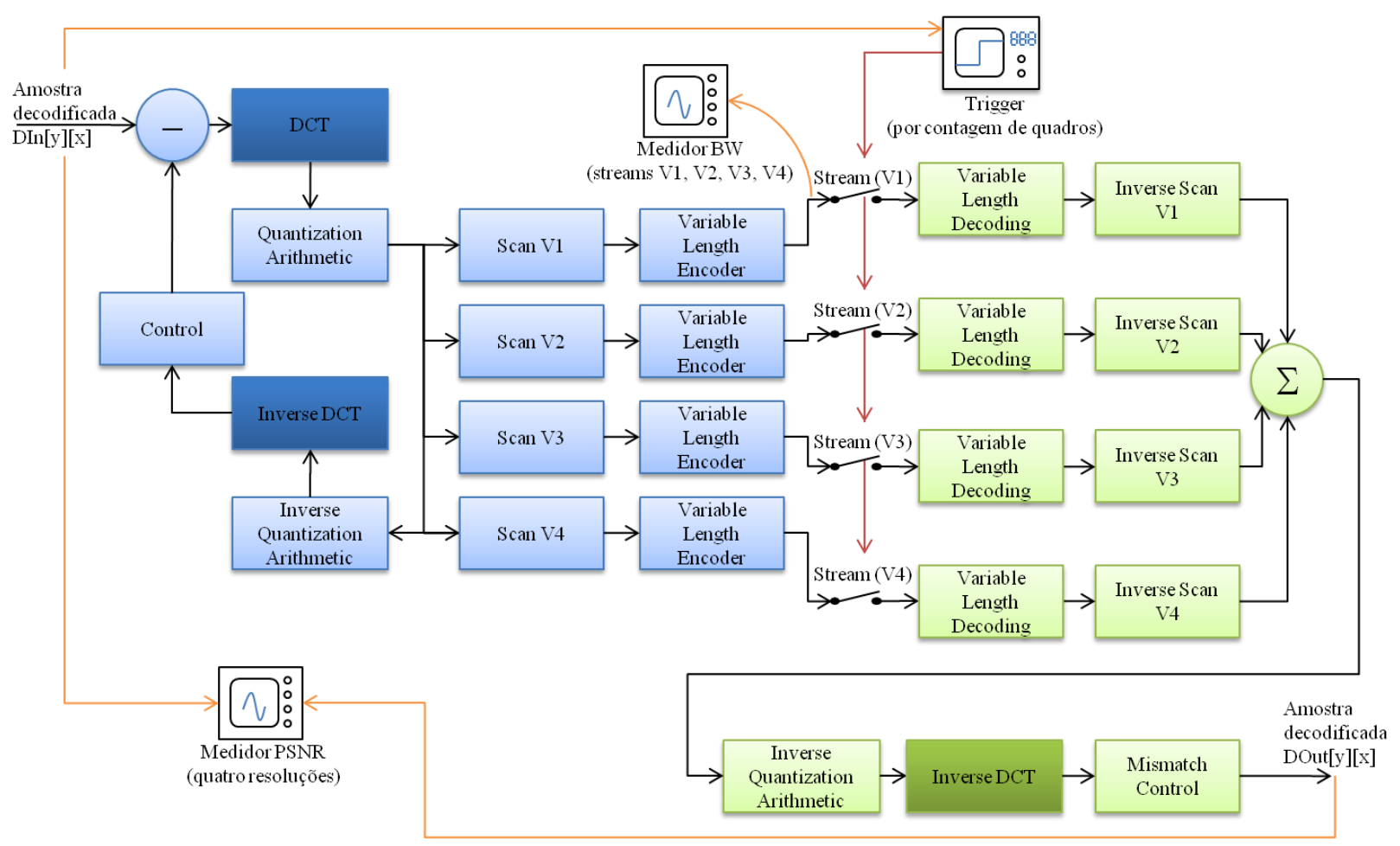

Figura 38 - Conjunto codificador/decodificador de teste

Tanto DIn[y][x] quanto DOut[y][x] são vídeos sem compressão em YCbCr. V1 a V4 são os streams de vídeo comprimidos, que podem ser transmitidos via rede multicast Ethernet. As chaves nestes streams possibilitam que cada um deles seja ou não entregue ao decodificador. Estas chaves são alteradas de forma automáticas pelo software com o disparo da mudança de 
estado (aberta ou fechada) sendo feito pelo no número do quadro. Elas servem para gerar os diversos experimentos necessários para a prova do conceito.

A banda necessária para cada um dos streams é amostrada após o 'Variable Length Encoder'. Para a transmissão e a correta recuperação da informação, um cabeçalho médio com 50 Bytes é acrescentado a cada um dos streams. Os outros componentes estão descritos a seguir (note que nem todos os componentes do MPEG-2 foram implementados).

- DCT: É a transformada do cosseno discreto.

- Quantization Arithmetic: Neste bloco os coeficientes resultantes da DCT são divididos pelas matrizes da Figura 33, dependendo do quadro ser I ou P. Na saída deste bloco os valores são arredondados eliminando-se a parte fracionária do número. A matriz de quantização utilizada é transmitida em cada um dos stream correspondentes.

- Inverse Quantization Arithmetic: Neste bloco os coeficientes são multiplicados pelas matrizes recebidas junto com os streams, dependendo do quadro ser I ou P.

- IDCT: É a transformada inversa do cosseno discreto.

- Control: Define se o quadro transmitido será I ou P. Em princípio, haverá um quadro I para cada 31 Ps. Isto pode ser alterado dependendo da diferença entre os quadros. Caso o PSNR entre estes dois quadros seja inferior a $22 \mathrm{~dB}$, um quadro I será enviado mesmo antes de completar os 31 Ps.

- Scan V1 à V4: Executa a varredura do macrobloco 4:4:4 para o respectivo stream conforme mostrado na Figura 33.

- Variable Length Encoder: A codificação variável é feita em duas etapas. Na primeira, o sistema desloca a varredura na imagem para os macroblocos onde existem informações a serem transmitidas; para cada salto de macroblocos um par de bytes é usado para indicar o quanto o decodificador deve saltar. Em seguida, todas as sequências de zeros dos macroblocos que serão transmitidos são substituídas por um par de bytes que indica quantos zeros devem ser colocados naquele ponto.

- Variable Length Decoder: A decodificação variável é feita em duas etapas. Na primeira, as sequências de zeros são reconstituídas dentro dos macroblocos. Na segunda, os macroblocos são reposicionados na imagem. Apesar de não estar representada desta forma na Figura 38, a segunda etapa é realizada após o 'Inverse Scan'. 
- Inverse Scan V1 à V4: Recompõe as sequências nos macroblocos somando os stream disponíveis dentro do macrobloco. As posições correspondentes aos streams não disponíveis são preenchidas com 0 .

- Mismatch Control: Caso o quadro seja P, soma a imagem resultante da IDCT com o quadro anterior para obter o novo quadro. Este bloco também é responsável por melhorar a qualidade da decodificação quando as DCTs empregadas na codificação e na decodificação são diferentes, porém, isto não ocorre neste trabalho.

Para cada experimento, o PSNR é calculado no Medidor PSNR que está detalhado na Figura 39. No medidor, o vídeo de entrada $\operatorname{DIn}[\mathrm{y}][\mathrm{x}]$ é comparado com o de saída DOut[y][x] para quatro resoluções, padrão de entrada (HDTV), 1/4 do padrão (SDTV), 1/8 do padrão (LRTV) e 1/16 do padrão (PPTV). Neste caso, o valor do PSNR deve ser uma representação da qualidade do vídeo assistido pelo assinante em quatro dispositivos distintos, em HDTV seria o equivalente ao assinante com uma televisão de alta definição, o SDTV equivale a uma televisão padrão, o LRTV equivale a uma tela de 1/4 de VGA, por exemplo, uma tela de celular e por fim PPTV equivale a uma tela de 1/16 de VGA que pode ser empregado, por exemplo, em imagens picture in picture.

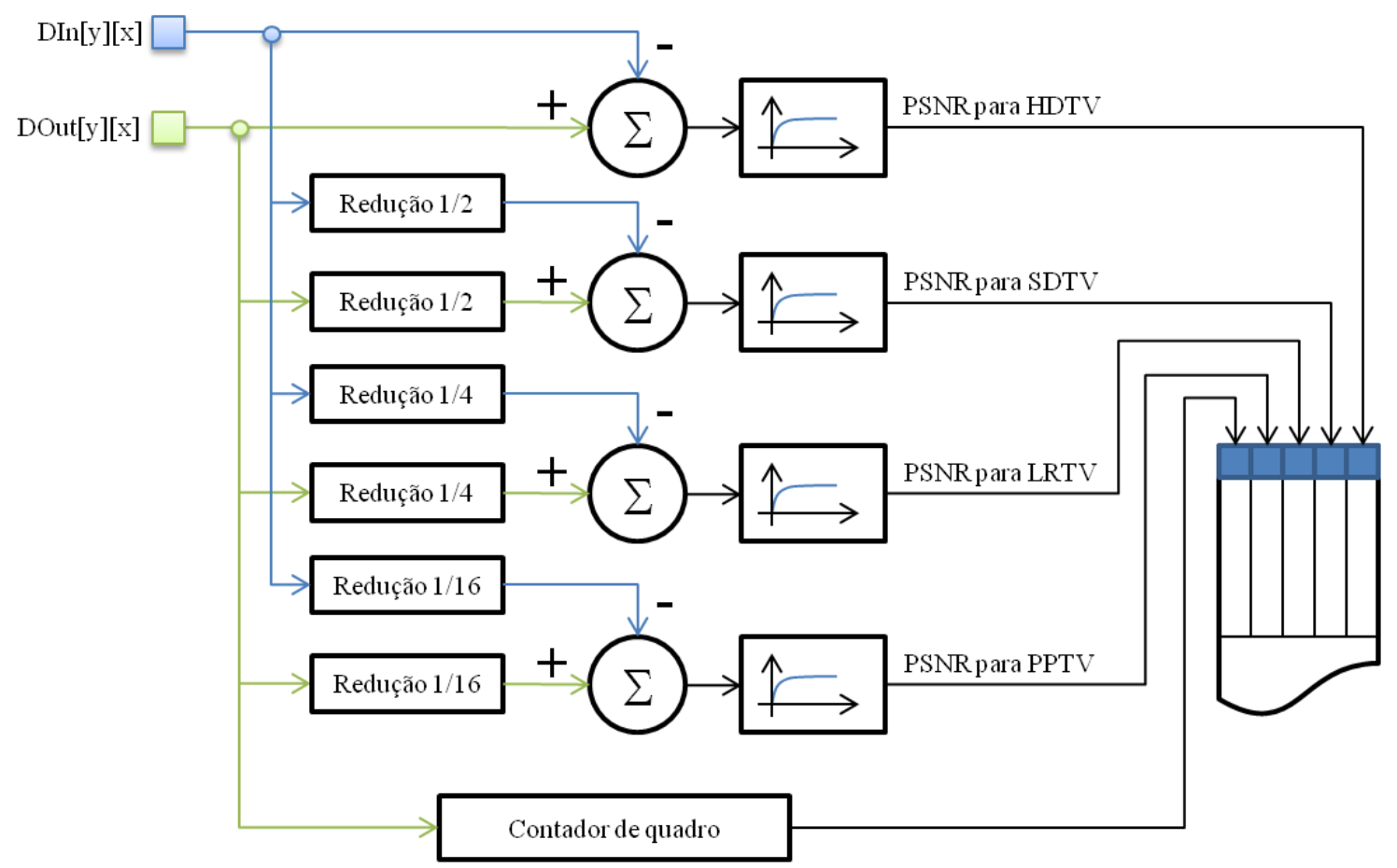

Figura 39 - Detalhe do medidor de PSNR para as quatro resoluções (HDTV, SDTV, LRTV e PPTV) 
Observe que tanto a imagem de entrada $\operatorname{DIn}[\mathrm{y}][\mathrm{x}]$ quanto a de DOut[y][x] possuem a resolução máxima de acordo com o arquivo AVI de origem, mesmo quando menos streams são empregados. Então a geração das resoluções menores é feita com uma redução da imagem através da média dos pixels que serão agrupados.

\subsection{RESULTADOS OBTIDOS}

Para medir a qualidade deste processo, os vídeos DIn[y][x] e DOut[y][x] foram comparados usando o PSNR em quatro resoluções distintas, sendo o primeiro vídeo na resolução original e cada um dos três subsequentes um quarto da anterior (cada pixel de baixa resolução formado pela média de quatro pixels de alta resolução). Foram executados testes com diversos vídeos, para obter os resultados (Figura 40) empregamos os 20 primeiros segundos do vídeo "UNI Mulheres salvando o planeta" [56] codificado na resolução 640 x 480 com 30 quatros por segundo, por possuir imagens dinâmicas com movimentos de pessoas e carros, também por propiciar simulações relativamente rápidas se comparadas com as simulações em FullHD.
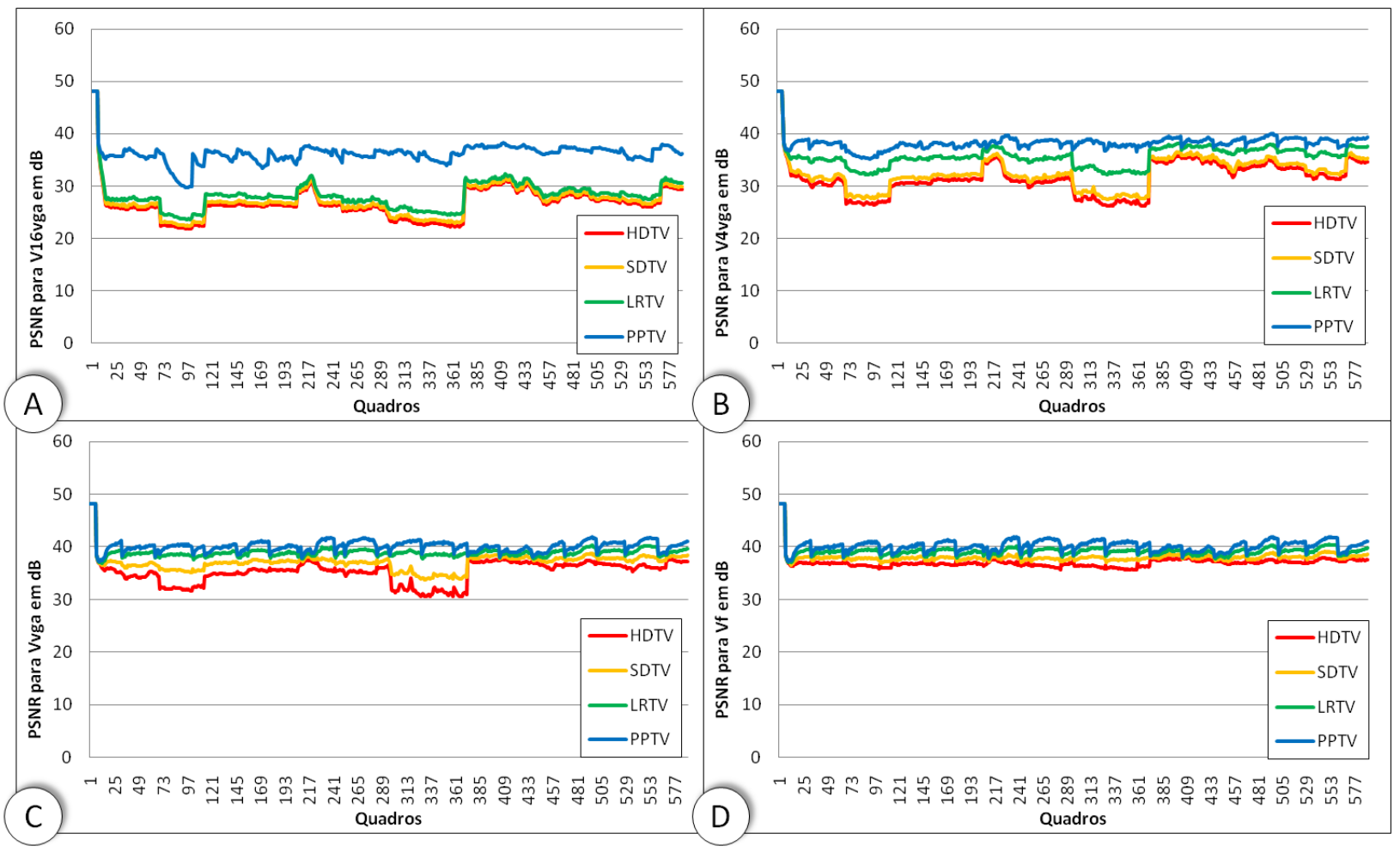

Figura 40 - Comparação da qualidade dos vídeos gerados em quatro formatos: A) usando o stream V1; B) usando os streams V1+V2; C) usando os streams V1+V2+V3; D) usando os streams $\mathrm{V} 1+\mathrm{V} 2+\mathrm{V} 3+\mathrm{V} 4$ 
Os quatro gráficos da Figura 40 mostram a diferença de qualidade entre cada um dos formatos propostos, compostos pela soma dos streams. Nestes, HDTV indica a resolução máxima, SDTV corresponde a 1/4 da resolução HDTV, LRTV (low resolution television) corresponde a 1/4 de SDTV e PPTV (picture in picture television) corresponde a $1 / 4$ de LRTV. A Tabela 4 resume os resultados destes gráficos, levando em conta apenas o valor médio de cada uma das qualidades.

Tabela 4 - Valor médio das qualidades de vídeo composto pelas combinações dos streams e BW (bandwidth) média necessária para cada stream

\begin{tabular}{|c|c|c|c|c|c|c|}
\cline { 2 - 7 } \multicolumn{1}{c|}{} & \multicolumn{2}{c|}{ BW (Mbit/s) } & \multicolumn{4}{c|}{ PSNR (dB) } \\
\cline { 2 - 7 } \multicolumn{1}{c|}{} & Acréscimo & Total & HDTV & SDTV & LRTV & PPTV \\
\hline V16vga & 3,01 & 3,01 & 27 & 27 & 28 & 36 \\
\hline V4vga & 2,46 & 5,47 & 32 & 32 & 36 & 38 \\
\hline Vvga & 3,15 & 8,62 & 35 & 37 & 39 & 40 \\
\hline Vf & 2,94 & 11,56 & 37 & 38 & 39 & 40 \\
\hline
\end{tabular}

A banda necessária para cada um dos streams é mostrada no gráfico da Figura 41a. A taxa de compressão média foi de 94\%. Apesar de cada resolução transportar seu próprio cabeçalho, aumentando a banda, o codificador se mostrou mais eficiente com a divisão, pois sequências maiores de zeros foram formadas nos macroblocos em V3 e V4. O gráfico da Figura 41B compara a banda necessária para transportar o vídeo original em um único stream com a soma da banda dos quatro streams.
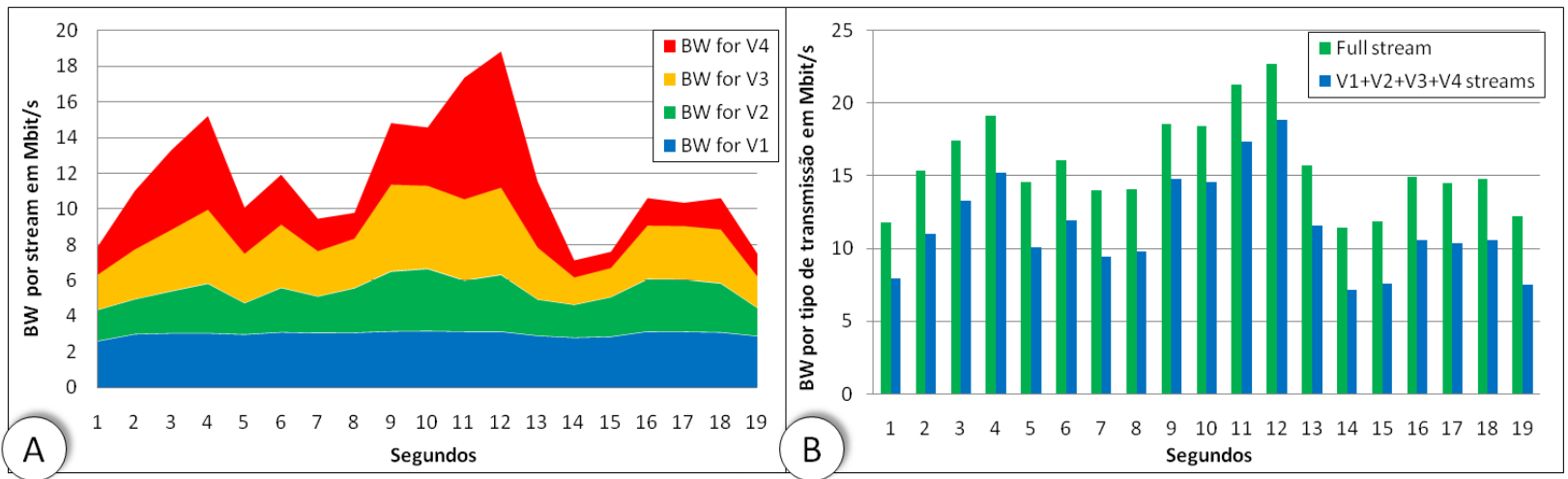

Figura 41 - Banda necessária no sistema: A) Banda para cada um dos streams que compõem o vídeo. B) Comparação entre a banda necessária para o transporte do vídeo em um único stream com o transporte do vídeo em quatro streams 


\subsection{CONSIDERAÇÕES SOBRE O SISTEMA}

\subsubsection{Possibilidade de resoluções distintas}

Tanto a resolução necessária para o vídeo quanto a banda disponível podem variar ao longo do tempo. A resolução pode variar de acordo com a programação, pois mesmo em canais HD (high definition) haverá imagens em SD (standard definition), neste caso, o codificador pode suspender temporariamente o envio de V4 sem que o STB tenha qualquer problema para decodificar o vídeo. A resolução também pode variar com o STB, pois não existe a necessidade de se enviar um vídeo HD para um PDA, por exemplo. Em alguns casos o meio de transmissão também pode limitar a banda, por exemplo, se uma ONU estiver conectada a um sistema WiMax (worldwide interoperability for microwave access) cuja banda destinada a IPTV é menor que a necessária para HDTV. Nestes casos, o sistema proposto propicia a adequação da resolução final, sem que o servidor precise atender, de forma particularizada, cada um dos STBs como ilustrado na Figura 42.

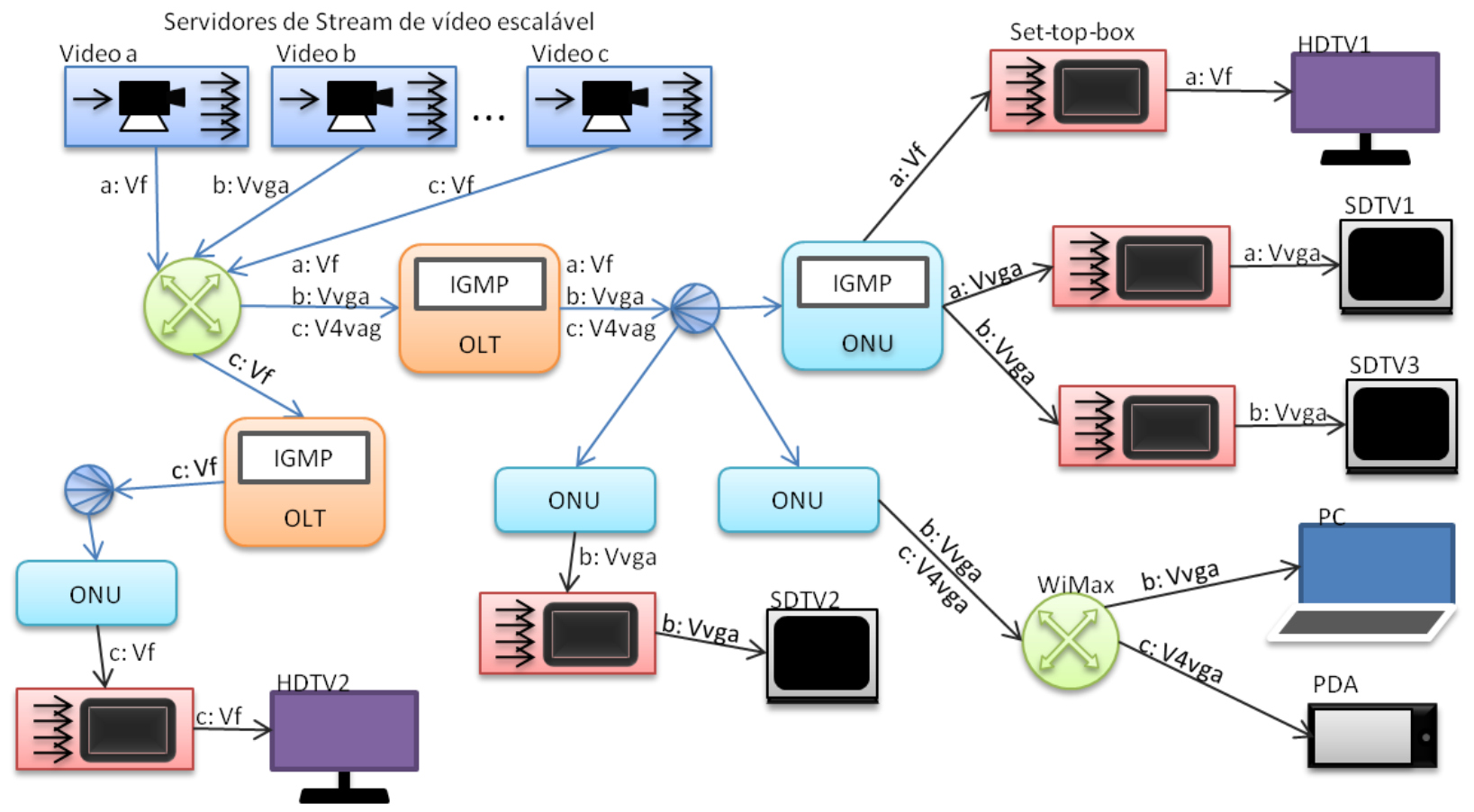

Figura 42 - Diversas resoluções sendo transmitidas pela rede GPON dependendo da necessidade do assinante e disponibilidade da rede

Partindo do princípio de que os servidores da Figura 42 são HD, é possível observar que o vídeo "b" só é transmitido em Vvga, pois não existe assinante com a necessidade de V4. O PC 
conectado ao sistema via WiMax pode receber HD, porém a rede WiMax limitou a banda baixando a resolução para Vvga, observe que neste caso o PC solicitou de V1 a V3, caso ele tivesse solicitado V4 também, o vídeo "b" seria enviado em Vf até o WiMax, como o V4 tem prioridade menor e a banda disponível não suporta todos os streams, o V4 seria descartado. O vídeo "c" é enviado em Vf até o roteador que antecede as OLTs, neste ponto ele segue em Vf para HDTV2 e em V4vga para o PDA.

\subsubsection{Qualidade no momento da mudança do canal}

Empregando vídeo escalável, o assinante recebe o vídeo de forma imediata (tempo de recuperação de 1 quadro) sempre que comandar a mudança de canal para um dos já disponíveis no STB, sendo que este canal pode, inicialmente, entrar com qualidade inferior ao desejado (abaixo de $36 \mathrm{~dB}$ ), e melhorar à medida em que os streams faltantes do vídeo são recebidos. Em testes qualitativos, o vídeo V4vga exibido em HDTV foi considerado aceitável nos primeiros segundos após a mudança do canal, apresentando uma PSNR, na média, 5dB abaixo do vídeo Vf.

Utilizando a rede da Figura 14, o diagrama da Figura 16 e o assinante 1 da Figura 37 como referência, adotando um buffer de dejittering de, no mínimo, 600ms e um intervalo médio de 100ms para o processamento do Join em cada um dos nós da rede, temos os gráficos da Figura 43.

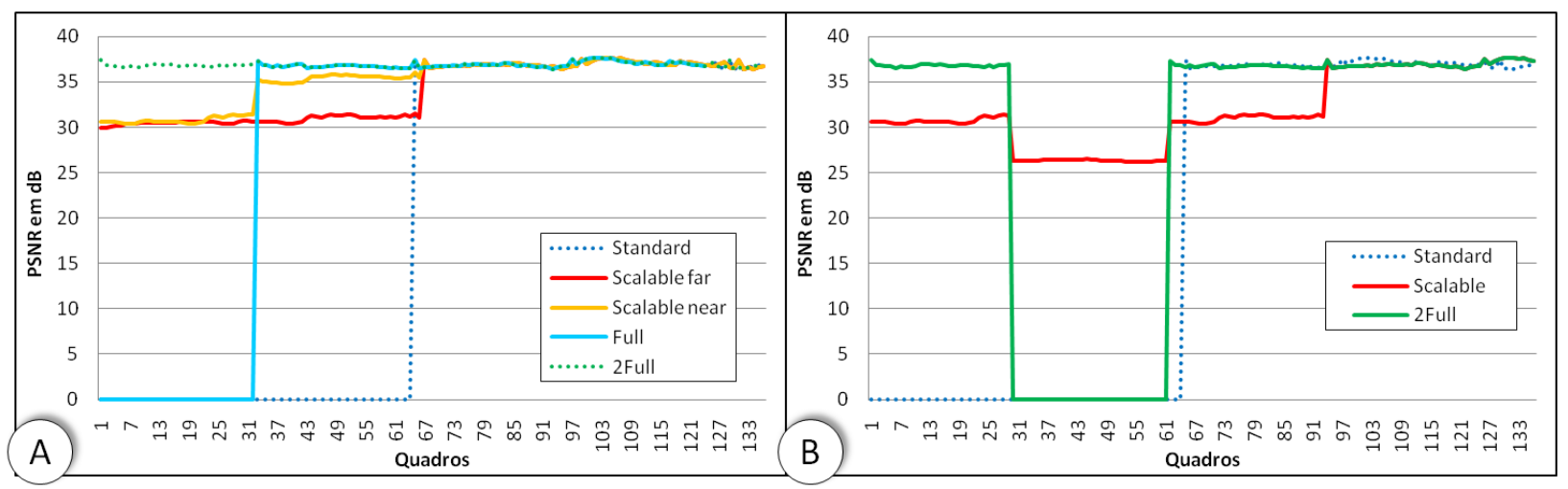

Figura 43 - Análise de alguns casos de entrada de canal onde o instante 1 do gráfico é o momento da mudança do canal. A) Mudança única de canal; B) Mudança dupla de canal com intervalo de 1 segundo.

Na Figura 43A, Standard representa a mudança do canal 35 para o 50 sem a utilização de vídeo escalável. Scalable far é a mudança para o canal 36 que já possuía V4vga no buffer e que não possuía mais ninguém assistindo, sendo assim é necessário o tempo para aguardar e armazenar 
V2 e V1 em buffer. O pequeno atraso entre a entrada do canal Standard e a entrada do canal em alta resolução do Scalable far se deve ao fato de que o sistema deve manter o tamanho do buffer (inicialmente dimensionado para V4vga) para a nova resolução Vf, a fim de manter o sincronismo do vídeo na transição de V4vga para Vf.

Scalable near é idêntico a Scalable far, porém a ONU já está recebendo o stream em Vvga devido a outro assinante que está assistindo a este canal, é o caso do assinante HDTV1 da Figura 42, alterar do canal ' $a$ ' para o canal ' $b$ ' que está sendo assistido pelo assinante SDTV3. Neste caso, a entrada do canal em Vvga acontece antes da chegada do canal em Vf melhorando a qualidade do vídeo.

Full representa a proposta [16], de transmitir todos os vídeos até a ONU. Devido aos tempos de dejitter e decodificação, o novo canal só é exibido a partir do frame 33. A proposta [51], de enviar além do canal assistido os dois adjacentes, é representada pela curva $2 F u l l$, contando que os dois canais adjacentes podem ser armazenados no STB, eles são exibidos no frame 1 .

Na curva Scalable da Figura 43B, o assinante muda para o canal 36, que possui V4vga no buffer, e 1 segundo depois muda novamente para o canal 37 que só possui V16vga, mas cujo V4vga foi solicitado no instante da mudança para o canal 36. No momento da mudança para o canal 37, o primeiro quadro I está a menos de 600ms por isto a exibição do vídeo inicia do segundo quadro I anterior, com isto o vídeo exibido possui um atraso em relação ao gerado no servidor de aproximadamente 1,5 segundo.

Para fins comparativos, o mesmo foi feito com a proposta [51], o resultado é mostrado na curva 2Full. Observe que, neste caso, o assinante fica sem imagem por um intervalo de aproximadamente 1 segundo na segunda troca do canal. Uma possível solução para evitar o tempo sem imagem seria enviar dois canais adjacentes ao invés de um, neste caso, a curva para as duas trocas seria equivalente a Standard da Figura 43A. A contrapartida para isto é o aumento do custo em termos de banda ocupada e buffer no STB.

\subsubsection{Ocupação da banda}

Conforme mostrado na Figura 37, na nossa proposta, para cada canal assistido o STB solicitará um conjunto de outros, isto aumentará a banda necessária por assinante. Por exemplo, baseando 
na disposição de canais do assinante 1 e na Tabela 4 , ao invés de $\approx 12 \mathrm{Mbit} / \mathrm{s}$ referente ao Vf do canal 35, este assinante ocupa $6(\mathrm{~V} 16 \mathrm{vga})+2(\mathrm{~V} 4 \mathrm{vga})+\mathrm{Vf} \approx 51 \mathrm{Mbit} / \mathrm{s}$.

Com a utilização da característica multicast da rede GPON, se outro assinante assiste a um canal próximo, por exemplo, o canal 30, o canal 31 já estará disponível em V16vga. Desta forma, ele precisará apenas do complemento V2 para atingir o V4vga. Os canais 32, 33 e 34 já possuem a resolução V16vga disponível, portanto este assinante ocupará apenas 3(V16vga)+V4vga+V2+Vf $\approx 29 \mathrm{Mbit} / \mathrm{s}$.

A fim de analisar as consequências desta distribuição, foram simulados aleatoriamente até 128 assinantes em grades de 100, 200 e 500 canais, todos com a mesma probabilidade de ocorrência. Para cada um deles foi computada a banda complementar necessária para atender o esquema do assinante 1 da Figura 37. Os resultados podem ser verificados na Figura 44.

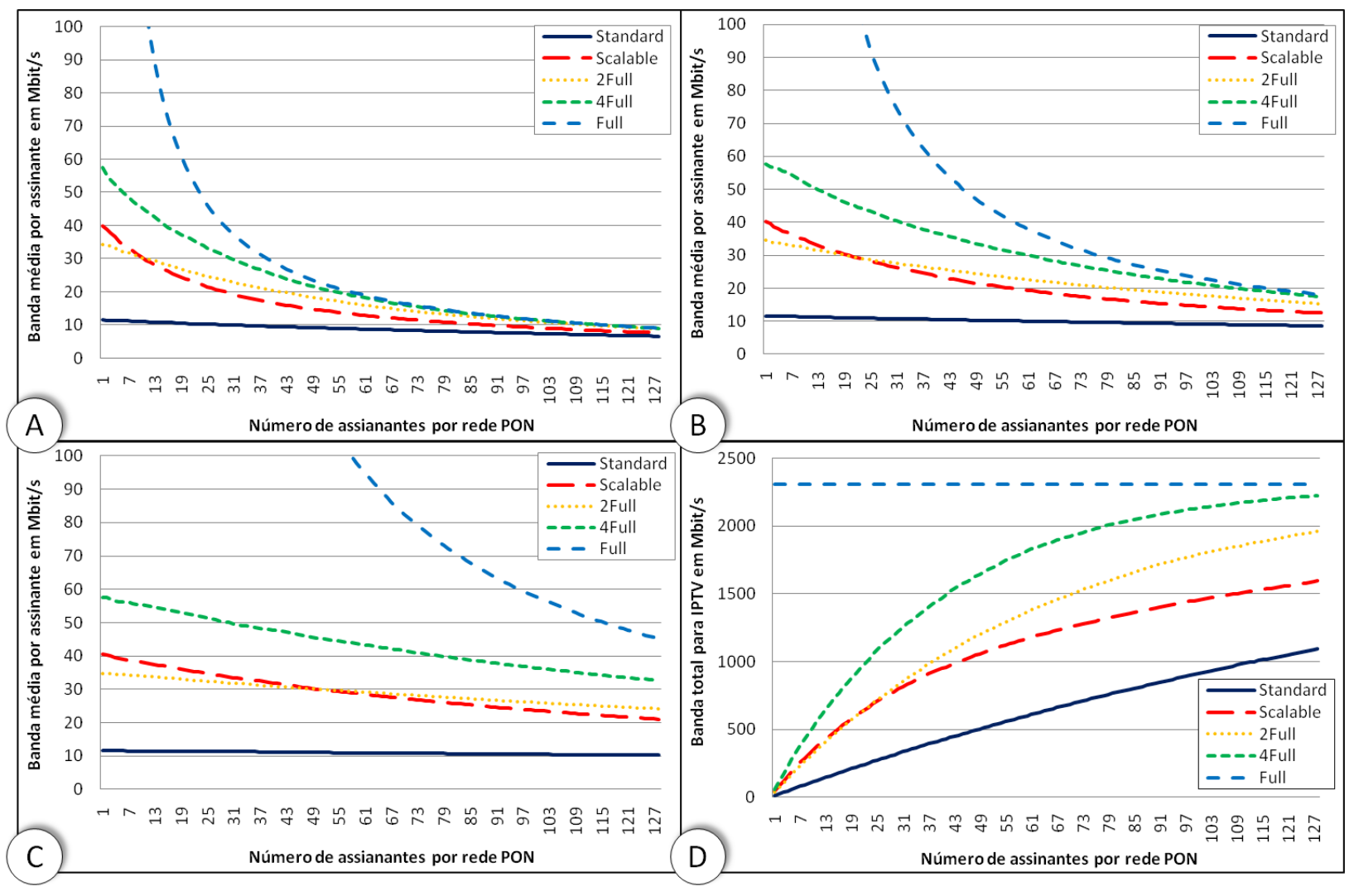

Figura 44 - Comparação de banda média utilizada por assinante na rede GPON. Simulação com grades de 100, 200 e 500 canais transmitidos de forma padrão e em vídeo escalável conforme proposto neste documento: A) Grade com 100 canais; B) Grade com 200 canais; C) Grade com 500 canais; D) Banda total ocupada para IPTV com 200 canais. 
Na Figura 44, Full representa a proposta [16], ela é a mais custosa de todas. Observe no gráfico B, que 200 canais seriam o limite máximo para o número de canais para uma rede GPON a 2,5Gbit/s e que neste caso, não seria possível o trafego de voz ou dados junto com os vídeos.

$2 F u l l$ e $4 F u l l$, são baseados nas proposta [51], em $2 F u l l$ além do canal assistido, dois adjacentes são enviados, como observado na parte B da Figura 29. Este sistema pode apresentar falhas no caso de mudanças rápidas de canais como apresentado no gráfico B da Figura 43, então, foi simulado também o envio de quatro canais adjacentes, este experimento é mostrado em $4 F u l l$.

Scalable é o envio conforme proposto neste trabalho, para o assinante 1 da Figura 37 e Standard representa a curva para o envio apenas do canal assistido. Observe que para um número grande de assinantes, as curvas tendem a se aproximar. Como ponto de análise, foi escolhido 200 canais e 64 assinantes, neste caso a solução de vídeo escalável se mostrou melhor tanto em termos de banda (só perdendo para o sistema convencional) quanto em termos de continuidade da imagem.

No pior caso, onde cada assinante está assistindo um canal diferente e todos os canais assistidos estão distribuídos de forma equidistantes na grade, com 512 canais e 128 assinantes, há um espaçamento de 4 canais entre cada canal assistido. Desta forma, cada assinante ocupa $\mathrm{Vf}+2(\mathrm{~V} 4 \mathrm{vga})+\mathrm{V} 16 \mathrm{vga} \approx 25 \mathrm{Mbit} / \mathrm{s}$. Isto corresponde a uma ocupação total de aproximadamente $3,2 \mathrm{Mbit} / \mathrm{s}$, que é superior à banda disponível na rede GPON. Como mostrado no estudo descrito em [57], este caso foge ao comportamento típico de um conjunto de assinantes, porém, ao priorizar as resoluções de cada canal, este problema é resolvido, pois a rede GPON descartará corretamente parte dos canais, fazendo com que a banda fique dentro do limite estipulado pela operadora.

\subsubsection{Canais não previstos}

O STB deve prever o melhor possível o comportamento do assinante, mas isto não garante que o próximo canal selecionado pelo assinante será um dos previstos. Neste caso, o tempo de zapping será o mesmo para o sistema padrão (sem vídeo escalável e sem transmissão de múltiplos canais), como mostrado pela curva C1 da Figura 44 [52].

Para resolver este problema, pode ser estudada a variação do intervalo entre quadros Is para cada um dos stream gerados. Isto minimiza o tempo de espera pelo quadro I, que é um dos maiores observados na curva C3 da Figura 44 [14]. 


\section{CAPÍTULO 6 - CONCLUSÃO E SUGESTÕES DE TRABALHOS FUTUROS}

Nesta dissertação, apresentamos uma possível solução para reduzir o tempo de espera pela entrada do vídeo após a mudança de canal nos sistemas IPTVs em redes GPON. O sistema expande a característica do MPEG-2, de prover vídeos escaláveis e as características multicast das redes GPON para resolver este problema enviando o vídeo em 4 streams distintos e complementares que, quando agregados no STB, recompõem o vídeo original. Adotando a técnica Scalable, a banda necessária por assinante é maior que a Standard, de um único stream com o vídeo completo, ficando na média, 90\% maior para uma grade de 200 canais com 64 assinantes na rede, porém ela é inferior a de outras propostas, que ficaram $123 \%$ para o 2 Full, $193 \%$ para o 4 Full e $264 \%$ para o Full.

O tempo de troca para um canal que está no grupo previsto pelo STB ficou menor que 30ms com qualidade superior a $35 \mathrm{~dB}$. No pior caso, onde o canal escolhido não foi previsto pelo STB o sistema se comportou como nos sistemas convencionais.

Dando continuidade a este trabalho, será pesquisado o comportamento do sistema usando o padrão MPEG-4. Também serão estudadas técnicas para prever o comportamento do assinante com o emprego de inteligência artificial. A fim de resolver o problema dos canais não previstos, a redução do intervalo entre quadros Is será estudada, avaliando o impacto desta variação na qualidade do vídeo gerado, no tempo de troca dos canais e na banda média ocupada por assinante.

Apesar do estudo feito neste trabalho se referir a sistemas ponto-multiponto, os sistemas ponto-aponto ou P2P [58] - [62] também apresentam o mesmo problema [57], [63] com relação ao tempo de zapping. Um possível trabalho futuro é o emprego da metodologia aqui apresentada para o sistema P2P proposto em [57]. 


\section{REFERÊNCIAS}

[1] IEEE 802.1 Working Group. " IEEE std. 802.1: LAN/MAN standard". [Online] www.ieee802.org/1/.

[2] IEEE 802.11 Working Group. " IEEE std. 802.11-2007: Wireless LAN Medium Access Control (MAC) and Physical Layer (Phy) Specification". 2007. 12 June 2007.

[3] ITU-T. "ITU-T Rec. G.984.1: Gigabit-capable Passive Optical Networks (GPON): General Characteristics". 2003.

[4] ITU-T. "ITU-T Rec. G.984.2: Gigabit-capable Passive Optical Networks (GPON): Physical Media Dependent (PMD) layer specification". 2003.

[5] ITU_T. "ITU-T Rec. G.984.3: Gigabit-capable Passive Optical Networks (GPON): Transmission convergence layer specification". 2008.

[6] ITU_T. "ITU-T Rec. G.984.4: Gigabit-capable Passive Optical Networks (GPON): ONT management and control interface specification". 2004.

[7] Koonen, T. "Fiber to the Home / Fiber to the Premisses: What, Where, and When?". Proceedings of the IEEE. No. 5, 2006, Vol. 94, May 2006.

[8] Frigo, N. J., Iannone, P.P., and Reichmann, K.C. "A View of Fiber to the Home Economics". IEEE Optical Communications Magazine. pg. 516 - 523, 2004, Vols. 42, n.8, August 2004.

[9] Howard, M. "PON \& FTTX Update". s.l. : Lightreading em (www.lightreading.com), 2005.

[10] ITU-T. "ITU-T Rec. H.262: Generic coding of moving pictures and associated audio information: Video". 2000.

[11] ITU-T and ISO/IEC JTC1. "ITU-T Rec. H.264 - ISO/IEC 14496 AVC: Advanced Video Coding for Generic Audiovisual Services". 2003. 
[12] Foschini G.J., Habbab I.M.I. "Capacity of Broadcast Channels in the Near-Future CATV Architecture". Journal of Lightwave Technology. 1995, Vols. 10, n. 3, March 1995.

[13] Huffman, D. A. "A Method for the Construction of Minimum-Redundancy Codes". PROCEEDINGS OF THE I.R.E. - PIRE(40). 1952, No. 9, pgs. 1098 - 2202. September 1952

[14] Architecture \& Transport Working Group. “Technical Report TR-126 - Triple-play Services Quality of Experience (QoE) Requirements". DSL Forum (www.dslforum.org). 2006.

[15] ITU-T and ISO/IEC JTC1. "ITU-T Rec. H.262: Generic coding of moving pictures and associated audio information: Video". 2000.

[16] Ikeda, H., Sugawa, J., Ashi, Y., and Sakamoto, K. "High-definition IPTV Broadcasting Architecture over Gigabit-capable Passive Optical Network". IEEE GLOBECOM. 2007.

[17] ITU-T and ISO/IEC JTC1. "Scalable Video Coding - Joint Draft 4". JVT-Q201. 2005, Octuber 2005.

[18] ITU-T and ISO/IEC JTC1. "Adaptive Motion Refinement for FGS Slices". JVT-Q031. 2005, Octuber 2005.

[19] Aravind R., Civanlar M.R., and Reibman R. "Packet Loss Resilience of MPEG-2 Sacalable Video Coding Algorithms". IEEE Transactions on Circuits and Systems for Video Technology. pgs. 426 - 435, 1996, Vols. 6, n. 5, October 1996.

[20] Schierl T., Schwarz H., Marpe D., and Wiegand T. "Wireless Broadcasting Using the Scalable Extension of H.264/AVC". IEEE International Conference on Multimedia and Expo. Pgs. 884 - 887, 2005, July 2005.

[21] Van Der Schaar, M., Radha, H. and Dufour, C. "Scalable MPEG-4 video coding with graceful packet-loss resilienceover bandwidth-varying networks". IEEE International Conference on Multimedia and Expo. Pgs. 1487 - 1490, 2000, Vol. 3, 2000. 
[22] Gopalakrishnan A.P., Yousefi’zadeh H., Jafarkhani H. "A Performance Evaluation of H.264 FGS Sequences over Hybrid Networks". Seventh International Conference on Networking. pgs. 734 - 739, 2008, April 2008.

[23] Shen H., Sun X., Wu F., Li H., Li S. "Transcoding to FGS Streams from H.264/AVC Hierarchical B-Pictures". ICIP. pgs. 861 - 864, 2006, 2006.

[24] GREEN, P.E. "Fiber to the home: the next big broadband thing". IEEE Communications Magazine. pg. 100 - 106, 2004, Vols. 42, n. 9, September 2004.

[25] ABRAMS, M., et al. "FTTP Deployments in the United States and Japan-equipment choices and wervice provider imperactives". Journal of Lightwave Technology. 2005, Vols. 23, n. 1, p. 236, January 2005.

[26] SHINOHARA, H. "FTTH Market - Growth and Expansion in Japan". Proceedings of Optical Fiber Communications Conference. 2006.

[27] CAUVIN, A. "FSAN Common Technical specification on a GPON System: first decision". [Online] 2005. [Cited: March 2, 2007.] www.fsanweb.org.

[28] KENNEDY, M. "Building Out FTTH: Cost Effective Technology And Consumer Demand Drive Growth". Telecommunication Online. [Online] 2007. [Cited: April 24, 2007.] http://www.telecommagazine.com.

[29] ÁVILA, V. J. "Projeto GPON - Requisitos Técnicos". 9 Fórum de Certificação de Produtos para Telecomunicações - Anatel. 2007, June 2007.

[30] IEEE 802.1 Working Group. "IEEE std. 802.1q-2005: Virtual Bridged Local Area Networks". [Online] 2005. www.ieee802.org/1/.

[31] F., Hodis. "Video-on-Demand and IPTV: Two Distinct Technologies". EXFO Expertise Reaching Out. [Online] January 2009. [Cited: February 13, 2010.] http://www.exfo.com/en/Library/WaveReview/WRArticle.aspx?Id=158.

[32] Albanna Z., Almeroth K., Meyer D., Schipper M. "RFC 3171: IANA Guidelines for IPv4 Multicast Address Assignments". Network Working Group. 2001, August 2001. 
[33] J., Postel. "RFC 768: User Datagram Protocol". Network Working Group. 1980, August 1980.

[34] Schulzrinne H., Casner S., and Jacobson V. "RFC 3550: RTP: A Transport Protocol for Real-Time Applications". Network Working Group. 2003, July 2003.

[35] Johansson I., Westerlund M. "RFC 5506: Support for Reduced-Size Real-Time Transport Control Protocol (RTCP): Opportunities and Consequences". Network Working Group. 2009, April 2009.

[36] Schulzrinne H., Rao A., Lanphier R. "RFC 2326: Real Time Streaming Protocol (RTSP)". Network Working Group. 1998, April 1998.

[37] W., Fenner. "RFC 2236: Internet Group Management Protocol, Version 2". Network Working Group. 1997, November 1997.

[38] Cain B., Deering S., Kouvelas I., Fenner B., and Thyagarajan A. "RFC 3376: Internet Group Management Protocol, Version 3". Network Working Group. 2002, October 2002.

[39] Vida R., and Costa L. "RFC 3810: Multicast Listener Discovery Version 2 (MLDv2) for IPv6". Network Working Group. 2004, June 2004.

[40] Holbrook H., Cain B., and Haberman B. "RFC 4604: Using Internet Group Management Protocol Version 3 (IGMPv3) and Multicast Listener Discovery Protocol Version 2 (MLDv2) for Source-Specific Multicast". Network Working Group. 2006, August 2006.

[41] Juniper Networks, Inc. "Introduction to IGMP for IPTV Networks: Understanding IGMP Processing in the Broadband Access Network". White Paper. 2007, Oct 2007.

[42] j., Postel. "RFC 792: Internet Control Message Protocol". Network Working Group. 1981, September 1981.

[43] Microsoft Technet. "Microsoft Security Bulletin MS06-007 - Vulnerability in TCP/IP Could Allow Denial of Service (913446)". Microsoft Technet. [Online] March 17, 2006. 
[Cited: February 18, 2010.] http://www.microsoft.com/technet/security/Bulletin/MS06007.mspx.

[44] Microsoft Technet. "Fragmented IGMP Packet May Promote "Denial of Service" Attack". Microsoft Technet. [Online] August 13, 2007. [Cited: February 18, 2010.] http://support.microsoft.com/default.aspx?scid=kb;en-us;238329\&sd=tech.

[45] Fenner B., Handley M., Holbrook H., and Kouvelas I. "RFC 4601: Protocol Independent Multicast - Sparse Mode (PIM-SM): Protocol Specification (Revised)". Network Working Group. 2006, August 2006.

[46] Christensen M., Kimball K., and Solensky F. "RFC 4541: Considerations for Internet Group Management Protocol (IGMP) and Multicast Listener Discovery (MLD) Snooping Switches". Network Working Group. 2006, May 2006.

[47] Martins L., Amorim F., and Bertolo P. "Técnicas de Transmissão Multicast nos Protocolos IPV4 e IPV6". PD.30.11.90A.0002A/RT-13. AA, 2003, September 2003.

[48] Nigri H.S., Albuquerque, Marcio P., Albuquerque Marcelo P., and Taves M. "O Padrão MPEG para compressão de vídeo". CBPF-NT_002/00. 2000, April 2000.

[49] Gonzalez, R.c., and Woods, R.E. "Digital Image Processing - Second Edition". Upper Saddle River, New Jersey : Prentice Hall, 2001. ISBN:0-201-18075-8.

[50] Huynh-Thu, Q. and Ghanbari, M. "Scope of validity of PSNR in image/video quality assessment". IET - Electronics Letters. pgs. 800 - 801, 2008, Vol. 44, June 2008.

[51] Cho, C., Han, I., Jun, Y., and Lee, H. "Improvement of channel zapping time in IPTV services using the adjacent groups join-leave method". The 6th International Conference on Advanced Communication Technology. Pgs. 971 - 975, 2004, Vol. 2, October 2004.

[52] Joo, H., Song, H., Lee, D., and Lee, I. "An Effective IPTV Channel Control Algorithm Considering Channel Zapping Time and Network Utilization". IEEE Transactions on Broadcasting. Pgs. 208 - 216, 2008, Vol. 54 Issue:2, May 2008 . 
[53] Boyce, J. M., and Tourapis, A. M. "Fast efficient channel change [set- top box applications]". International Conference on Computers in Education Digest of Technical Papers. Pgs. 1-2, 2005, January 2005.

[54] Li, W. "Overview of Fine Granularity Scalability in MPEG-4 video Standard". IEEE Transactions on Circuits and Systems for Video Technology. 2001, Vols. 11, n. 3, March 2001.

[55] Shaar M., Radha H., and Dufour C. "Scalable MPEG-4 Video Coding With Graceful Packet-loss Resilience Over Bandwidth-varying Networks". IEEE Multimedia and Expo, ICME 2000. pg. 1487 - 1490, 2000, Vol. 3, 2000.

[56] Lage, J. "UNI-Mulheres salvando o planeta". Imagem\&Cia <www.imagemcia.com.br>, 2008.

[57] Hei, X., Liang, C., Liang, J., Liu, Y., and Ross, K. "A Measurement Study of a LargeScale P2P IPTV System". IEEE Transactions on Multimedia. No. 8, 2007, Vol. 9, December 2007.

[58] Zhang, X., Lui, J., Li, B., and Yum, T. S. P. "DONet/CoolStreaming: A Data-driven Overlay Network for Peer-to-Peer Live Media Streaming". IEEE INFOCOM. 2005, March 2005.

[59] PPLive. PPLive. [Online] [Cited: March 09, 2010.] http://www.pplive.com.

[60] PPStream. PPStream. [Online] [Cited: March 09, 2010.] http://www.pps.tv.

[61] UUSee. UUSee. [Online] [Cited: March 09, 2010.] http://www.uusee.com.

[62] Sopcast. Sopcast. [Online] [Cited: March 09, 2010.] http://www.sopcast.com.

[63] Hei, X., Liu, Y., and Ross, K. "Inferring Network-Wide Quality in P2P Live Streaming Systems". IEEE Journal on Selected Areas in Communications. 2007, December 2007. 